\title{
STUDIES OF ENVIRONMENTAL FACTORS IN A FAMILY-SIZE UNDERGROUND SHELTER
}

\author{
OCDM-NBS-60-1 \\ nBS $\# 9369$ \\ Prepared for \\ OFFICE OF CIVIL AND DEFENSE MOBILIZATION \\ PROJECT NO. EN-104.1 \\ by the
}

NATIONAL BUREAU OF STANDARDS

WASHINGTON, D. C.

CONTRACT NO. CDM-SR-59-53

March 1961

This is Anproved for public release of

Civil a Approved for public release by the tract. It is distribi Director of the National Institute of e contents do not Standards and Technology (NIST) policy. on October 9, 2015. 

STUDIES OF ENVIRONMENTAL FACTORS IN A FAMILY-SIZE UNDERGROUND SHELTER

\author{
by \\ PAUL R. ACHENBACH \\ F. J. JEROME DRAPEAU \\ CLINTON W. PHILIIPS \\ OCDM-NBS-60-1 \\ March 1961 \\ PREPARED FOR \\ PROJECT NO. EN-104.1
}

OFFICE OF CIVIL AND DEFENSE MOBILIZATION

\begin{abstract}
BY THE
MECHANICAL SYSTEMS SECTION

BUILDING RESEARCH DIVISION

NATIONAL BUREAU OF STANDARDS

WASHINGTON, D. C.
\end{abstract}

CONTRACT NO. CDM-SR-59-53 



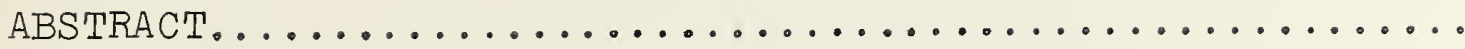

1. Introduction............................. I

2. Description of Test Installation.................. 2

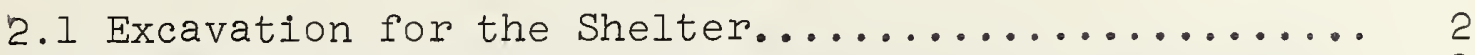

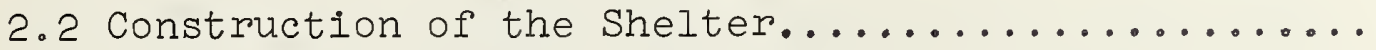

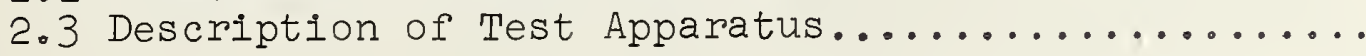

a. Thermocouple System for Concrete and Surrounding

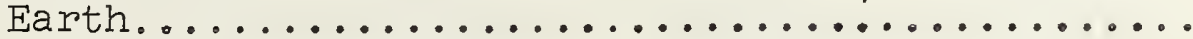

b. Conditioning Apparatus for Ventilating Air.....

c. Temperature and Humidity Measurements in the

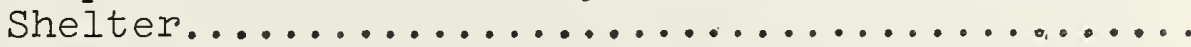

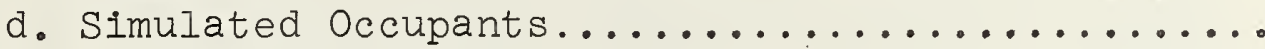

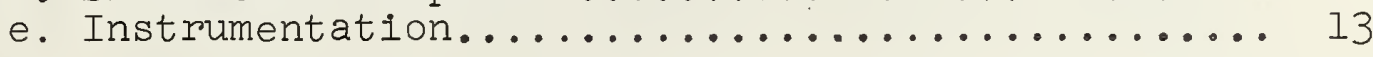

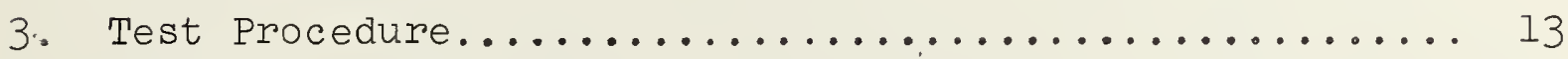

4. Test Results.................................. 19

4.I. Inlet and Outlet Air Conditions of the Shelter..... 19

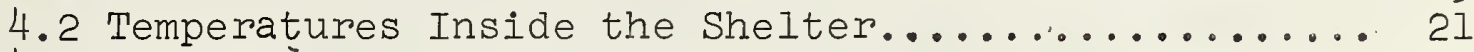

4.3 Condensation and Humidity Inside the Shelter....... 21

4.4 Enthalpy Change of the Ventilating Air in the

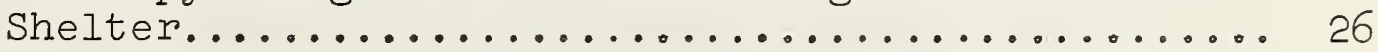

4.5 Heat Transfer to Shelter Walls and Surrounding

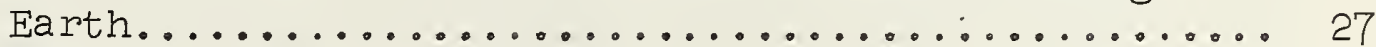

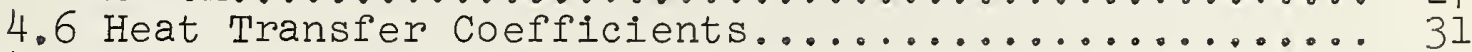

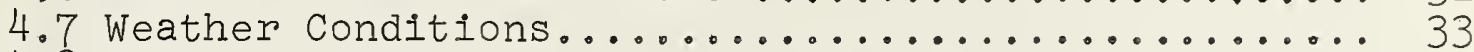

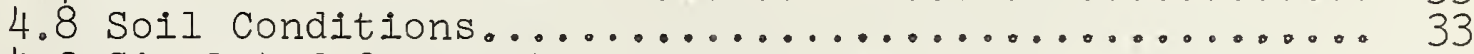

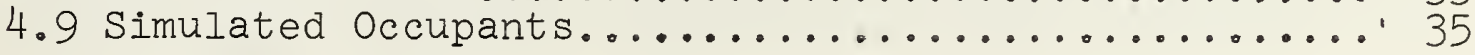

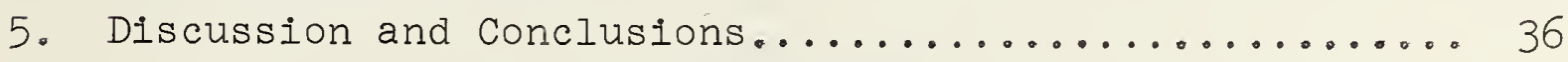

5.1 Factors Affecting Shelter Condensation........... 36

5.2 Validity of Supply Air Conditions Selected........ 38

5.3 Factors Affecting Temperature Rise in the Sheiter.. 40 5.4 Further Analysis of Environmental Factors......... 43

6. References............................... 44 

STUDIES OF ENVIRONMENTAL FACTORS IN A FAMILY-SIZE UNDERGROUND SHELTER

by

P. R. Achenbach, F. J.J. Drapeau, and C. W. Phillips

\section{ABSTRACT}

Five tests of a family-size concrete underground fallout shelter, built in accordance with basic plans in Bulletin MP-15 of the Office of Civil and Defense Mobilization, were made, with six simulated occupants in four of the tests, to study the environmental factors of temperature, humidity, ventilation, and heat exchange in the shelter for periods of occupancy up to 14 days. Four of the tests were made under summer conditions, the initial one without occupants, and one test was made under winter conditions with the earth surrounding the shelter at approximately seasonal maximum and minimum temperatures, respectively. Ventilation rates ranged from 0 to $42 \mathrm{cfm}$ for the five tests, and the ventilating air supply was maintained at controlled dry bulb and dew point temperatures representative of summer and winter weather in Washington, D. C. The heat emission of the simulated occupants during four of the tests averaged about $2400 \mathrm{Btu} / \mathrm{hr}$, a part of which was latent heat. Condensation of moisture began in the shelter almost immediately during the summer tests and was continuous throughout the tests, whereas during the winter test, it was very limited in amount and stopped after about 4 days. In a 2-week period, the dry bulb temperature in the shelter rose from 12 to 15 degrees F from initial values of about $46^{\circ} \mathrm{F}$ in the winter and about $69^{\circ} \mathrm{F}$ in the summer. The ventilating air removed some or all of the moisture liberated inside the shelter; it removed some of the sensible heat in the winter time, but always contributed a little sensible heat during the summer tests.

\section{INTRODUCTION}

At the request of the office of Civil and Defense Mobilization, a study was conducted to determine the thermal characteristics of a family-size underground concrete shelter for protection against radioactive fallout. 
The primary objective of this study was to obtain engineering data and other physical observations on the environmental factors of temperature, humidity, ventilation, and heat exchange in an underground family shelter during periods of occupancy up to 14 days, using simulated occupants having sensible and latent heat output characteristics equivalent to those of human occupants.

These measurements and observations would then be used as a basis for:

a. Graphical representation of the thermal behavior of the shelter,

b. Determination of the total and unit heat transfer rates through the shelter walls,

c. Computation of the amount of sensible and latent heat added to or removed from the shelter by the ventilating air,

d. Determination of the minimum amount of ventilating air required to remove the heat produced by six occupants whose total heat output was assumed to be $2400 \mathrm{Btu} / \mathrm{hr}$ and with the latent and sensible fractions approximately equal to those shown in the "Guide" of the American Society of Heating, Refrigerating, and AirConditioning Engineers for sedentary individuals,

e. Conclusions regarding the adequacy of the space allowance, the control of moisture, and the effect of the above-ground diurnal temperature cycle in the basic family shelter,

f. Future analysis of the effect of soil characteristics, moisture content of the soil, thickness of the concrete walls, ambient temperature and humidity, latitude of the site, and quantity of ventilating air on the thermal behavior of shelters in a range of sizes during an occupancy of 2 -weeks' duration.

\section{DESCRIPTION OF TEST INSTALLATION}

\subsection{Excavation for the Shelter}

On a suitable and well-drained site on the grounds of the National Bureau of Standards in washington, D. C., an underground concrete fallout shelter of family size was built in 
general accordance with the basic plans outlined in Bulletin MP-15 of the Office of Civil and Defense Mobilization.I

A pit approximately $13 \mathrm{ft} 6 \mathrm{in}$. wide, $16 \mathrm{ft}$ long, and $7 \mathrm{ft}$ deep, on the average, was excavated, and the excavated earth was mounded around the pit for future use as backfill material. The dimensions of the pit were chosen to provide a construction area clearance of approximately 2 feet beyond the perimeter outline of the shelter. The pit was excavated in accordance with a predetermined directional orientation on the selected location. This resulted in the major or 16-foot central axis of the pit being oriented about 20 degrees west of magnetic north, or in approximately a north-northwest direction. However, for descriptive purposes and ease of reference in this report, the major axis was assumed to be a north-south line. The site selected for the shelter had a natural downward slope from west to east of approximately 36 inches per 25 feet, or about 12 percent, assuring good drainage. The excavated earth was relatively free of roots, debris, and stones. The bottom of the excavation was leveled and tamped where necessary to provide uniform bearing conditions for the floor slab.

Immediately upon completion of the excavation, representative samples of earth were removed from the undisturbed bank for density measurements and determination of moisture content. Examination of the west wall of the excavation, the deepest and most representative surface. showed four contrasting layers of soil of wide textural variety. The first or top layer consisted of yellow sandy loam and was approximately 2 feet thick. The second layer consisted of black humus loam about $11 / 2$ feet thick. The third layer consisted of yellow clay varying in thickness from $21 / 2$ feet in the southwest corner of the excavation to $4 \mathrm{l} / 2$ feet in the center of the west surface. The fourth or bottom layer consisted of blue clay approximately 2 feet thick in the southwest corner, sloping downward and vanishing at or about the bottom center point of the west wall. This layer of blue clay also sloped downward and vanished into the south surface about 3 feet from the southwest corner. No samples were obtalned from this layer. Table 1 summarizes the characteristics of the soil at the shelter site.

\subsection{Construction of the Shelter}

Except for a few modifications to facilitate testing, the reinforced concrete shelter constructed in the pit conformed to the specifications and drawings for the Underground Concrete Shelter shown in Bulletin MP-15 of the office of Civil and 

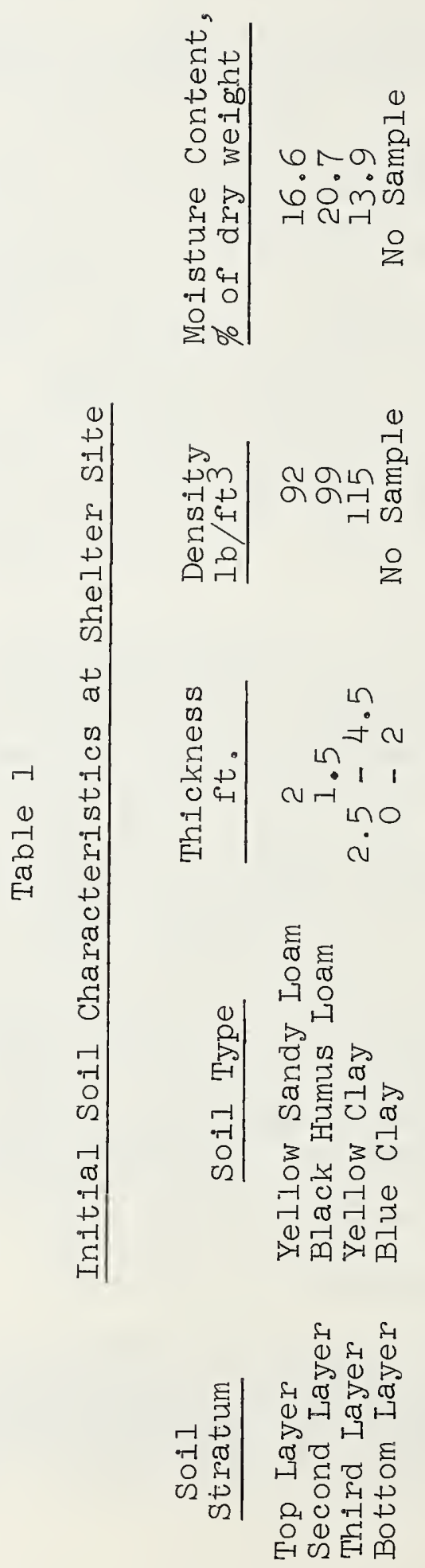
Defense Mobilization. The principal modifications were as follows:

a. Two steel cables, 1 1/8 inches in diameter and 70 feet long, were placed underneath the shelter for use as a means of lifting the shelter from its present location, should that be required at some future time.

b. A second grid of reinforcing steel was placed in the floor, near the bottom of the slab, to provide additional strength in the floor, in the event that the shelter should be lifted from its present site.

c. The floor was sloped $1 / 16$ inch per foot to provide condensate drainage to a sump 10 inches square and 1 inch deep in the northwest corner of the shelter.

d. Duplicate systems of ventilation pipes were installed, with supply pipes in the south wall and in the interior partition used for shielding, and exhaust pipes in the north and south walls, respectively.

e. Ten holes were cast or drilled in the concrete comprising the walls, floor, and roof of the shelter for the insertion of thermocouple systems, and recesses were made near the center of each exposure for affixing heat flow meters to the concrete.

Figures 1 to 4 show the shelter in various stages of construction. Figure 1 shows the form and grids of reinforcing steel for the floor just before placing the concrete. The polyethylene film, used as a moisture barrier on the ground surface, is visible inside the form. Figure 2 shows the construction at the stage when the inside forms for the four exterior walls, and the forms for the interior partition or shielding wall, were in position. The horizontal and vertical reinforcing bars for the walls can be seen in this figure. One of the two cables, installed for lifting the shelter from the ground, can be seen at the left of the shelter. Figure 3 shows the roof form and reinforcing steel in place prior to placing the concrete. The pipes of the ventilating air system and the building used to house the instruments and air conditioning apparatus can be seen in this figure. Figure 4 is a photograph of the shelter site after the sod covering was in place and after installation of the conditioned air supply system. Figures 5 and 6 are schematic drawings of the shelter and some of the test apparatus. 
The exterior dimensions of the shelter were: length, $12 \mathrm{ft}$ : width, 9 ft 4 in.; height, not including hatch, 7 ft 6 in. The interior dimensions were: length, $10 \mathrm{ft} 8 \mathrm{in.;}$ width, $8 \mathrm{ft}$; and height, $6 \mathrm{ft} 6 \mathrm{in.}$ The hatchway on the north side of the room was 2 feet wide and the shielding wall was 8 inches thick, thus leaving the main room of a square shape with dimensions of $8 \mathrm{ft}$ $x 8$ ft. Approximately $123 / 4$ cu yd of concrete were used for the structure and the calculated total weight was approximately
$49,6001 \mathrm{~b}$.

Samples of the concrete placed in the walls, roof, and hatch were taken for compression tests. The duration of the curing period before making the strength tests and the compression load at failure of each of the three test cylinders are summarized in

\section{Table 2}

Compression Tests of Concrete Samples

\begin{tabular}{|c|c|c|}
\hline $\begin{array}{c}\text { Shelter Element } \\
\text { Sampled }\end{array}$ & $\begin{array}{c}\text { Curing Period, } \\
\text { days }\end{array}$ & $\begin{array}{c}\text { Compression Load } \\
\text { at Failure, } \\
\text { Ib/sqin. }\end{array}$ \\
\hline $\begin{array}{l}\text { Walls } \\
\text { Roof } \\
\text { Hatch }\end{array}$ & $\begin{array}{l}31 \\
31 \\
28\end{array}$ & $\begin{array}{l}2600 \\
2830 \\
2860\end{array}$ \\
\hline
\end{tabular}

After applying hot asphalt to the exterior of the walls and roof as a moisture barrier, the process of backfilling the excavation, constructing the shape of the embankment, grading, and embankment and ire area with new sod to prevent erosion of the stages. Approximately half of the carried out in successive and top sides of the embankment the soil used on the north, east, The backfill was placed in layers obtained from another site. tamped thoroughly with a pneumatic tamp 18 inches thick and sucessive layers about 12 inches tamping machine to obtain Large stones and other 12 inches thick of the proper density. countered. A layer of dry ice objects were removed when enbackfill. This method dry ice was placed between each layer of of the embankment.

The dry ice was introduced to remove the excess heat absorbed by the excavated earth while it lay on the ground surface and to shorten the preconditioning time of the shelter before a test perature of the backfill to approximately the temperature of the 
undisturbed earth was determined by calculation. Even though the amount of dry ice required to cool the backfill could not be determined exactly, the results indicated that this method for reducing the preconditioning time for the shelter was effective and practical.

Samples of tamped backfill were obtained at three separate levels for moisture content and density measurements. The first sample was taken about 5 feet below the roof level of the shelter; the second sample was taken about 3 feet below the roof level; and the third sample was taken at a level even with the top of the roof. The density and moisture content, in percent of dry weight, of these samples are summarized in Table 3.

\section{Table 3}

Density and Moisture Content of Samples of Tamped Fill

Level of Sampling below Roof Level ft

5
3
0 $\frac{\text { Density of Sample }}{\text { lb/cu ft }}$

Not measured

108.5

109
Moisture Content, $\frac{\text { Relative to Dry Weight }}{\%}$

14.1

16.7

15.5

The entire area was graded and covered with 225 square yards of sod. The top of the embankment was leveled and graded horizontally so that the surface line of the sod was 3 inches below the top edge of the hatch and provided an earth cover 2 ft 3 in. thick over the shelter roof.

A chronological summary of the principal events in the construction of the shelter and preparation of the site is shown in Table 4.

\section{Table 4}

Completion Dates of Shelter Components and Site Preparation

Completed Excavation

Placed Concrete in Shelter Floor

Placed Concrete in Shelter Walls

Placed Concrete in Shelter Roof

Placed Concrete in Shelter Hatchway

Waterproofed Shelter Exterior

Backfill Completed

Began First Test
May 26, 1959

June 9, 1959

June 19, 1959

June 29, 1959

July 2, 1959

July 8, 1959

July 22, 1959

August 13, 1959 
Light fixtures were installed on the center ceiling surfaces of the room and hatchway areas. A 25-watt incandescent light bulb was used in the room area and a $71 / 2$-watt bulb was used in the hatchway area.

\subsection{Description of Test Apparatus}

The principal components of the test apparatus were as follows:

(1) A thermocouple system for measuring the temperature of the concrete in the walls of the shelter, in the adjacent earth to a distance of 4 feet from the walls, and in the undisturbed earth at some distance away from the excavation,

(2) Apparatus for conditioning the ventilating air to the selected dry bulb and dew point temperatures and regulating the rate of flow of air,

(3) Temperature and humidity elements for measuring the "state condition" of the air entering the shelter and at various stations inside the shelter,

(4) Six simulated occupants to provide sensible and latent heat emissions similar to that for real occupants,

(5) A water-feeding system for the simulated occupants to represent the moisture emission of real occupants,

(6) Heat flow meters to measure the rate of heat transmission at the interior surfaces of the shelter,

(7) Selected instruments for measuring temperature, humidity, air flow rate, electrical energy consumption, heat flow rate, and solar radiation.

a. Thermocouple System for Concrete and Surrounding Earth

Six strings of thermocouples, made of No. 30 AWG wire, were used to obtain temperatures in the concrete and earth surrounding the shelter. The six strings of thermocouples were supported on rods and were installed normal to the roof, floor. and walls through a hole provided at the center of each of these surfaces. The supporting rods consisted of bakelite tubes of $7 / 16-$ inch outside diameter and 1/32-inch wall thickness. The sensirg end of each thermocouple and about 2 inches of the leads were 
wrapped around the exterior of the bakelite tube with the soldered junction taped to the tube at a measured distance from one end of the tube. The leads for the several thermocouples in each string were inserted through separate holes drilled in the tube wall and thence through the inside of the tube. A tapered wooden spike was pressed into one end of the tube to facilitate driving it into the earth and the entire length of the tube was wrapped with masking tape. The tube was filled with sand, the other end sealed with molten paraffin wax, and the device completely covered with shellac.

Each thermocouple support rod was pushed into the surrounding earth through the hole in the shelter wall until its inner end was flush with the inside surface of the concrete, which served as the reference point for thermocouple location. Since the position of each thermocouple sensing junction had been previously determined by its distance relative to this point of reference, the extent of its penetration into the concrete and surrounding earth was thereby also known. The rods were grouted into the concrete walls, floor, and roof with cement mortar to the full thickness of the concrete. The location of each thermocouple junction on these six rods is indicated by a cross on Figures 5 and 6. The thermocouple stations in or on the concrete were at positions $0,2,4$, and 8 inches from the inside surface of the concrete and those in the earth were $6,12,24,36$, and 48 inches from the nominal exterior surface of the concrete except for the roof rod. In this latter case, the most remote station was placed 24 inches from the top surface of the concrete roof because the earth cover was only 27 inches deep. Within a radius of about 2 inches from the axis of each rod, a thermocouple sensing junction was grouted to the inside surface of the concrete, and one sensing junction was placed in air 1 inch from the inside wall surface, approximately on the projected axis of each rod.

Two thermocouple supporting rods, similar in material and construction to those previously described, were inserted into holes provided at the apex of the dihedral angles formed by tre south wall with the roof and floor slabs, respectively. Two other rods were inserted in holes provided at the apex of the trihedral angles formed by the south and east walls with the roof and floor slabs, respectively. In each case, the thermocouple rods, as installed, formed equal angles with the adm. jacent surfaces. Thermocouples were spaced at $1 / 4,1 / 2$, arid $3 / 4$ the thickness of the concrete at each station. Thermocouples were also fixed in the air 1 inch from the inside surface of the concrete at these four stations. These rods are not shown in Figures 5 and 6. 
Two strings of thermocouples were installed on supporting rods in the ground remote from the shelter to obtain a daily record of undisturbed earth temperatures at various depths. One rod, designated as ground rod No. 2, was located approximately 15 feet from the outside surface of the west wall of the shelter, in the plane of the shielding wall or partition of the shelter. The other rod, designated as ground rod No. 1, was located approximately 40 feet south of ground rod No. 2, in a plane 15 feet from and parallel to the west wall. Ground rod No. 1 was about 9 ft 6 in. long with thermocouples at depths of 6 inches, 1 foot, 2 feet, 3 feet, 4 feet, 5 feet, and 6 feet, and an air thermocouple 3 feet above the ground. Ground rod No. 2, which was about 6 ft 6 in. long, was placed entirely below ground level with identical thermocouple spacing below the surface.

Plan and sectional schematic drawings of the shelter installation in Figures 5 and 6 show the locations of the thermocouples in the concrete and earth surrounding the shelter, in the undisturbed earth at ground rod No, 2, and inside the shelter itself。

\section{b. Conditioning Apparatus for Ventilating Air}

An air washer, illustrated diagrammatically in Figure 7, was designed and constructed to saturate the supply air and control its dew point temperature. It consisted of a duct 12 inches square and about 4 feet long made of 16-gage galvanized steel, four water sprays, an eliminator, and a sump at one end. The sprays had an included angle of 80 degrees and were equally spaced in a counterflow relationship to the air flow. The water sprays were designed to bathe the internal walls of the duct and to provide enough evaporative surface to essentially saturate the air at the water temperature. The sump collected the excess water for recirculation and incorporated a float-controlled water feed for makeup. A mat of plastic fibers was used to eliminate water droplets from the air stream at the washer outlet. Air from the instrument building was forced through the washer, a measuring orifice, the supply line to the shelter and the shelter itself by a centrifugal blower. A by-pass pipe around the orifice permitted higher air flow rates to be used during the reconditioning periods between tests. The air flow rate was controlled manually at the blower outlet by an adjustable damper.

Chilled water from an oversize chiller was pumped to the water sprays at a temperature controlled by an evaporator pressure regulator valve. A condensing unit provided refrigeration for the water chiller. 
An electric heater was mounted inside the air supply duct downstream from the air washer and eliminator to reheat the air to the desired dry bulb temperature. Since the air washer was about 50 feet from the shelter inlet, considerable heat was transferred between the air supply line and the ambient air. The direction of heat flow depended on whether the outdoor temperature was below or above the a1r temperature in the supply Iine. For the summer tests the entire alr supply line was well insulated and covered with an aluminum wrapper to reduce the heat transfer and to prevent the entry of molsture into the insulation. For the winter test a part of the air supply line was jacketed with crushed ice after starting the test to maintain the desired dry bulb temperature at the shelter inlet. Figure 7 shows all of the conditioning and control apparatus for the ventilating air, diagrammatically.

\section{c. Temperature and Humldity Measurements in the Shelter}

The control point for the supply alr conditions was at a station 2 feet above the ground and vertically above the partition wall of the shelter as shown in Figure 6. The electric heater at the washer outlet was controlled by a temperaturesensing element at this station and the chilled water temperature was adjusted to maintain the dew point temperature at this same location at $69^{\circ} \mathrm{F}$ for the summer tests and at $33^{\circ} \mathrm{F}$ for the winter test.

Thermocouples were installed in the air inlet pipe, in the air exhaust pipe, and at the 1-, 2-, 3-, 4-, 5-, and 6-foot levels above the surface of the floor at the center of the room and hatchway areas, as indicated in the plan and section views of Figure 6. Lithium-chloride electric hygrometer elements were placed in the a1r exhaust pipe, and at 5-foot levels of the room and hatchway areas.

\section{d. Simulated Occupants}

The simulated occupants were made of 24-gage galvanized steel. Each consisted of a cylindrical section 22 inches in diameter and $385 / 8$ inches high and a conical cap with a helght of $5 \mathrm{l} / 2$ inches. An aluminum liner 15 inches in diameter and 36 inches hlgh was used to reduce the radiation from the heat source to the outer cylinder and to increase internal convect1on. The liner was wrapped externally with 1/2-inch thickness of fibrous insulation, and it terminated 2 inches above the bottom of the outer shell. An aluminum foll radiation shield was also installed underneath the conical dome. A 200-watt 
light bulb at reduced voltage was used as the heat source in each of the four $400 \mathrm{Btu} / \mathrm{hr}$ occupants and the one $200 \mathrm{Btu} / \mathrm{hr}$ occupant, whereas a 660-watt cone-shaped resistance heater at reduced voltage served as the heat source in the one 600 Btu/hr occupant. The heaters were mounted inside the liner near the bottom of the device, and were operated at a steady voltage adjusted to produce the desired heat outputs.

A smooth closely-woven rayon fabric with long fibers was used to spread the water over the exterior surface of the simulated occupants for evaporation into the air. A snug-fitting wrapper of this fabric was fitted over the cylindrical portion of each occupant, and it was gathered into folds over the conical dome and sewed together at the top. Elastic bands were used to hold the fabric snugly against the metal at top, midheight, and bottom of the cylinder. The soldered joint connecting the dome to the cylindrical wall was made smooth so as not to inhibit movement of moisture over the edge. Water was dripped into the gathered fabric at the top of the dome and allowed to spread over the exterior surface by wick action. Five thermocouples were soldered to the cylindrical walls of the devices and one additional thermocouple was similarly attached to the dome 3 inches from the top. The five thermocouples on the inside surface of the cylindrical walls were spaced 9 inches apart vertically and 13 inches apart circumferentially in a spiral pattern with the lowest one being 1 inch from the bottom of the cylinder.

Each simulated occupant was supported in a pan, 2 ieet square and 2 inches deep, which served to collect any excess water not evaporated from the surface. The pan rested on a 2inch thick board of glass fiber insulation to limit heat transfer from the bottom of the pan. The pans and occupants were mounted on cinder blocks in the arrangement shown in Figure 6 for the tests, with a clearance of 8 inches between the floor and the bottom of the pan. A 1/4-inch sheet of plywood separated the insulation board from the cinder block support.

The water-feeding system for the simulated occupants, a gravity system, consisted of six separatory funnels for gradual feeding of water through separate plastic tubes to each of the simulated occupants. The funnels were located in the instrument room and the tubes ran parallel to the air supply system and entered the shelter through the alternate air exhaust pipe installed in the south wall. The tube outlets in the shelter were located directly above and about 1 inch from the peak of each dome. A thermocouple was installed in the tube outlet above simulated occupant No. 1 to measure the temperature of the water. 
e. Instrumentation

Thermocouple lead wires and hygrometer cables were taken out of the shelter through an opening near the top edge of the hatch wall and connected to indicating and recording instruments located in the instrument bullding. Electrical power cables from the instrument bullaing were brought into the shelter through the alternate air supply piping system installed in the south wall. Temperatures were observed and recorded on electronic potent1ometers. Separate watthour meters integrated the electrical energy used by each of the six simulated occupants and by the light bulbs.

The ventilation air flow rate was measured with a squareedged orifice in the supply line downstream from the air washer and reheater. The orifice diameter was 1.296 inches and $1 t$ was mounted in a 2-inch brass pipe. The relation between pressure drop and flow rate was determined using the ASME coefficients for square-edged orifices. The pressure drop across the orifice was about 0.53 inch $W$.G. for a flow rate of $18 \mathrm{cfm}$ and about 2.92 inches $W . G$. for a flow rate of $42 \mathrm{cfm}$.

A pyrheliometer was mounted on a horizontal platform and supported on the alternate exhaust duct at the south end of the shelter at a level about 3 feet above the ground as 1ndicated in Figure 6. This instrument provided measurements of the solar and sky radiation incident at the site during the-tests.

Heat flow meters were placed in depressions, 1/4-inch deep, cast in the inside surfaces of the walls and roof, and a similar depression chiseled out of the floor surface about 6 inches south of the floor rod location along the major axis. Cement grout was placed on both sides of the heat flow meters as they were installed in the depressions to eliminate air films at the meter surfaces and to provide a smooth concrete surface on the room side of the meter.

\section{TEST PROCEDURE}

During the time interval between completing the construction of the shelter 1tself, and the beginning of the first test about 5 weeks later, chilled a1r was circulated through the interior of the shelter. The concrete in the shelter and the walls of the p1t excavated for the shelter were considerably warmer than the undisturbed earth because of exposure to the ambient air 
and solar radiation during construction. Because the walls of the pit were about 2 feet from the outside surface of the shelter, It was necessary to undercool the shelter for several days after backfilling to withdraw this heat. When this was accomplished, the air temperature in the shelter was raised to warm the concrete and the earth adjacent to it to approximately the temperature of the undisturbed earth.

Five tests were made of the shelter with variations in duration, ventilation rate, ventilating air conditions, and occupancy in accordance with the schedule shown in Table 5. Four tests were made when the earth temperature surrounding the shelter was near the summer maximum and one test when the earth temperature was near the winter minimum.

Table 5

Schedule of Test Conditions

Test

Number

Duration of

$\frac{\text { Test }}{\text { days }}$

1
2
3
4
5

7
7
14
14
14

$\frac{\text { Vent1lating Air Supply }}{\text { Avg。 Dew }}$

Flow Dry Bulb Point

$\frac{\text { Rate }}{\text { cfm }}$

$\frac{\text { Temp. }}{{ }^{\circ} \mathrm{F}}$

42
0
42
18
18

85
-
85
85
35 $\frac{\text { Temp. }}{\mathrm{F}}$

69

69

69

33

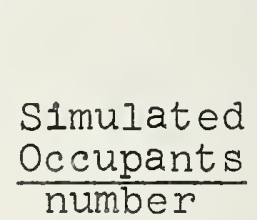

0

6

6

6

6
Approx. Internal Heat Input Btu/hr 110 2500 2500 2500 2500

It was found that mounding the earth over the roof of the shelter altered the position of the isothermal lines beneath the surface of the earth at the shelter site. The isotherms tended to become established at surfaces parallel to the earth's surface, so the thermocouples on the horizontal rods penetrating the shelter walls at midheight did not lie in an isothermal plane in the surrounding earth. The thermocouples at the exterior surface of the shelter walls were about 6 feet below the surface, whereas those 4 feet from the walls were 4 ft 6 in. and 2 ft 9 in. from the nearest point on the surface on the west and east sides of the shelter, respectively, as shown in Figure 5. Consequently, the temperatures 4 feet from the exterior walls were found to be 3 to 5 degrees higher during the late summer than those on the interlor wall surfaces of the shelter for steady state conditions with no heat being supplied inside the shelter. 
Initial temperatures in the range from $67^{\circ} \mathrm{F}$ to $69^{\circ} \mathrm{F}$ at the interior surface of the shelter walls and from $70^{\circ} \mathrm{F}$ to $74^{\circ} \mathrm{F}$ at, a distance of 4 feet from the exterior surface were selected for the starting condition for each of the summer tests as being representative of the undisturbed earth temperatures at the corresponding depths. It was necessary to recondition the shelter walls and surrounding earth after each of the first three summer tests to remove the heat stored in these materials during the tests. This was accomplished by undercooling the interior of the shelter for a few days at the end of each test to establish a heat flow into the shelter from the earth a few feet away, followed by a shorter period of gradual warming of the interior to adjust the temperature of the concrete walls and the earth near to them to desired values. The shelter was allowed to stand without cooling or heating for 1 or 2 days just prior to the start of each test. Reconditioning the shelter with respect to temperature required about as many days as was required for the test immediately preceding it. It was found that the selected initial condition could not always be reproduced exactly during the reconditioning process because of the effects of outdoor conditions and the lag in response of the large mass of materials to heating or cooling. Since only one winter test was made, the existing earth temperatures around the shelter were used without adjustment.

For each 7-days' duration of tests 1, 3, and 4, the conditions of the ventilating air in the supply duct 2 feet above the shelter were controlled as follows:

A steady dry bulb temperature of $85^{\circ} \mathrm{F}$ was maintained for 2 days, followed by a sinusoidal variation of the dry bulb temperature between the limits of $75^{\circ} \mathrm{F}$ and $95^{\circ} \mathrm{F}$ for three 24 -hour cycles, and followed by 2 additional days at a steady temperature of $85^{\circ} \mathrm{F}$. The dew point temperature was maintained at $69^{\circ} \mathrm{F}$ throughout the test, within the limits permitted by the apparatus. A steady air flow rate was maintained for the duration of each test.

For the one winter test a steady dry bulb temperature of $35^{\circ} \mathrm{F}$, a steady dew point temperature of $33^{\circ} \mathrm{F}$, and a steady flow rate of $18 \mathrm{cfm}$ were selected as test conditions for the ventilating air supply.

The latent and sensible heat outputs of the simulated occupants were controlled, first, by adjusting the total elec. trical energy supplied to the electric heater inside each one and, secondly, by adjusting the amount of water dripped on the fabric covering the device on the assumption that ali the water would be evaporated and the remainder of the heat would be 
transferred as sensible heat. The adjustments of total and later heat outputs were made in accordance with the schedule shown in Table 6 .

Table 6

Schedule of Total, Sensible and Latent Heat Transfer of Simulated Occupants

Shelter

$\frac{\text { Temp. }}{{ }^{\circ} \mathrm{F}}$

45
50
55
60
65
70
75
80
85
90

Heat Output, Btu/hr

\begin{tabular}{|c|c|c|c|c|c|}
\hline$\frac{400 \text { Bt }}{\text { Sensible }}$ & $\frac{\text { hr Occ }}{\text { Latent }}$ & $\frac{a n t}{\text { Total }}$ & $\frac{600 \text { Bt }}{\text { Sensible }}$ & Latent & Total \\
\hline 350 & 50 & 400 & 500 & 100 & 600 \\
\hline 350 & 50 & 400 & 500 & 100 & \\
\hline 350 & 50 & 400 & 500 & 100 & 60 \\
\hline 350 & 50 & 400 & 465 & 135 & 600 \\
\hline 350 & 50 & 400 & 400 & 200 & 60 \\
\hline 300 & 100 & 400 & 335 & 265 & 600 \\
\hline 250 & 150 & 400 & 265 & 335 & 600 \\
\hline 200 & 200 & 400 & 200 & 400 & 60 \\
\hline 150 & 250 & 400 & 135 & 465 & 600 \\
\hline 100 & 300 & 400 & 65 & 535 & \\
\hline
\end{tabular}

The relative values of the sensible and latent components in this table agree approximately with those published in the "Guide of the American Society of Heating, Refrigerating and AirConditioning Engineers for persons at rest with a metabolic rate of $400 \mathrm{Btu} / \mathrm{hr}$ and persons doing light work with a metabolic rate of $660 \mathrm{Btu} / \mathrm{hr}$, respectively. They represent some simplification of the published data in that the variations of the components were made linear with temperature throughout most of the range for ease in adjusting the water feed rates to the simulated occupants. The heat input values to the one $200 \mathrm{Btu} / \mathrm{hr}$ occupant were made exactly half of those shown for a 400 Btu/hr occupant.

Prior to the start of each test, the temperatures of the shelter air, the shelter wall surfaces, and a.l the temperatures within the shelter walls and adjacent earth, the weather conditions, the watthour meters on the electric heaters, and the heat flow meters were observed and recorded as the initial condition. At the time selected for beginning each test, usually between $9 \mathrm{a} . \mathrm{m}_{\text {. and }} l \mathrm{l}$ a.m., the conditioned air supply was turned on, the electric heaters in the simulated occupants were energized, and water was fed to each occupant in amounts equivalent to the latent heat outputs in the schedule previously cited. The water was measured in a burette and fed into a separatory funnel for each occupant at 30-minute intervals throughout tests 2, 3, 4, 
and hourly throughout test 5. The rate of dripping from the separatory funnels was adjusted, as nearly as possible, so each increment of water was dripped on the simulated occupant throughout the succeeding time interval.

The following variables were observed at 2-hour intervals, except as otherwise noted, for the duration of each test. The watthour meters on the heaters for the simulated occupants were read at staggered clock times so the interval between readings would be exactly 2 hours.

1. Temperatures at four stations on or in the concrete walls, floor, and roof,

2. Temperatures of the earth at five distances from the concrete walls,

3. Temperature of the air 1 inch from each inside wall surface,

4. Air temperature at center of shelter at six heights above floor,

5. Air temperature at center of hatchway at six heights above floor,

6. Relative humidity at center of shelter at the 5-foot height,

7. Relative humidity at center of hatchway at the 5-foot height,

8. Wet and dry bulb temperature of supply air 2 feet above the earth cover,

9. Dry bulb temperature of ventilating air at outlet of supply pipe,

10. Relative humidity and dry bulb temperature of exhaust air from shelter,

11. Temperature of undisturbed earth at seven depths at two stations,

12. Temperature of supply air at the measuring orifice,

13. Temperature of outdoor air, 
14. Temperature at six stations on each of six simulated occupants,

15. EMF of each of six heat flow meters on shelter walls, floor, and ceiling,

16. EMF output of pyrheliometer,

17. Total water fed to each simulated occupant at 30-minute or l-hour intervals,

18. Pressure drop across air-metering orifice,

19. Electric energy consumption of the six occupants and the electric light bulbs,

20. Temperature of water dripped on simulated occupant No. 1。

In addition, continuous recordings were made on electronic potentiometers of the following variables for monitoring purposes

1. Wet and dry bulb temperature of the supply air,

2. Dry bulb temperature of exhaust air,

3. Temperature of the air at the air-metering orifice,

4. Temperature of the air and water entering the air washer,

5. Ambient air temperature,

6. Shelter air at the 5-foot level,

7. Pyrheliometer output,

8. Earth temperature 1 foot from shelter at two stations,

9. Undisturbed earth temperature at 6-foot depth,

10. ENF of three heat flow meters.

With a few exceptions, tre condensate collected in the floor sump of the shelter was pumped out once each day by a suction pump located above ground and its quantity determined. During tests 3, 4, and 5 an observer entered the shelter for about 10 minutes once a week to observe whether the simulated occupants were evaporating all the water supplied to them and to observe the condensation inside the shelter. 


\section{TEST RESULTS}

The test conditions established and the results observed during the five tests of the prototype family-size underground shelter are shown graphically under the following titles and numbering system, in which the first digit of each number designates the test number.

Figure Numbers

$1-1,3-1,4-1$, and $5-1$

$\begin{array}{lll}1-2 & \text { to } & 5-2 \\ 1-3 & \text { to } & 5-3 \\ 1-4 & \text { to } & 5-4 \\ 1-5 & \text { to } & 5-5 \\ 3-6 & \text { to } & 5-6 \\ 1-7 & \text { to } & 5-7 \\ 1-8 & \text { to } & 5-8 \\ 3-9 & \text { to } & 5-9 \\ 1-10 & \text { to } & 5-10 \\ 3-11 & \text { to } & 5-11 \\ 3-12 & \text { to } & 5-12\end{array}$

Inlet and Outlet Air Conditions of Underground Shelter

Weather Conditions

Undisturbed Earth Temperatures

Air Properties Inside Underground Shelter

Inside Surface Temperatures of Underground Shelter

Total Heat Input to Shelter and Moisture Input to Occupants

Heat Transmission Rate Through Shelter Walls

Temperatures in Shelter Walls and Surrounding Earth at Start of Test Temperatures in Shelter Walls and Surrounding Earth after 7 Days Temperatures in Shelter Walls and Surrounding Earth at End of Test Simulated Occupant Temperatures, $600 \mathrm{Btu} / \mathrm{hr}$ Occupant, Simulated Occupant Temperatures, $400 \mathrm{Btu} / \mathrm{hr}$ Occupant

Daily averages of supply and exhaust air dry bulb and dew point temperatures, shelter air temperatures, shelter wall temperatures, enthalpy changes of the ventilating a1r, heat transfer to the shelter walls, internal heat input, and rise of shelter wall temperature above the initial value, are summarized in Tables 7 to 11 for tests 1 to 5, respectively. Significant variables involving heat transfer rates to the shelter walls and to the ventilating air for tests 2 to 5 have been plotted additionally in Figures 8 to 20 , inclusive.

4.1 Inlet and Outlet Air Conditions of the Shelter

Figures 1-1, 3-1, and 4-1 show that the air temperature in the insulated supply line 2 feet above the ground was maintained at $85^{\circ} \mathrm{F} \pm 1$ degree most of the time during the days selected for 
Tablo ?

SUMAARY OF UNDEROROUND SHELTER TEST RO. 1

2ATE IN AUOUST, 1959

2AILY AVERA QESS (1000 - 1000 HOURS)

Supply A1r Temp D.B.,

Supply A1r Temp D.P.,

Inlet Alr Temp D.B.,

Exhaust A1r Temp D.B.,

Exhaust A1r Temp D.P.,

Wall Surface Temp,

Shalter Alr Temp 1 In. from Wall,

Shelter Alr Temp 5 It Level,

Shelter Alr Temp 2 ft Lovel,

Enthalpy of Exhaust A1r,

Enthalpy of Supply A1r,

Enthalpy Change,

Sensible Heat Added,

Latent Heat Added,

Internal Heat Input,

Sensible Heat Carried Out by Alr,

Latent Heat Carried out by Air,

Total Heat Carried Out by A1r,

Total Heat Absorbed by Walls,

Total Heat Absorbed by A1r \& Partit

Cumilattyo Total Hent Abrorbed by Iolde.

Heat Flux through Wa1is,

Btu/hr(st) $)^{2}$

* Surf. Heat Transfor Coesf. to Wallo

TENP. RISE OF WALLS FRON START OF TEST,

- Btu/hr(rt) $)^{2}$ (OF)

USCOMM-NBS-DC
$13-14 \quad 24-15 \quad 15-16 \quad 16-17 \quad 27-18 \quad 18-19$

$\begin{array}{llllll}\text { of } \quad 84.5 & 85.2 & 84.4 . & 84.2 & 84.2 & 84.3\end{array}$

$\begin{array}{llllll}.08 & 68.7 & 68.1 & 68.5 & 68.4 & 68.4\end{array} \quad 68.2$

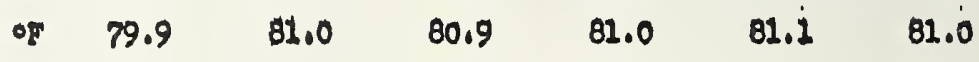

$\begin{array}{lllllll}\text { of } & 71.7 & 72.7 & 73.3 & 73.9 & 74.5 & 74.7\end{array}$

$\begin{array}{lllllll}\circ 8 & 68.2 & 68.5 & 69.0 & 69.5 & .69 .7 & 69.9\end{array}$

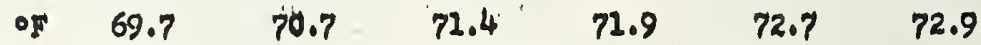

$\begin{array}{lllllll}\text { of } & 70.9 & 7.8 & 72.5 & 72.8 & 73.7 & 73.8\end{array}$

$\begin{array}{lllllll}\circ & 71.4 & 72.4 & 73.1 & 73.6 & 74.3 & 74.6\end{array}$

아. $71.0 \quad 71.9 .72 .4 \quad \ldots 72.8 \ldots 73.5 \quad 73.7$

$\begin{array}{llllllll}\text { Btu/16 } 33.44 & 33.90 & 34.32 & 34.78 & 35.04 & 35.20\end{array}$

$\begin{array}{llllllll}\text { Btw/2b } \quad 36.90 & 36.66 \quad 36.74 & 36.64 & 36.64 & 36.54\end{array}$

$\begin{array}{lllllll}B t u / 2 b & -3.46 & -2.76 & -2.42 & -1.86, & -1.60 & -1.34\end{array}$

$\begin{array}{llllllll}B t u / 2 b & -3.07 & -2.98 & -2.66 & , & -2.47 & -2.33 & -2.30\end{array}$

$\begin{array}{lllllll}\text { Btu/16 } & -0.39 & 0.22 & 0.24 & 0.62 & 0.73 & 0.96\end{array}$

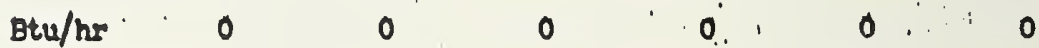

Btu/hr $\quad \begin{array}{llllll}-562 & -547 & -490^{\circ} & -454 ; & -425 & -423\end{array}$

Btu/hr $\quad-72 \quad 40 \quad 44,112,133,177$

$\begin{array}{lllllllll}\mathrm{Btu} / \mathrm{hr} & -633 & -507 & -446 & -342 & -292 & -246\end{array}$

$\begin{array}{llllll}\text { Btiu/hr } 596 \quad 477,433 & 322 & 266 & 233\end{array}$

$37: 30 \quad 23 \quad 20 \cdot 26 \quad 13$

$14300 \quad 25750 \quad 36150 \quad 43850 \quad 50250 \quad 55850$

1.49. $\quad 2.19 \quad 1.08 \quad 0.80 \quad 0.66 \quad 0.58$

$1.244^{\prime} \quad 2.08,0.98 \quad 0.89,0.66,0.64$

$\begin{array}{llllllll}\circ & 1.1 & 2.0 & 2.4 & 3.0 & 3.0 & 4.2\end{array}$ 


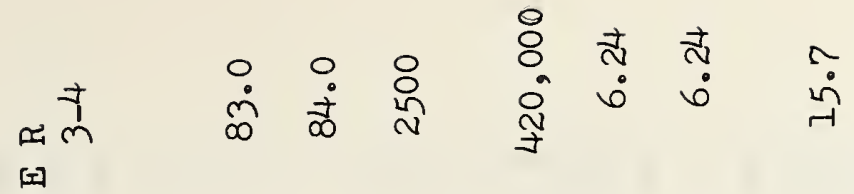

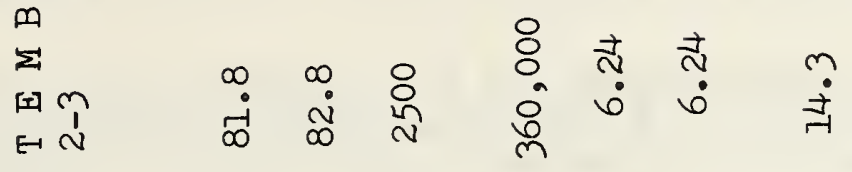

A.

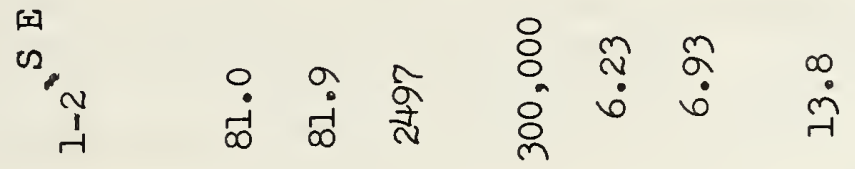

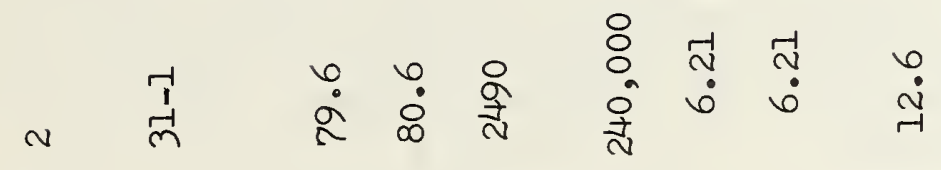

울

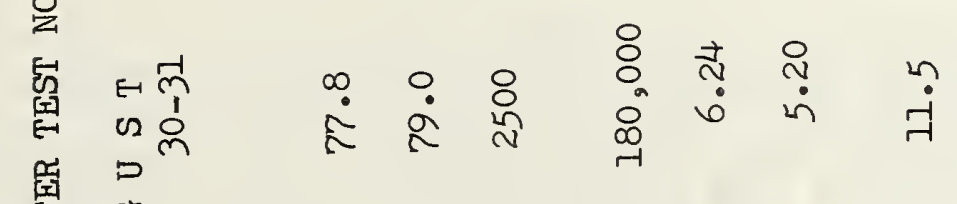

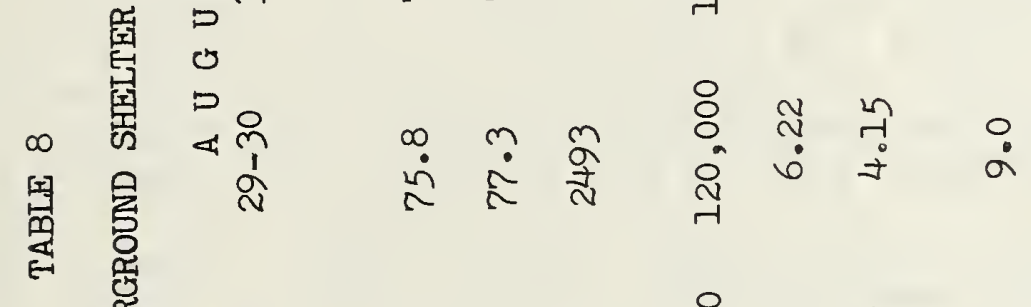

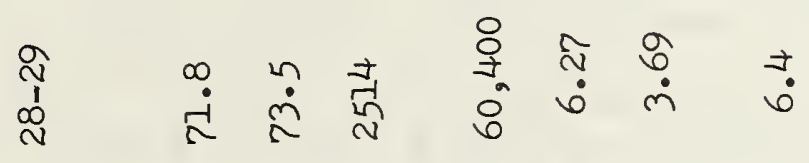

동

突

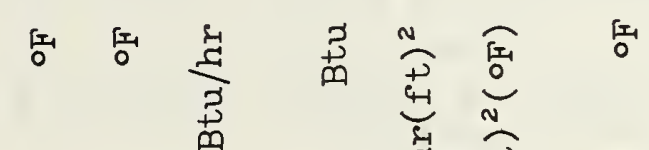

兽

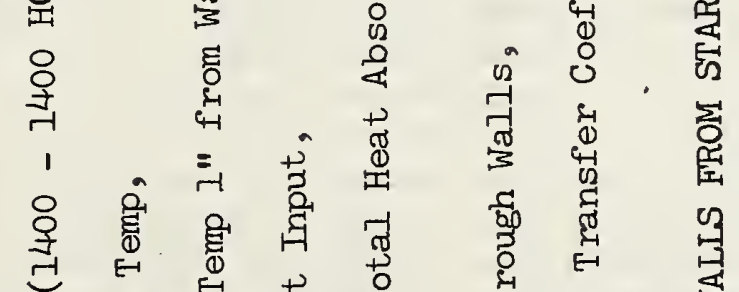

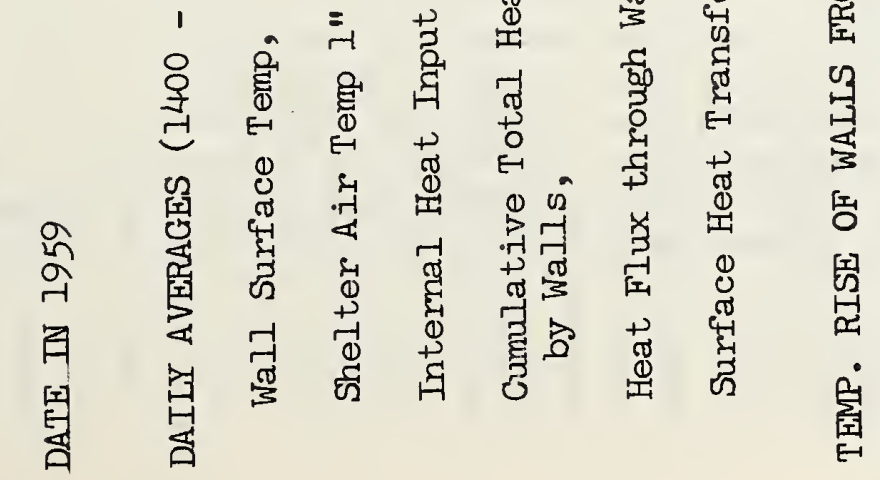


steady supply air temperatures in the summer tests. When the dry bulb temperature of the supply air was varied sinusoidally in a repetitive cycle for 3 days in succession, the maximum and minimum values were maintained at $95^{\circ} \mathrm{F} \pm 1$ degree and $75^{\circ} \mathrm{F} \pm 1$ degree, in most cases. The dew point temperature of the supply air at the same location was controlled at $69^{\circ} \mathrm{F} \pm 1$ degree with a few exceptions. During the winter test, the supply air temperature at the same station was maintained at a dry bulb temperature of $35^{\circ} \mathrm{F} \pm 1$ and a dew point temperature of $33^{\circ} \mathrm{F} \pm 1$ for most observations during the last 10 days of the test. These temperatures averaged 2 to 3 degrees higher during the first 4 days of the test before the crushed ice was applied to a part of the air supply line.

During the periods of the summer tests when a steady supply air temperature was maintained, its temperature decreased 5 or 6 degrees at the beginning of the test and 2 to 3 degrees near the end of the test between the control point 2 feet above the ground surface and the inlet to the shelter space about $81 / 2$ feet below. During the winter test, the direction of heat transfer between the ventilating air and the surrounding materials was reversed, resulting in a temperature rise in the supply air of about 5 degrees at the beginning of the test and about 9 degrees near the end of the test between the control point and the inlet to the shelter space. Some of this sensible heat was exchanged with the shielding wall, some with the earth cover of the shelter, and the remainder with the atmosphere above the shelter. The magnitude of this sensible heat transfer ranged from an initial value of about $230 \mathrm{Btu} / \mathrm{hr}$ downward to about $80 \mathrm{Btu} / \mathrm{hr}$ at the end of test 3 , and from an initial value of about $120 \mathrm{Btu} / \mathrm{hr}$ to a final value of about $40 \mathrm{Btu} / \mathrm{hr}$ in test 4. During test 5, the sensible heat absorption ranged from an initial value of about $100 \mathrm{Btu} / \mathrm{hr}$ to a final value of about $190 \mathrm{Btu} / \mathrm{hr}$.

During the periods of the summer tests when the supply air temperature was varied sinusoidally between $75^{\circ} \mathrm{F}$ and $95^{\circ} \mathrm{F}$, the shelter inlet air temperature varied 5 to 6 degrees above and below an average value of $81^{\circ} \mathrm{F}$ to $82^{\circ} \mathrm{F}$. In tests 1 and 3 , with a ventilating air supply rate of $42 \mathrm{cfm}$, the exhaust air temperature varied about 2 degrees in response to the 20-degree variation in supply air temperature, whereas, in test 4 with a ventilating rate of $18 \mathrm{cfm}$, the exhaust air temperature varied no more than 1 degree for the same variation in supply air temperature. In most cases, the heat flow meters on the roof and the east, west, and south walls of the shelter responded to the cyclic supply air temperature pattern by revealing a cyclic heat transfer to the shelter walls. This response is shown in Figures $1-7,3-7$, and 4-7. The heat flow meter on the south wall revealed 


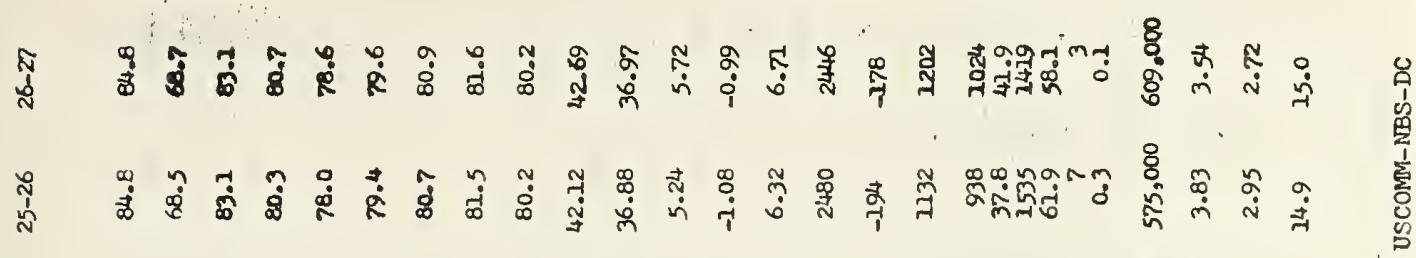

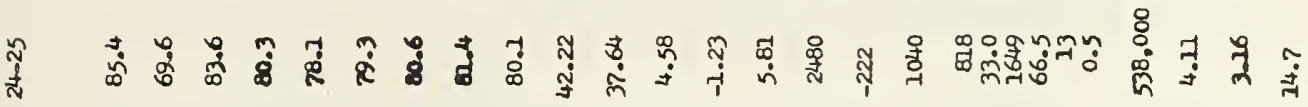

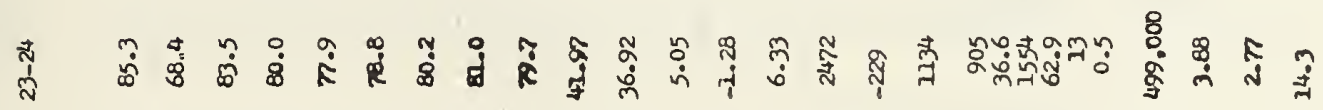

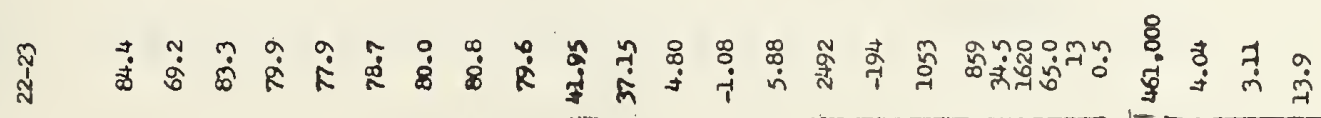

สุ ส่

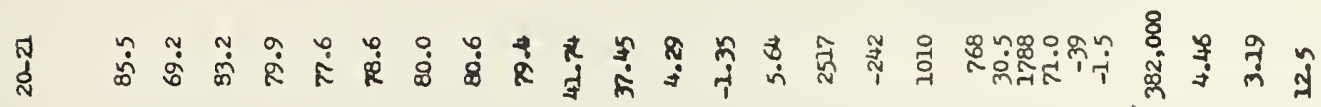

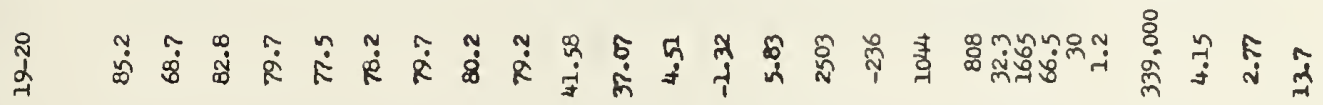

官

ఫ్ने

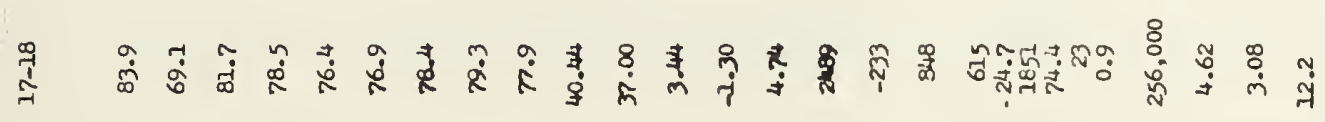

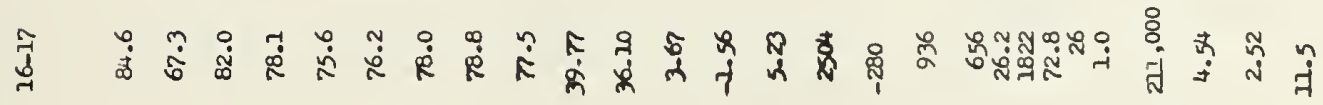

岁 话

青 㟧

声

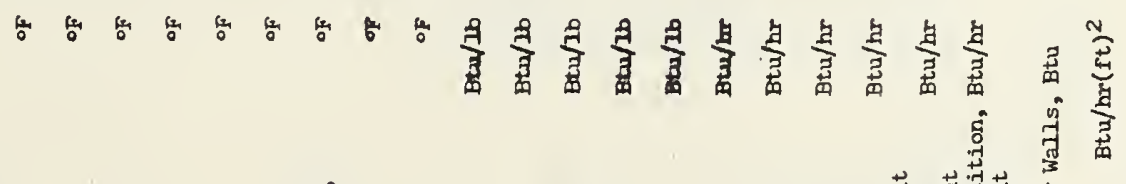

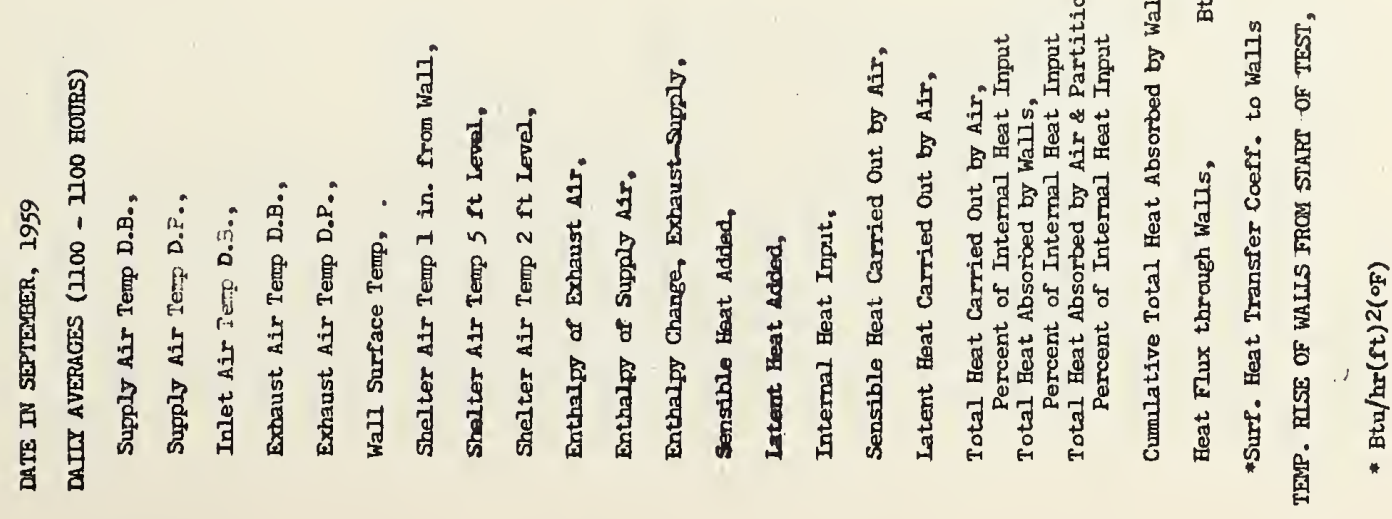




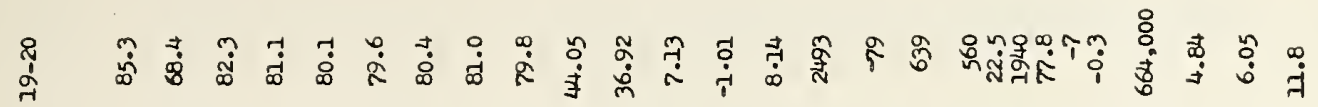

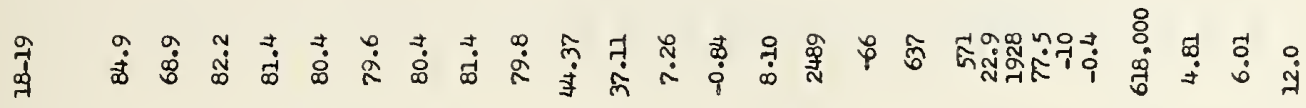

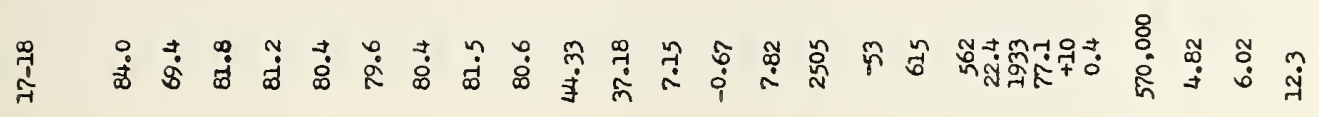

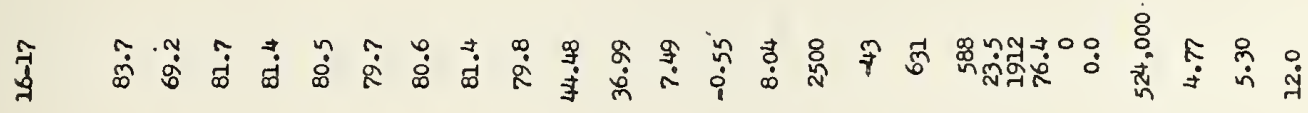

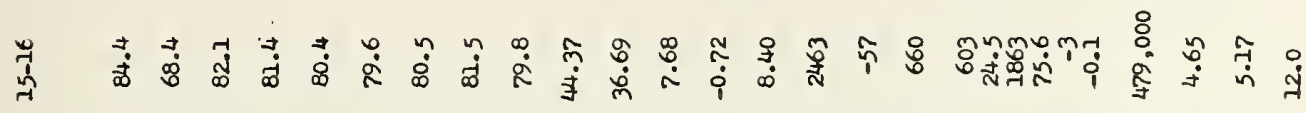

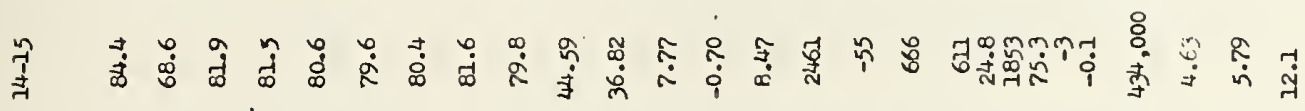

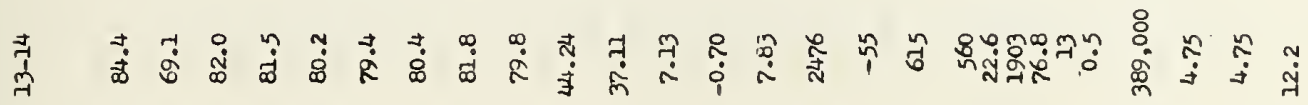

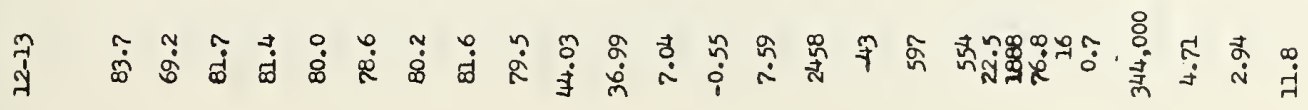

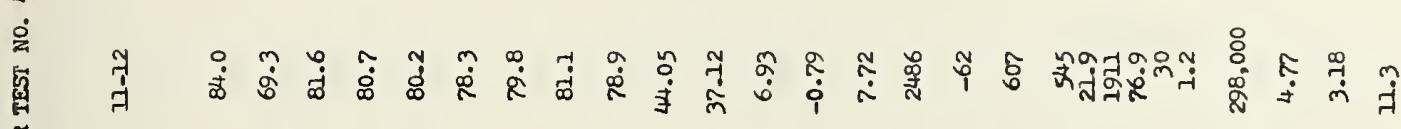

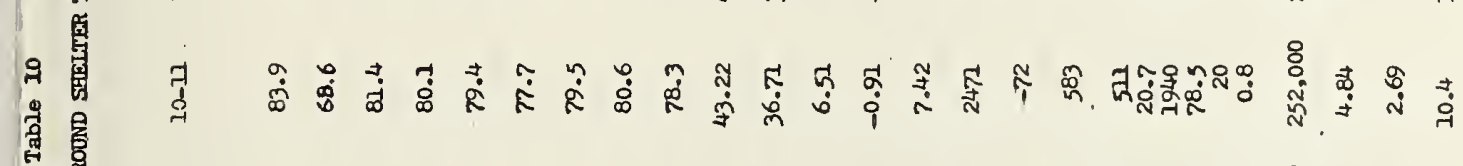

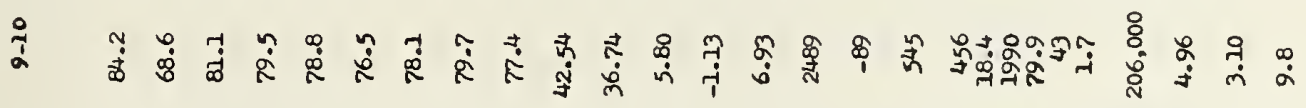

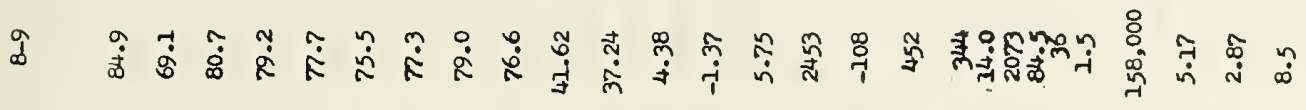

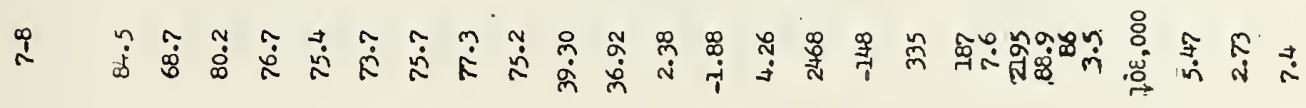

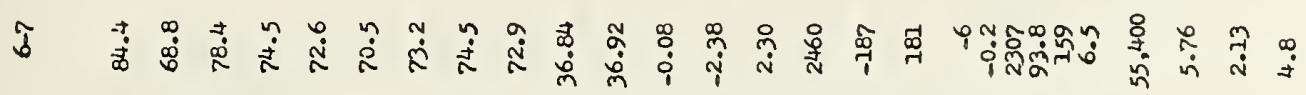

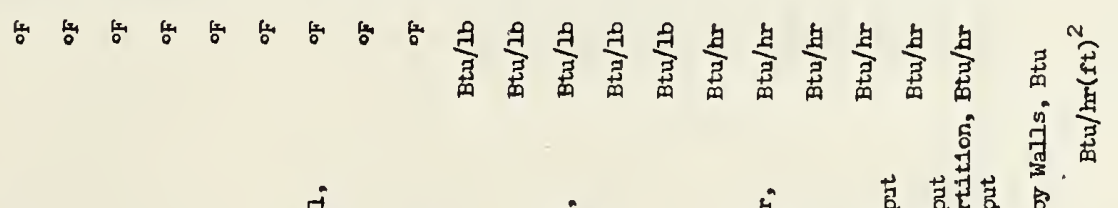

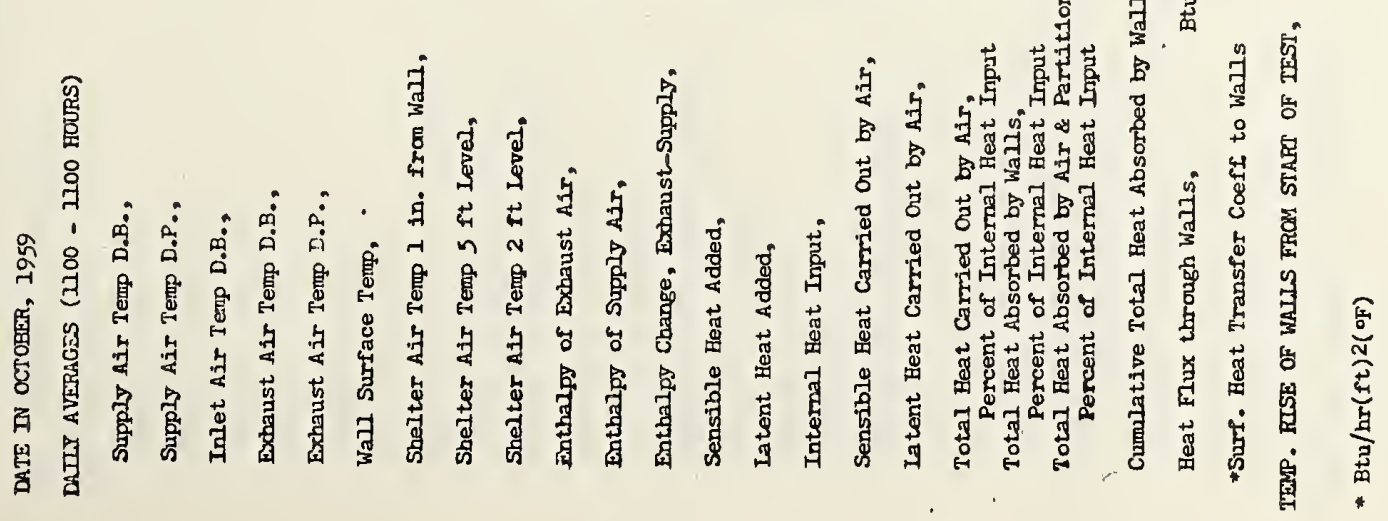





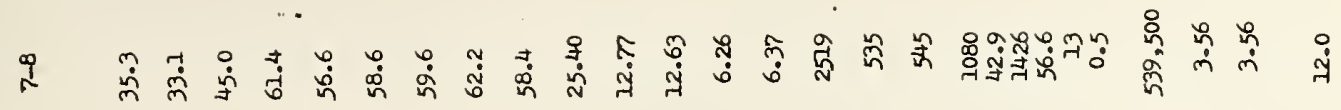

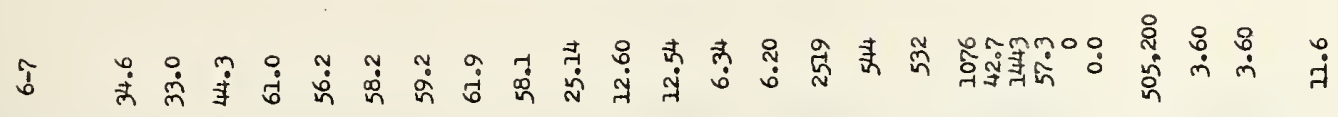

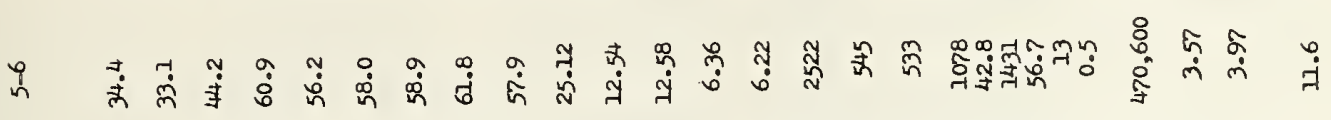

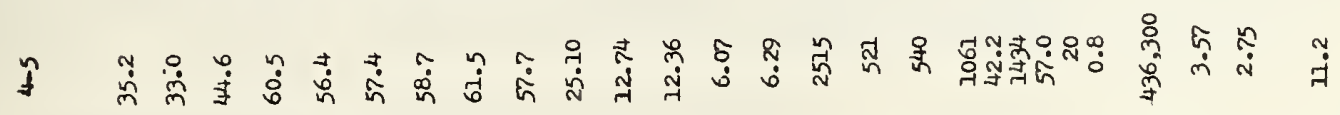

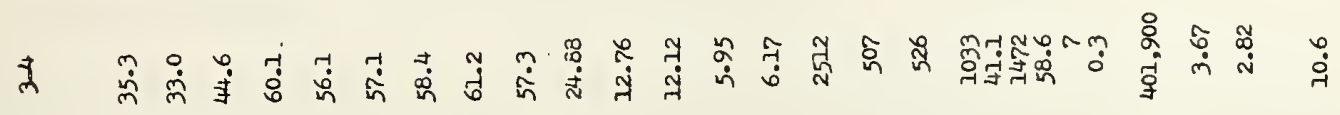

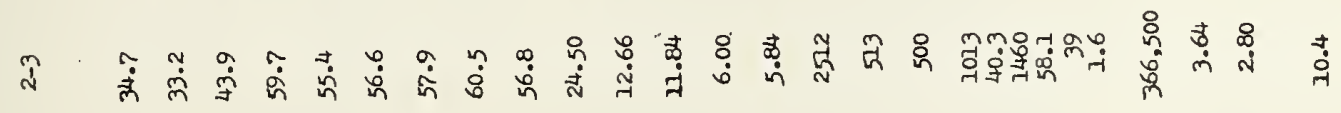

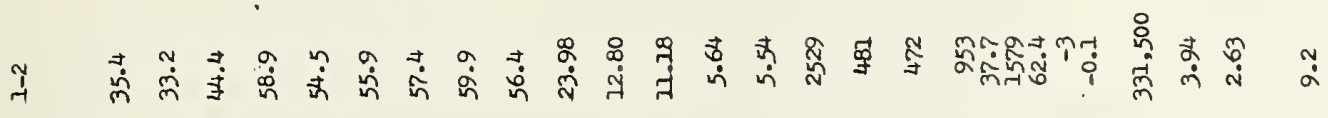

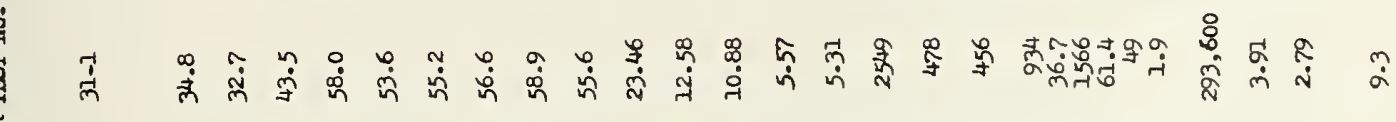

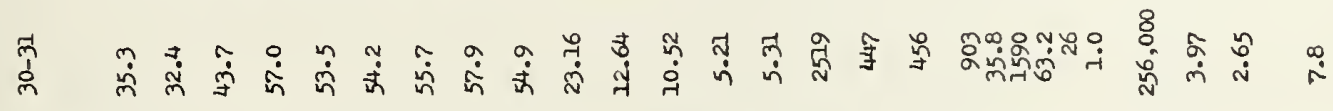

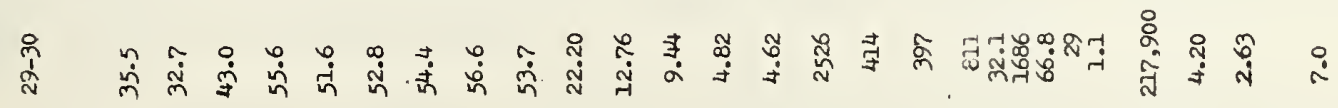

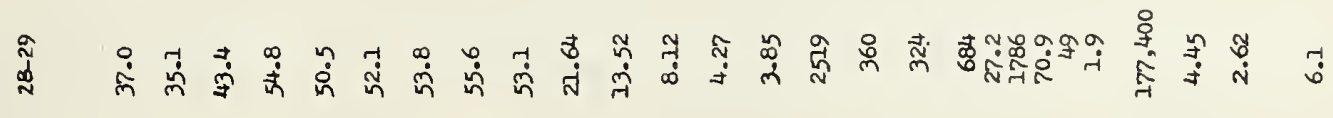

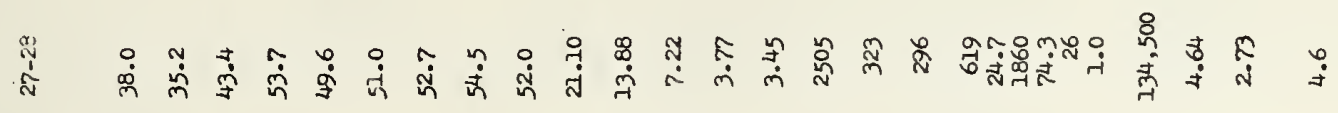

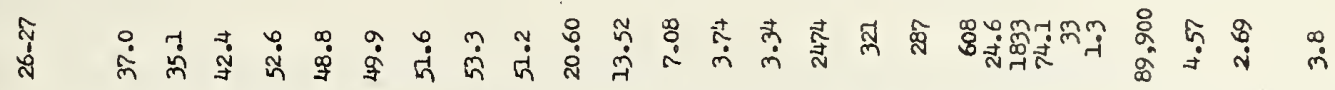

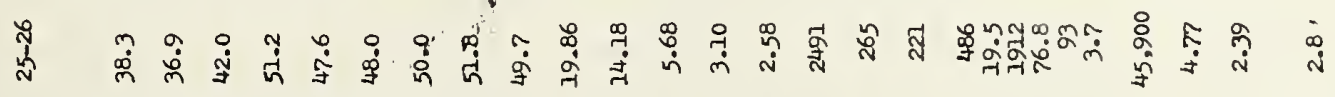

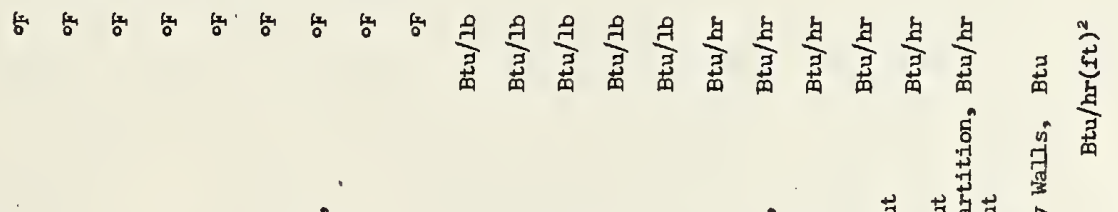

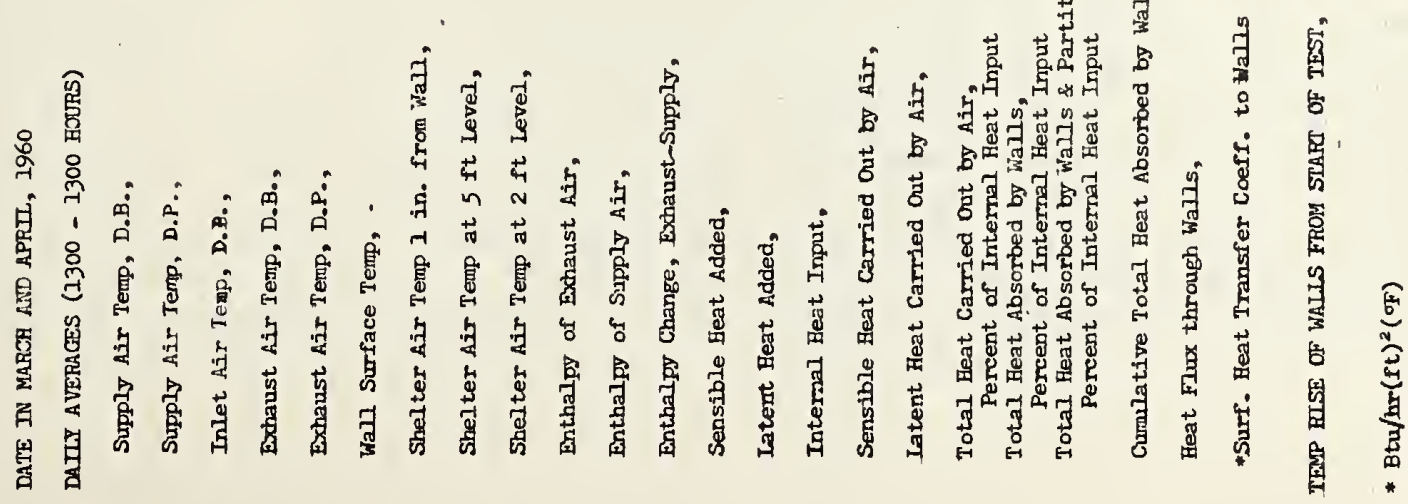



the greatest fluctuation in output as a result of variations in supply air temperature indicating that the air stream from the inlet probably carried across the longer dimension of the room to the south wall. The inlet air velocity was about $820 \mathrm{ft} / \mathrm{min}$ in tests 1 and 3 , and about $350 \mathrm{ft} / \mathrm{min}$ in tests 4 and 5 .

\subsection{Temperatures Inside the Shelter}

Figures 2-4 to 5-4 show the air temperatures at the 2- and 5-foot levels in the main room of the shelter at the center, and at the 5-foot level in the center of the hatchway. Tables 7 to 11 show daily averages of the air temperatures at several stations in the shelter. The graphs show that the air temperatures rose several degrees during the first few hours of each test, with the rate of temperature rise becoming progressively smaller as the test continued. The rise of shelter air temperature at two levels is shown in Table 12 for the first day, the first week, and the second week of the test during tests 2 to 5 when the simulated occupants were in use. This table shows that the temperature rise during the first day was equal to or greater than the rise during the following 6 days in five of the eight cases, and that a small change in air temperature occurred during the second week of the 2-week tests.

The highest daily average temperature observed in the shelter at the 5 -foot level during the summer tests was $86.9^{\circ} \mathrm{F}$ in test 2 , $81.6^{\circ} \mathrm{F}$ in test 3 , and $81.8^{\circ} \mathrm{F}$ in test 4 ; and during the winter test $62.2^{\circ} \mathrm{F}$ in test 5. No ventilating air was supplied to the shelter during test 2. The possible effect of weather conditions on the shelter air temperatures is discussed in section 4.7 of this report.

\subsection{Condensation and Humidity Inside the Shelter}

Condensation began to appear on the interior surfaces of the shelter during the first day of tests 2,3 , and 4, and condensation continued throughout the tests, as indicated by the fact that water collected daily in the sump at the low point of the floor. Figures 3-6, 4-6, and 5-6 show the rates at which water was dripped on the simulated occupants during tests 3, 4, and 5, respectively. Table 13 summarizes the daily totals of the water fed to the simulated occupants in accordance with the planned schedule, and the weight of water siphoned from the sump at daily intervals. This table shows that the water collection in the sump reached about 65 percent of the water fed to the occupants in test 2, and the percentage was essentially constant during the last 5 days of the test. In test 4 , with $18 \mathrm{cfm}$ of ventilating air, the condensation rate reached a reasonably steady value 


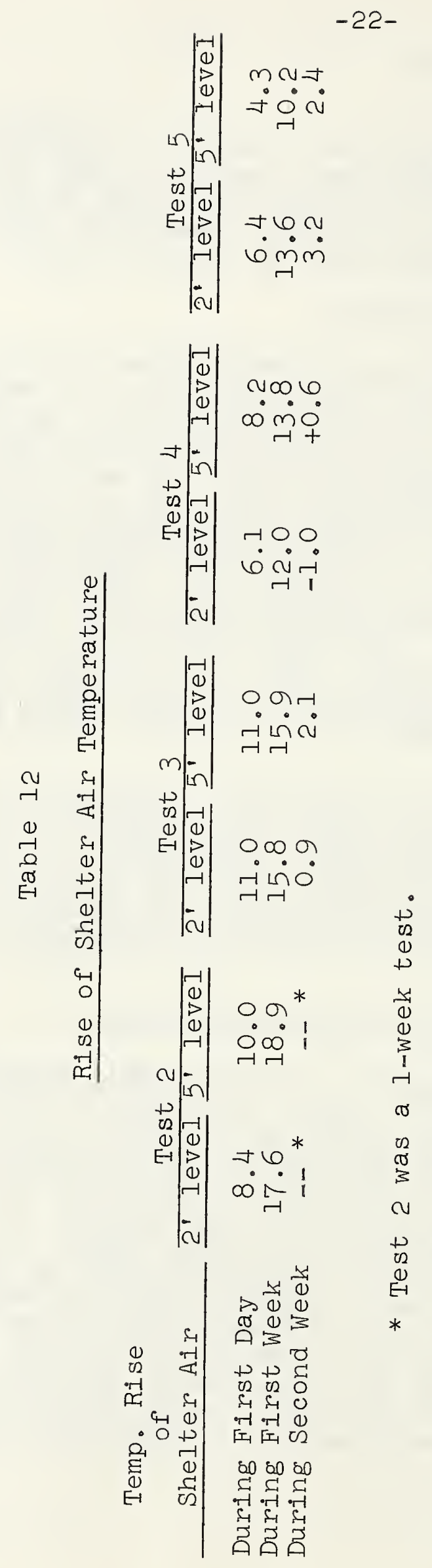


Table 13

Daily Totals of Water Fed to Simulated Occupants and Condensation collected from Floor sump, lb

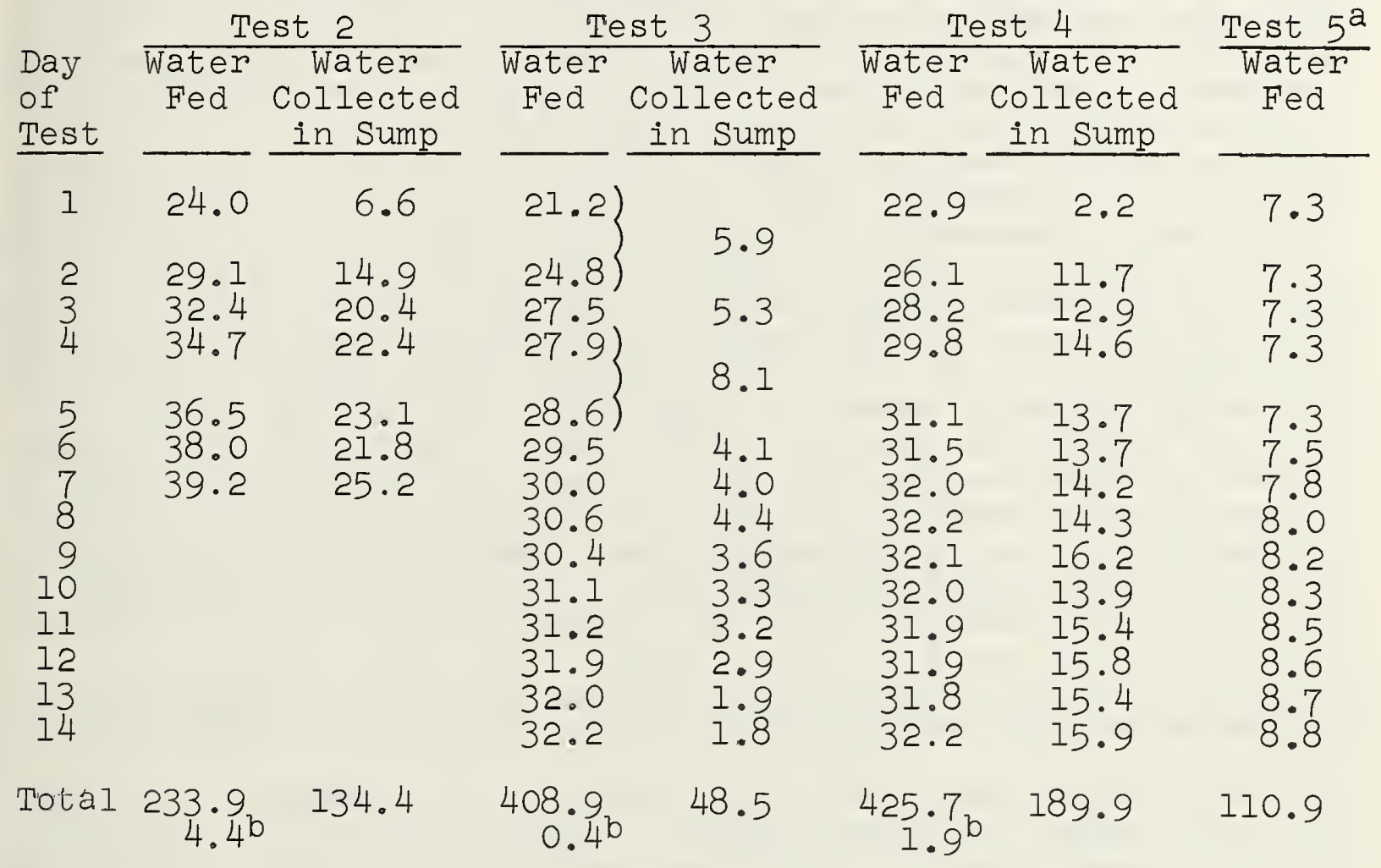

a Only a trace of water collected in the sump at the start of the test.

b Average daily amount of water fed to simulated occupants, but not evaporated, in pounds. This water was collected in the overflow pans under the simulated occupants. 
of about 50 percent of the water fed to the simulated occupants, whereas in test 3 with $42 \mathrm{cfm}$ of ventilating air, the condensation rate decreased as the test progressed from a high value of about 20 percent to a final value of only about 5.5 percent of the water fed to the simulated occupants. In the latter case, the walls of the shelter had dried off at the end of the test although the ceiling and floor were still wet. The apparent dis crepancy in Table 13 between the water fed to the simulated occupants and the water collected in the sump for test 2 without ventilation may be due to water absorption by the shelter walls or to some air leakage around the hatch cover, or a combination of these two processes. The occurrence of selective condensatiol on the interior exposures of the shelter is probably accounted for by differences in the moisture content of air coming in contact with the various surfaces and the differences in temperaturt of the surfaces. The warm, moist air rising from the simulated occupants probably came in contact with the ceiling first, and then the walls and floor, in that order. The floor surface was always colder than the ceiling and wall surfaces during these summer tests. During an inspection of the shelter 3 days after the start of test 5, it was observed that the ceiling of the hatchway was wet and dripping, the north wall of the hatchway was damp along the top for a distance of about 1 foot from the ceiling, and a small amount of water lay in the sump in the floor; otherwise, the shelter surfaces were dry. There were no wet surfaces inside the shelter at the erd of the winter test.

High relative humidities prevailed in the shelter during both the summer and winter tests. Figures $1-4$ to 5-4 show the relative humidities at the 5-foot level in the shelter during the five tests. In test 1, with no simulated occupants, the relative humidity in the center of the room gradually decreased from an initial value of 87 percent to a final value of 82 percent as the wall temperatures increased. In test 2, without ventilation, the moisture evaporated from the simulated occupants quickly saturated the air, and it remained saturated for the remainder of the 7-day test. In test 3, with a ventilation rate of $42 \mathrm{cfm}$, the relative humidity rose to 93 percent during the first haIf day of the test and remained nearly constant until the last 2 days of the test, except that it increased and decreased cyclically during the periods when the supply air temperature was varied. The relative humidity decreased to about 89 percent at the end of test 3 accompanied by drying of the wall surfaces in the shelter. In test 4, with a ventilation rate of $18 \mathrm{cfm}$, the relative humidity in the center of the room increased to 96 percent in about 1 week and remalned essentially constant at this level during the last 7 days of the test. In test 5, with a ventilation rate of $18 \mathrm{cfm}$ under winter conditions, the relative humidity in the center of the room gradually decreased from an initial value of 92 percent to a final value of 89 percent. 
The amount of water vapor released in the shelter by the simulated occupants and the small temperature differences that existed between the air and wall surfaces accounts for the high relative humidity observed during the summer tests. Tables 9 and 10 show that the average wall surface temperature, the temperature of the air 1 inch from the wall, the temperature of the air at the 5-foot level in the center of the room, and the exhaust air temperature seldom differed more than 2 or 3 degrees during tests 3 and 4. The relation of interior surface area in the shelter to the sensible heat release was such that the temperature difference required between air and surface to transfer all of this heat to the walls was about 3 degrees at the beginning of a test and only about 1 degree at the end of the test. Thus it can be said that the wall temperature controlled the dew point temperature of the exhaust air. Tables 9 and 10 show that these temperatures were in close agreement, but not consistently in a fixed relation to each other. In test 4, the dew point temperature of the exhaust air always exceeded the average wall surface temperature by 1 degree more or less, whereas in test 3, the dew point temperature of the exhaust air was higher than the average wall surface temperature during the first 2 days only, and gradually decreased to a value about 1 degree below the average wall surface temperature at the end of test 3 .

During the winter test, the average wall surface temperature, the temperature of the air 1 inch from the walls, the temperature of the air at the 5-foot level in the center of the room, and the exhaust air temperature never differed from each other more than 4 degrees at any time during the test, as shown in Table 11 . In this test, the ceiling surface temperature of the hatchway probably limited the dew point of the exhaust air for the first few days of the test, but later in the test the moisture release inside the shelter did not quite saturate the ventilating air and all interior surfaces were dry at the end of the 2-week test.

It is evident from the data and experience gained in these tests that the amount of ventilating air required to prevent condensation in a small shelter such as the one tested is determined by the wall surface temperature of the shelter, the dew point of the entering air, and the amount of latent heat release in the shelter. These relationships could be represented graphically with a family of curves. Such a family of curves has been prepared and will be described in the section on Discussion and Conclusions. 
4.4 Enthalpy Change of the Ventilating Air in the Shelter

Figures 1-1, 3-1, and 4-1 show that the dry bulb temperature of the ventilating air decreased as it passed through the shelter for the summer tests except during the periods when the supply air temperature was being varied sinusoidally between the limits of $75^{\circ} \mathrm{F}$ and $95^{\circ} \mathrm{F}$ in tests 3 and 4. In these periods, the ventilating air was warmed by the shelter for a few hours when the dry bulb temperature of the supply air was near $75^{\circ} \mathrm{F}$. But, on the average, the ventilating air contributed a small amount of sensible heat to the shelter. At the same time, moisture was always added to the ventilating air, as it passed through the shelter, since the dew point temperature of the exhaust air was higher than that of the supply air as shown in Figures 1-1, 3-1, and 4-1. On the other hand, the dry bulb temperature and dew point temperature of the ventilating air increased as it passed through the shelter for the one winter test, as shown in Figure 5-1.

Daily averages of the dew point and dry bulb temperatures of the supply and exhaust air and the enthalpy changes of the air between inlet and outlet of the shelter are summarized in Tables 9 to 11 for tests 3, 4, and 5, respectively.

Figures 9 and 13 show the enthalpy increase of the ventilatin air caused by latent heat absorption, the enthalpy decrease caused by cooling the air as it passed through the shelter, and the algebraic sum of the two components on a daily average basis for tests 3 and 4 , respectively. In test 3 , with a ventilation rate of 42 cfm, the sensible heat contributed to the shelter by the air ranged from $465 \mathrm{Btu} / \mathrm{hr}$ during the first day of the test to 174 Btu/hr during the last day, whereas the moisture carried out by the air represented 158 Btu/hr during the first day and increased to $1215 \mathrm{Btu} / \mathrm{hr}$ during the final day of the test. At the end of test 3, the ventilating air was removing about 90 percent of the latent heat supplied to the simulated occupants. In test 4, the sensible heat added to the shelter and the latent heat removed from the shelter by the ventilating air were considerably less than for test 3 because the ventilation rate was less than half as large in test 4. On the ninth day of test 4, when the latent heat removal was a maximum, it represented about 50 percent of the moisture supplied to the simulated occupants.

Figure 17 shows the enthalpy increase of the ventilating air caused by latent and sensible heat absorption as the air passed through the shelter during the one winter test. In this test, with an air flow rate of $18 \mathrm{cfm}$, the sensible heat absorbed by the ventilating air ranged from an initial value of 
$265 \mathrm{Btu} / \mathrm{hr}$ to a final value of $545 \mathrm{Btu} / \mathrm{hr}$, and the latent heat absorption ranged from $220 \mathrm{Btu} / \mathrm{hr}$ to $535 \mathrm{Btu} / \mathrm{hr}$ between the first and last days of the test. During the first 5 days of the test, the water evaporated by the six simulated occupants had a latent heat equivalent of about $325 \mathrm{Btu} / \mathrm{hr}$, whereas the rate of moisture evaporation at the end of the test represented a latent heat exchange of about $385 \mathrm{Btu} / \mathrm{hr}$. Thus, Figure 17 indicates that some condensation occurred during the first 3 or 4 days of the test, after which the ventilating air was able to remove all the moisture evaporated by the simulated occupants and additionally effect some reduction in moisture content of the concrete walls.

In tests 2 to 5, heat was released inside the shelter at a rate of about $2500 \mathrm{Btu} / \mathrm{hr}$ of which about $2400 \mathrm{Btu} / \mathrm{hr}$ was emitted by the six simulated occupants in the form of sensible heat and water vapor. Figures 10, 14, and 18 show the percent of the internal heat input to the shelter that was carried out by the ventilating air plotted against elapsed time, and Figures 11, 15, and 19 show these percentages plotted against wall surface temperature, for tests 3, 4, and 5, respectively. In 2-weeks' time this percentage reached a value of 42 in test 3 and would probably have increased somewhat more if the test had been continued, whereas the percentage reached 24 on the ninth day of test 4 and then decreased slightly thereafter.

In test 5, the ventilating air was removing 43 percent of the internal heat input after 12 days, and the percentage was essentially constant for the remainder of the test. The slope of the curves in Figures 11 and 15 suggest that the percent of the total heat carried out by the ventilating air would have continued to increase, if the wall temperature continued to increase. However, since the rate of change of wall temperature was small after 2 weeks in tests 3 to 5, further substantial increase in the percentage of the internal heat carried out by the ventilating air would be unlikely for these test conditions.

4.5 Heat Transfer to Shelter Walls and Surrounding Earth

Daily average values of the heat transfer rate to the shelter walls were determined for tests 2 to 5 by subtracting the heat carried out by the ventilating air from the total heat released inside the shelter. These daily average values are summarized in Tables 7 to 1l, respectively. In test 2, the heat transfer rate to the walls was equal to the heat release rate inside the shelter, for practical purposes, since no ventilation air was supplied during this test. 
Figures 10, 14, and 18 show the percent of the total heat input transferred by the shelter walls plotted against elapsed time, and Figures 11, 15, and 19 show these percentages plotted against wall surface temperature for tests 3, 4, and 5, respectively. In test 3 , the percent of the internal heat input to the shelter that was absorbed by the shelter walls decreased from a value of about 103 during the first day of the test to a value of 57 during the fourteenth day. In test 4, the corresponding initial and final values of the heat transfer to the walls were 94 percent and 78 percent, and in test 5 the initial and final values were 77 percent and 57 percent of the internal heat input to the shelter. Figures 11 and 15 indicate that the heat transfer to the shelter walls would have become a smaller and smaller percentage of the internal heat input as the shelter wall temperatures increased, whereas Figure 19 shows that the heat transfer to the shelter walls had leveled off for practical purposes after 2 weeks.

Figures $8,12,16$, and 20 show the temperature rise of the wall surfaces versus the total heat absorption of the shelter walls. Each plotted point in these graphs represents a cumulative total heat transfer for an integral number of days after the beginning of the test. Figures 12 and 20 show that the wall surface temperature had nearly leveled off in 14 days in tests 3 and 5, even though the rate of heat transfer to the shelter walls was about 35,000 Btu/day at that time. Figure 16 shows that the wall surface temperature had become steady or started to decrease after 14 days in test 4, coincidental with a daily heat transfer of about 46,000 Btu/day. The lowering of the outdoor temperature and earth temperature during the latter half of test 4 probably accounts for the earlier leveling off of the wall temperatures in test 4 even though the heat transfer rate to the walls exceeded that for test 3 at the corresponding time. The temperature rise of the wall surfaces during test 2 was more rapid with respect to time and with respect to the total heat absorbed tran for tests 3 and 4. No ventilation air was provided in test 2 so heat was transferred to the walls at a greater rate during this test.

Figures 1-7 to 5-7 show the heat flow into the inner surface. of the shelter for tests 1 to 5 as indicated by the heat flow meters embedded in the concrete near the inner surface. An inspection of these graphs indicates the following conclusions regarding the unit heat transfer rates through the six interior surfaces of the shelter. 
(1) The highest heat transfer rate occurred through the floor during the summer tests, whereas the heat transfer rate through the floor was equal to the lowest of the other five surfaces in the winter test. These results would be expected from the relative average temperature of the several exposures, winter and summer.

(2) With the exception of test 1 , the heat transfer rate through the north wall was lower than for the other three walls during all tests with ventilating air supplied to the shelter. Since the heat flow meter on the north wall was shielded from direct radiation by the interior partition, and since it was relatively near to the air exhaust duct, a smaller heat transfer rate would be expected through this meter.

(3) The heat flow meter on the south wall, opposite the ventilating air inlet, was usually more sensitive to the cyclic variations in dry bulb temperature of the supply air during the summer tests than any of the other heat flow meters.

(4) The heat flow meter on the ceiling reflected the outdoor weather conditions to some extent. In test 1 , without internal heat input in the shelter, this meter registered inward heat flow throughout the test.

By assuming that each heat flow meter indicated the average heat flow rate through the entire interior exposure to which it was attached, an overall value for the amount of heat absorbed by the concrete can be obtained for any selected period of time for comparison with the value obtained by the difference method already described. Such a comparison shows that the values for heat absorption by the concrete during the last 24 hours of tiests 2 , 3, and 4, as determined by the heat flow meters, was 61, 64, and 52 percent, respectively, of the values computed by the difference method, whereas in tests 1 and 5, the ratios of the heat flow meter value to the difference value were 92 and 108 percent, respectively. In tests 2, 3, and 4, condensation was occurring on the shelter surfaces, whereas in tests 1 and 5, there was no condensation on the surfaces during the day chosen for comparisor. These results suggest that the heat flow meter locations were much more representative of the entire interior surface of the shelter with respect to sensible heat transfer than with respect to condensation and latert heat transfer. 
The temperatures at several stations in the shelter walls, in the surrounding earth, and in the shelter space 1 inch from the wall surfaces are shown graphically in Figures 1-8 to 5-8 for the initial condition, in Figures 3-9, 4-9, and 5-9 after 7 days, and in Figures 1-10 to 5-10 at the end of the test. A comparison of Figures 3-9, 4-9, and 5-9 with Figures 3-10, 4-10, and 5-10 shows that the temperature pattern in the shelter walls and adjacent 4 feet of earth changed very little during the second week of tests 3 to 5. This indicates that a near steady state heat transfer existed during the second week of these two tests. The temperature gradient in the earth over the roof of the shelter changed appreciably between the midpoint and the end of tests 3 and 4, indicating that the outdoor weather influenced these temperatures considerably.

The heat storage of the concrete walls of the shelter and surrounding earth was large. By computing the mass of concrete in the shelter and its temperature change during the test, the amount of heat stored in the concrete can be approximated. Similar computations can be made for any l-foot thickness of the earth adjacent to the shelter up to a distance of 4 feet from the exterior surface of the walls. Such a computation was made for test 3 based on the initial and final temperatures shown in Figures 3-8 and 3-10, respectively. The results are summarized in Table 14.

\section{Table 14}

Heat Storage in Concrete and Surrounding Earth

\begin{tabular}{|c|c|c|}
\hline Material & $\begin{array}{c}\text { Incremental } \\
\text { Distance } \\
\text { from } \\
\text { Shelter } \\
\text { walls, } \\
\text { ft }\end{array}$ & $\begin{array}{l}\text { Increase in } \\
\text { Heat Content } \\
\text { During Test } \\
\text { Btu }\end{array}$ \\
\hline $\begin{array}{l}\text { elter and Shielding Wall } \\
\text { helter } \\
\text { helter } \\
\text { helter } \\
\text { helter }\end{array}$ & $\begin{array}{l}0-1 \\
0-1 \\
1-2 \\
2-3 \\
3-4\end{array}$ & $\begin{array}{r}132,000 \\
216,000 \\
156,000 \\
41,000 \\
-31,000\end{array}$ \\
\hline & & 514,000 \\
\hline
\end{tabular}

Concrete in Shelter and Shielding wall

Earth around Shelter

Earth around Shelter

Earth around Shelter

Earth around Shelter

Total Increase

Incremental

from

Shelter

walls.

$$
\begin{aligned}
& -- \\
& 0-1 \\
& 1-2 \\
& 2-3 \\
& 3-4
\end{aligned}
$$

132,000

216,000

156,000

$-31,000$

514,000 
Table 9 shows that the total heat transferred through the inner surface of the shelter walls during test 3 was 609,000 Btu based on the difference between the measured heat input and the enthalpy change of the ventilating air. This comparison shows that only a small fraction of the total heat absorbed by the shelter walls went beyond 4 feet in the surrounding earth. It is considered safe to assume that the heat causing the observed temperature rise in the shelter and surrounding 4 feet of earth came from inside the shelter because the undisturbed earth temperatures had already passed their maximum for the summer when test 3 was made. Figure 3-3 shows that the undisturbed earth temperatures were lower at the end of test 3 than at the beginning. The negative sign in Table 14 for the heat storage of the earth 3 to 4 feet from the shelter shows that the effect of the outdoor weather predominated at this distance, and that more heat was lost to the ground surface than was gained from the shelter in this region. In making the computations of heat storage in Table 14, the observed concrete and earth temperatures at the boundaries of each increment were used to determine an average temperature for all of the material in the increment. The specific heat of concrete was assumed to be $0.2 \mathrm{Btu} / \mathrm{lb}\left({ }^{\circ} \mathrm{F}\right)$ and that for earth with a 15-percent moisture content and 110 $\mathrm{lb} / \mathrm{ft} 3$ density was assumed to be $0.29 \mathrm{Btu} / \mathrm{Ib}\left({ }^{\circ} \mathrm{F}\right)$.

\subsection{Heat. Transfer Coefficients}

The average heat flux through the shelter walls was determined for tests 2 to 5 by dividing the total heat transfer to the shelter walls by the interior surface area. The total heat transfer to the shelter walls was computed by subtracting the enthalpy increase of the ventilating air as it passed through the shelter and the increase in heat content of the interior partition from the total internal heat input to the shelter. Figures 8, 9, 13, and 17 show that the average heat flux through the shelter walls in $\mathrm{Btu} / \mathrm{hr}$ (ft) $)^{2}$ was about 6.24 in test $2,4.21$ in test $3,4.73$ in test 4 , and 3.88 in test 5 after 1 week of operation. These comparisons reveal the beneficial effect of the ventilating air in removing a part of the heat input of the simulated occupants in the shelter. The average heat flux remained essentially constant in test 2 because there was no ventilation of the shelter and the heat input was constant. In tests 3 to 5, the average heat flux gradually decreased as the shelter walls rose in temperature because the latent fraction of the internal heat input became larger and the ventilating air had a greater capacity for removing the moisture liberated inside the shelter. 
Tables 8 to 11 show the heat transfer coefficient at the surface of the shelter walls expressed in Btu/hr(ft)2( $\left.{ }^{\circ} \mathrm{F}\right)$ based on the average of the air temperatures 1 inch from the center of each surface, the average of the surface temperatures at the center of the six exposures and the total heat transfer. In test 2, with no ventilation, the heat transfer coefficient increased from 3.7 to 6.2 in 7 days with the condensation collection rate quickly attaining a value of about 65 percent of the total moisture supplied (See Table 13). In test 3, with a ventilating air rate of $42 \mathrm{cfm}$, the heat transfer coefficient ranged from about 2 to 3 during the 14 days. In this test, the condensation of moisture on the walls was limited, never exceeding 19 percent of the total moisture supplied to the simulated occupants as measured by the water collection in the floor sump. In test 4, with a ventilating air rate of $18 \mathrm{cfm}$, the heat transfer coefficient gradually increased from 2 to 6 as the test progressed, while the condensation collected daily in the sump gradually increased from 45 percent to 50 percent of the total moisture supplied, after the first day of the test. In test 5, for which condensation was limited to the first 3 or 4 days of the test, the heat transfer coefficient ranged from 2.4 to 4.0 during the test. A separation of the sensible and latent components of the heat transfer to the shelter walls indicates that the coefficient of convective and radiant heat transfer was about $1.75 \mathrm{Btu} / \mathrm{hr}(\mathrm{ft})^{2}$ per degree temperature difference between air and wall surface during the early part of tests 3 and 4, and that it increased to a value of 2.5 to 3.5 in the same units near the end of the tests.

Nothing in the operating conditions for the tests suggests that the sensible heat transfer coefficient should have increased as the tests progressed, although the relative magnitudes of the convection and radiation components probably changed a little between the beginning and end of tests 3 to 5. A more probable explanation of the day by day fluctuations in the sensible heat transfer coefficient and the increase in the computed value from the beginning to the end of the tests is related to the precision of the temperature measurements at the wall surfaces and of the air near the surfaces. It is probable that the error in temperature measurements ranged up to $\pm 0.2^{\circ} \mathrm{F}$ for the conditions of these tests. Since the differences in average temperature between air and wall surfaces ranged from 2 to 3 degrees at the beginning of tests 3 to 5 and gradually decreased to about 1 degree at the end of the tests, variable errors of measurement of the order of $0.2^{\circ} \mathrm{F}$ could cause the observed variations in the computed heat transmission coefficient. It would be expected that the overall heat transfer coefficient would increase 
as the rate of condensation in the shelter increased, and that heat transfer due to condensation accounted for the heat transfer coefficients attaining values as high as $6 \mathrm{Btu} / \mathrm{hr}(\mathrm{ft}) 2\left({ }^{\circ} \mathrm{F}\right)$ in tests 2 and 4.

\subsection{Weather Conditions}

Figures 1-2 to 5-2 show the weather conditions that existed at the test site during the five tests with respect to dry bulb temperature, relative solar radiation intensity, wind velocity, and wind direction. The effect of the weather would not be reflected immediately in the heat transfer within the shelter, but might assist in explaining differences observed between consecutive tests. The undisturbed earth temperatures that existed at some distance from the shelter installation during the four tests, plotted in Figures 1-3 to 5-3, show how the earth mass from the surface to a depth of 6 feet was affected by the weather, and indicate how its function as a heat sink around the shelter may have changed from test to test. These graphs show that the diurnal temperature cycle was not felt much beyond a depth of 1 foot in the earth; that each 6 inches of earth near the surface introduced a lag of about 6 hours in the diurnal cycle of temperature; and that there was only a very small change in earth temperature at the 6-foot depth prior to the middle of october. Figure 4-3 shows that about 5 days elapsed before the effect of a sustained change in the weather reached a level 6 feet below the surface, which was about midheight of the shelter. It is probable, therefore, that the weather conditions had little effect on the heat transfer below midheight of the shelter, but could have had measurable effects in the upper part of the shelter.

\subsection{Soil Conditions}

The rainfall during August, September, and October 1959 was on the order of 50 to 60 percent of the average rainfall for these months in Washington. An unusual amount of snow, 17.1 inches, fell during March 1960, preceding the start of test 5, but none remained on the ground at the time of starting the test. The total precipitation in March was only about two-thirds the average value for the month. The rainfall that occurred during the five test periods, as recorded at the Washington National Airport, is summarized in Table 15. 
Table 15

Summary of Rainfall

Test Period

1

2

3

4
5
Rainfali, in.

None

1.77

None

1.63

3.04

The moisture content of the earth around the shelter apparently increased a few percent during the course of the summer tests as indicated by the results from earth samples taken at four periods. The observed moisture contents are summarized in Table 16.

\section{Table 16}

\section{Mo1sture Content of Earth at Shelter Site}

\section{Location and Time of Sampling}

Undisturbed earth at time of excavation (avg. of 3 depths)

Backfill at time of replacement (avg. of 3 depths)

Undisturbed earth and backfill

1 day after test 3 (midheight, east and west sides)

Undisturbed earth and backfill at completion of test 4 (midhelght, east and west sides)

Undisturbed earth and backfill

5 days after test 5 (midheight, east and west sides)
Mo1sture Content,

$\%$ of Dry We1ght

Kersten?/ has shown that the thermal conduct1v1ty and specific heat of soll are affected signiflcantly by density and moisture content. He has reported that an increase in mo1sture content of several fine-textured solls from 10 to 20 percent of dry weight increased the thermal conductivity about 35 percent and that a similar increase in moisture content of a graded sand increased the specific heat of the mixture about 30 percent. Based on Kersten's work, it is estimated that the spec1flc heat of the soil around the shelter was about $0.18 \mathrm{Btu} / \mathrm{lb}\left({ }^{\circ} \mathrm{F}\right)$, when dry; and about $0.29 \mathrm{Btu} / \mathrm{Ib}\left({ }^{\circ} \mathrm{F}\right)$ with a moisture content of 15 percent. 
4.9 Simulated Occupants

Figures 3-11, 3-12, 4-11, and 4-12 show the temperatures measured at various heights on the surfaces of two of the simulated occupants during tests 3 and 4; No. 1 having a nominal heat input of $600 \mathrm{Btu} / \mathrm{hr}$ representing an adult at mild exercise, and No. 3 having a nominal input of $400 \mathrm{Btu} / \mathrm{hr}$ representing a sedentary adult. These figures show that the temperatures on most of the surface of the simulated occupants exceeded the air temperature of the shelter by amounts ranging from 2 to 6 degrees during the summer tests. However, the domes of the simulated occupants operated at temperatures ranging from $94^{\circ} \mathrm{F}$ to $97^{\circ} \mathrm{F}$; that is, from 12 to 15 degrees above that of the shelter air. Since the domes were covered with cloth, kept moist by the water supply, some of the air rising from these surfaces probably had a moisture content comparable to that of the exhaled breath of a human being. The fabric covering on the occupants was able to evaporate all of the water associated with a total heat output of $400 \mathrm{Btu} / \mathrm{hr}$, but was not quite able to evaporate the water equivalent of the latent heat output selected for an individual with a total heat loss of $600 \mathrm{Btu} / \mathrm{hr}$ during the summer tests. A hygroscopic fabric with a nap or with a knitted characteristic might have presented more surface for evaporation of water than the smooth rayon selected for these tests.

In test 5, under winter conditions, the temperature of the vertical metal surfaces of the simulated occupants exceeded the air temperature by 7 to 12 degrees near the bottom and about twice as much near the top, whereas the dome temperatures exceeded the air temperature by about 25 degrees. Nearly all of the evaporation occurred on the conical domes of the simulated occupants in test 5.

Herrington $3 /$ has shown that the combined convection and radiation heat transfer per unit area from a capped cylinder is equal to that of a model of the human body in a standing position for equal mean surface temperatures. Since the simulated occupants used in these tests had an exposed surface area, 21.5 square feet, typical of the measured values for adult males, and the sensible and latent components of heat transmission were made representative of that commonly accepted for adults, resting or at light exercises, it is probable that the heat, transfer characteristics were not greatly different from those of human beings. 


\section{DISCUSSION AND CONCLUSIONS}

\subsection{Factors Affecting Shelter Condensation}

These tests of a family-size shelter showed that the heat transfer rate to the interior surfaces of the walls, floor, and celling was such that a heat release inside the shelter equivalent to that commonly accepted for six sedentary adults caused an initial temperature difference of 2.0 to 3.0 degrees between the shelter air and the wall surfaces during the:first day, and that this temperature difference decreased to about 1.0 to 1.5 degrees after l-week's time. The decreasing temperature difference was due to the decrease of the sensible heat fraction of the total heat input as the latent heat fraction was increased in accordance with the rising air temperature in the shelter; and in the winter test was also due to the increased capacity of the ventilating air for removing sensible heat from the shelter as the outlet air temperature rose. The tests further showed that the average wall surface temperature and the dew point temperature of the exhaust air were always in close agreement; the difference was frequently on the order of 1 degree and seldom as large as 2 degrees. Thus it can be concluded that the capacity of the ventilating air for removing moisture from this type and size shelter depends largely on the wall surface temperature, the dew point temperature of the incoming air, and the amount of heat released within the shelter.

A graph showing the relation between wall surface temperature, dew point temperature of the ventilating air, and the amount of ventilating air required per person to remove all the moisture liberated inside the shelter was prepared, as Figure 21. The following assumptions were made in preparing the figure:

(a) The exhaust air from the shelter had a dew point temperature equal to the average wall surface temperature,

(b) Each of the six occupants had a total heat emission equal to that shown in the ASHRAE "Guide" for an adult seated at rest, and

(c) Each of the six occupants had a molsture loss equal to that shown in Figure 7 , Chapter 6, of the 1960 ASHRAE "Guide" for a person seated at rest. 
In Figure 21, each curve is asymptotic to a vertical line representing a wall surface temperature equal to the dew point temperature of the supply air for that curve. Any point on the graph below or to the left of a curve represents a combination of wall surface temperature, dew point temperature, and ventilation rate that would result in condensation inside the shelter, and any point above or to the right of a curve represents a combination of variables for which all of the moisture would be carried out by the ventilating air.

Figure 21 shows that a ventilation rate of $7 \mathrm{cfm}$ per person with a dew point temperature of $70^{\circ} \mathrm{F}$ would not carry out all of the moisture liberated until the wall surface temperature reached about $78^{\circ} \mathrm{F}$. These were approximately the conditions for test 3 , and the results of the test tend to corroborate the predictions of the graph in that the walls of the shelter had dried off at the end of the test when the average wall surface temperature was about $79.5^{\circ} \mathrm{F}$. This figure also indicates that a ventilation rate of $3 \mathrm{cfm}$ per person with a dew point temperature of $70^{\circ} \mathrm{F}$, approximating the conditions for test 4, would not carry out all of the moisture liberated for any wall temperature up to $90^{\circ} \mathrm{F}$. The results of test 4 showed that the condensation on the shelter walls was still about 50 percent of the moisture liberated in the shelter at the end of the 2-weeks' test when the average wall surface temperature was about $80^{\circ} \mathrm{F}$. Figure 21 indicates that a ventilation rate of 3 cfm per person with a dew point temperature of $35^{\circ} \mathrm{F}$ would carry out all of the moisture liberated by an average sedentary adult at a shelter wall temperature of $55^{\circ} \mathrm{F}$, which is the average wall temperature attained during the seventh day of test 5. It is probable that condensation actually ceased in the shelter about the third or fourth day because the average amount of moisture liberated by each of the simulated occupants during the first 5 days of the test was about 77 percent of that assumed in the preparation of Figure 21. The use of this lower value of moisture evaporation resulted from the simplification of the published data on evaporative heat loss, shown in Table 6.

The results of these tests and the relationships illustrated in Figure 21 indicate that condensation of moisture in a familysize shelter would be prevalent during spring, summer, and fall seasons in locations having earth temperatures and summer weather conditions like those in Washington, D. C. Condensation could not be prevented in every case by increasing the ventilation rate because the wall temperatures would be lower than the dew point of the incoming air for more or less extended periods. Ori the other hand, the dew point temperature of the supply air would not always be as high as the values assumed for these tests. 
The duration of the condensation period in any given situation could be shortened by hastening the rise in wall surface temperature to a level that would permit the ventilating air to carry out all of the moisture liberated inside the shelter. The ceiling is considered to be the most critical surface from the standpoint of condensation because the condensed moisture would drip on everything in the shelter. The ceiling might be insulated or lined to prevent condensation, leaving the walls and floor as condensing surfaces from which drainage could be more readily controlled. Ceiling insulation would help to prevent condensation in all seasons of the year. During the summer tests, the celling was one of the poorer heat-absorbing surfaces of the test shelter because the shallow earth cover was more directly affected by above-ground air temperature and solar radiation. One alternate method for moisture control would be the storage of a quantity of desiccant in the shelter for absorbing the excess molsture during periods of occupancy. Table 13 shows that six simulated occupants liberated about 400 pounds of moisture in 14 days during the summer tests. About 48 pounds were collected from the floor in test 3 and about 190 pounds in test 4. Film-type movement of the condensate from the ceiling to the side walls would be promoted by doming or by sloping the ceiling surface downward to the side walls and treating the ceiling surface with a wetting agent. The wetting agent might have to be renewed periodically under condensing conditions.

A graph like Figure 21 is useful in analyzing condensation problems in small shelters because the wall surface area per occupant is so large that the air temperature never differs much from the wall surface temperature, and the minimum amount of ventilating air is likely to be determined by the amount of moisture generated in the shelter rather than the amount of sensible heat liberated. In larger shelters, the wall surface area per occupant would usually be less, making it necessary to remove a higher percentage of the total internal heat input with the ventilating air. When sensible heat removal determines the minimum amount of ventilating air that can be circulated, condensation is less likely to occur in the shelter, the temperature difference between shelter air and the shelter walls will be greater, and the relative humidity in the shelter will be lower. In such cases, Figure 21 would not be as useful in evaluating shelter environment.

\subsection{Validity of Supply Air Conditions Selected}

The average dry bulb temperature of $85^{\circ} \mathrm{F}$ and the constant dew point temperature of $69^{\circ} \mathrm{F}$ selected for the supply air conditions for the summer tests are considered to be approximately 
correct for a severe test of such a shelter in the washington area, based on wet and dry bulb temperatures recorded by the U.S. Weather Bureau for the latter part of August 1959. The average of the daily maximum and minimum dry bulb temperatures at the Washington National Airport for the 14-day period from August 13 to August 27, 1959 was $83.9^{\circ} \mathrm{F}$, and the average dew point temperature of the outdoor air for the same period was $70.1^{\circ} \mathrm{F}$. The average dew point temperature for this period ranged from a maximum of $71.6^{\circ} \mathrm{F}$ at $9 \mathrm{p} . \mathrm{m}$. to a minimum of $68^{\circ} .2^{\circ} \mathrm{F}$ at 2 p.m.

The design summer conditions of dry bulb and wet bulb temperatures in common use for air conditioning purposes in many of the states east of the Mississippi River are approximately equal to those for Washington, D. C., as shown in the ASHRAE "Guide." It is probable, therefore, that the supply air conditions chosen for Washington would be applicable in other areas with similar summer climatic conditions. Based on the same handbook data, it is expected that higher dew point temperatures than that used for these tests would be experienced in the areas near the Gulf of Mexico, and that higher average dry bulb temperatures would occur, at times, in the middle western and southwestern states.

The diurnal variation of $20^{\circ} \mathrm{F}$ in the supply air temperature used for the summer tests did not have an important effect on the comfort conditions in this small shelter. The maximum and minimum in supply air temperature were tempered considerably by heat transfer between the supply piping and the surrounding air and earth. Also, the amount of heat transfer surface in the shelter was of such a magnitude that the air temperature inside the shelter had to change only a degree or two to provide the additional sensible heat transfer to or from the walls that was associated with the assumed diurnal cycle in supply air temperature. In test 3 of the prototype shelter, the dry bulb temperature in the shelter varied only about 2 degrees in response to a 20-degree variation in supply air temperature, whereas the dew point temperature in the shelter remained constant for all practical purposes. A change of 2 degrees in dry bulb temperature in the range of 75 to $80^{\circ} \mathrm{F}$ at constant dew point temperature results in a fluctuation of less than $1 / 2$ degree in effective temperature, based on the ASHRAE comfort charts. In a larger shelter for which the ratio of interior shelter surface to shelter volume would be lower than for the family shelter, and for which the tempering action in the supply piping might be less effective, the diumal cycle in dry bulb temperature could have a significant effect on comfort conditions in the shelter. 
The supply air conditions selected for the winter test were the most severe that were possible without extensive modification of the air conditioning apparatus, but they do not represent the severest winter conditions that can occur in large areas of this country. The change in moisture content of the air at dew points below $33^{\circ} \mathrm{F}$ is small and would not be of great significance, but appreciably lower average dry bulb temperatures would remove more of the internal heat released in the shelter and retard the warming of the walls to a comfortable occupancy condition.

The use of a longer subterranean duct to condition the supply air would be advantageous for small shelters especially for the hottest summer conditions or the coldest winter conditions. The temperature gradient in the earth is in opposite directions at the warmest and coldest seasons of the year. Thus, if the supply air were introduced into the shelter through a duct installed beneath the floor of the shelter, the air could be cooled below the shelter temperature in the warmest weather and could be warmed above shelter temperature in the coldest weather by heat exchange between the duct and the surrounding earth. Some dehumidification of the supply air might also be accomplished during summer conditions in such a sub-floor duct, but the cross section and slope of the duct would have to be designed to prevent stoppage by accumulated water. Such a duct would also have to be watertight if the ground water level was high with respect to the shelter. Such sub-floor ducts would be less effective for larger shelters because the ratio of surface area to cross-section area would become less favorable as the duct became larger.

\subsection{Factors Affecting Temperature Rise in the Shelter}

The rise in dry bulb temperature observed in the family shelter during the summer tests as a result of an average internal heat release of about 2500 Btu/hr was not considered excessive under the prevailing test conditions in light of the limits cited in, the literature for human beings. Various investigators 4 have stated that saturated air at temperatures in the range from $88^{\circ} \mathrm{F}$ to $90^{\circ} \mathrm{F}$ is the upper limit for which man can compensate for atmospheric conditions and maintain the desired body temperature. This limit applies to exposures of no more than a few hours. Dole 6 has suggested that the maximum temperature of saturated air which can be tolerated by human beings continuously for a period of 10 days is in the range from $81^{\circ} \mathrm{F}$ to $86^{\circ} \mathrm{F}$. 
The effective temperature in the test shelter during the last day of tests 3 and 4 was about 80 degrees, equivalent in comfort to saturated air at the same temperature by definition of the effective temperature scale. The average effective temperature on a continuous basis corresponding to the observed wet and dry bulb temperatures at the Washington National Airport. for the period from August 13 to August 27, 1959 was about 80.3 degrees, neglecting the effects of solar radiation and wind. Thus, the comfort conditions in the family shelter at the end of tests 3 and 4 were probably no more adverse than the outdoor conditions during a 2-week period of the 1959 summer season in Washington.

The factors which could produce higher dry bulb temperatures in a similar shelter in this climate or other climates during actual occupancy by six people are listed and discussed below.

(a) An earth fill around the shelter having lower density, lower moisture content, or a soil composition of lower thermal conductivity. Kersten? has shown that the thermal conductivity of dry soils of sandy or clay loam composition may be as low as $2 \mathrm{Btu} / \mathrm{hr}(\mathrm{ft})^{2}\left({ }^{\circ} \mathrm{F} / \mathrm{in}.\right)$., but that the thermal conductivity may increase by a factor of 5 to 10 when these soils are saturated with moisture. In general, the thermal conductivity of sandy soil increases more rapidly with moisture content than it does for clay loam soils. The thermal conductivity also increases about 3 percent for each 1 pound per cubic foot increase in dry density. The thermal conductivity of the soil around the test shelter was estimated to be on the order of $10 \mathrm{Btu} / \mathrm{hr}(\mathrm{ft}) 2\left({ }^{\circ} \mathrm{F} / \mathrm{ir.}\right.$.) based on the soil type, its density, and moisture content. Kersten has also shown that the specific heat of soil increases considerably with moisture content, and that the specific heat of a soil-water mixture can be computed approximately from the proportions of the two materials and their separate densities.

(b) A higher heat output by the occupants than was used for the simulated occupants. It is uncertain how active the occupants would be in a real situation or how much energy would be expended in operating a blower to provide ventilation. It is linknown whether or not the mertal stress involved in actual emergency use of a shelter would increase the heat production of the occupants. The values used for these tests approximate weil-established values for sedentary adults in normal environments. 
(c) Higher initial earth temperatures. Well water temperatures are usually considered to be representative of eartr. temperatures from 30 to 60 feet below the surface in various lat: tudes. Well water temperatures 1 are 10 or more degrees warmer in the southern part of the United States than in Washington. The initial earth temperature at midheight of the test shelter was about $69^{\circ} \mathrm{F}$, whereas deep well water temperature reported for Washington is $57^{\circ} \mathrm{F}$. If the same difference between earth temperature existed farther south, as appears to exist for Washingtc the initial earth temperature at midhelght of a similar shelter might be near $80^{\circ} \mathrm{F}$ in the southern part of this country. The higher earth temperatures in warmer climates could probably be partly compensated for by placing the shelter farther beneath the surface. The temperature gradient in the earth was about 1 degree per foot of depth at the test site in Washington about the first of September when the earth temperatures were at a maximum. It is thought that unbearably hot conditions could develop in underground shelters during the summer in the hottest parts of the United States. Simple evaporative coolers employing manualiy operated fans could probably be developed to provide limited shelter cooling in hot arid climates.

\section{(d) Higher sensible and latent heat contents of the} ventilating air. The sensible heat lost by the ventilating air during the summer tests as it passed through the prototype shelte was about 20 percent of the internal heat input during the first day of test 3, and it decreased to about 10 percent after 4 days. In test 4, the sensible heat lost by the ventilating air as it passed through the shelter decreased from about 7 percent of the internal heat input on the first day to about 3 percent on the fifth day of the test. Ventilating air supplies with higher latent and sensible heat contents than those used for these test: would probably be associated with higher earth temperatures. Sir Figures 11 and 15 show that the percent of the total internal hei input that is carried out of the shelter by the ventilating air increased with increasing wall surface temperature, warmer suppl: air might not be associated with higher heat transfer rates to the shelter walls, but probably would be assoclated with higher initial earth temperature in most cases.

The one winter test of this family-size shelter conducted with a steady flow of supply air at a rate of $18 \mathrm{cfm}$ and a dry bulb temperature of $35^{\circ} \mathrm{F}$ at the time of the year when the earth temperatures were approximately at a minimum, revealed that the shelter temperatures would not reach comfortable levels in 2 weeks with an internal heat input equivalent to the accepted hea 
loss of six sedentary adults. The temperature rise of the walls of the structure in 2 weeks was about the same for the winter and summer tests; that is, in the range of 12 to 15 degrees. The initial wall temperature averaged $46^{\circ} \mathrm{F}$ in the winter test, whereas it ranged from 64 to $66^{\circ} \mathrm{F}$ for summer tests 3 and 4.

In some of the northern states of this country, the ground freezes to a depth of several feet during the winter, in which case the initial earth temperatures would be appreciably lower than those used in test 5. If some of the earth surrounding a shelter were frozen, the rise in wall temperature would be retarded during occupancy because the heat of fusion of the frost would increase the effective heat capacity of the moist earth.

Thus, it appears that some steps would need to be taken to increase the comfort of the shelter occupants during cold winter conditions. Any of the following courses might be followed to improve winter comfort:

(a) Use a small portable heater to warm the space,

(b) Wear additional clothing in the shelter,

(c) Use a curtain at the doorway of the main room to reduce the area for heat loss,

(d) Drape aluminum foll over all or parts of the walls to provide air spaces at the wall and present a reflective surface for reflection of body heat,

(e) Reduce the ventilation rate, if the resulting condensation could be tolerated.

Further study would be required to evaluate the relative effectiveness and economy of these various methods of increasing winter comfort.

\subsection{Further Analysis of Environmental Factors}

Further mathematical analysis of these and other data is being undertaken to provide information on the effect of variations in soil characteristics, moisture content of the soil, thickness of the concrete walls, lining of parts of the shelter, ambient temperature and humidity, latitude of the site, average heat flux through the shelter walls, and size of the shelter, during short occupancies. 
If a satisfactory mathematical expression can be found to approximate the heat transfer to the surroundings from a shelte placed a few feet below the earth's surface, the effect of thes variables on the heat transfer and on the environmental conditi in shelters can probably be predicted.

\section{REFERENCES}

I) The Family Fallout Shelter, Bulletin MP-15, office of Civil and Defense Mobilization.

2) M. S. Kersten, Thermal Properties of Solls, University of Minnesota, Engineering Experiment Station Bulletin No. 28, June 1949.

3/ I. P. Herrington, Full-Scale Human-Body-Model Thermal Exchange Compared with Equational Condensations of Human Calorimetric Data, Journal of Heat Transfer, (c) Vol. 81, August 1959.

4 C. E. A. Winslow and L. P. Herrington, Temperature and Human Iife, Princeton University Press, 1949.

5 W. J. McConnell, F. C. Houghten, C. P. Yaglou, Air Motion, High Temperature and Various Humidities - Reactions on Human Beings, ASHVE Transactions, Vol. 30, 1924.

$6 /$ S. H. Dole, Environmental Requirements for Extended Occupancy of Manned Satelittes, ASME Paper 59-AV-12, 1959.

If W. D. Collins, Temperature of water Available for Industrial Use in the United States, U.S. Geological Survey Water Supply Paper No. 520F, 1925. 


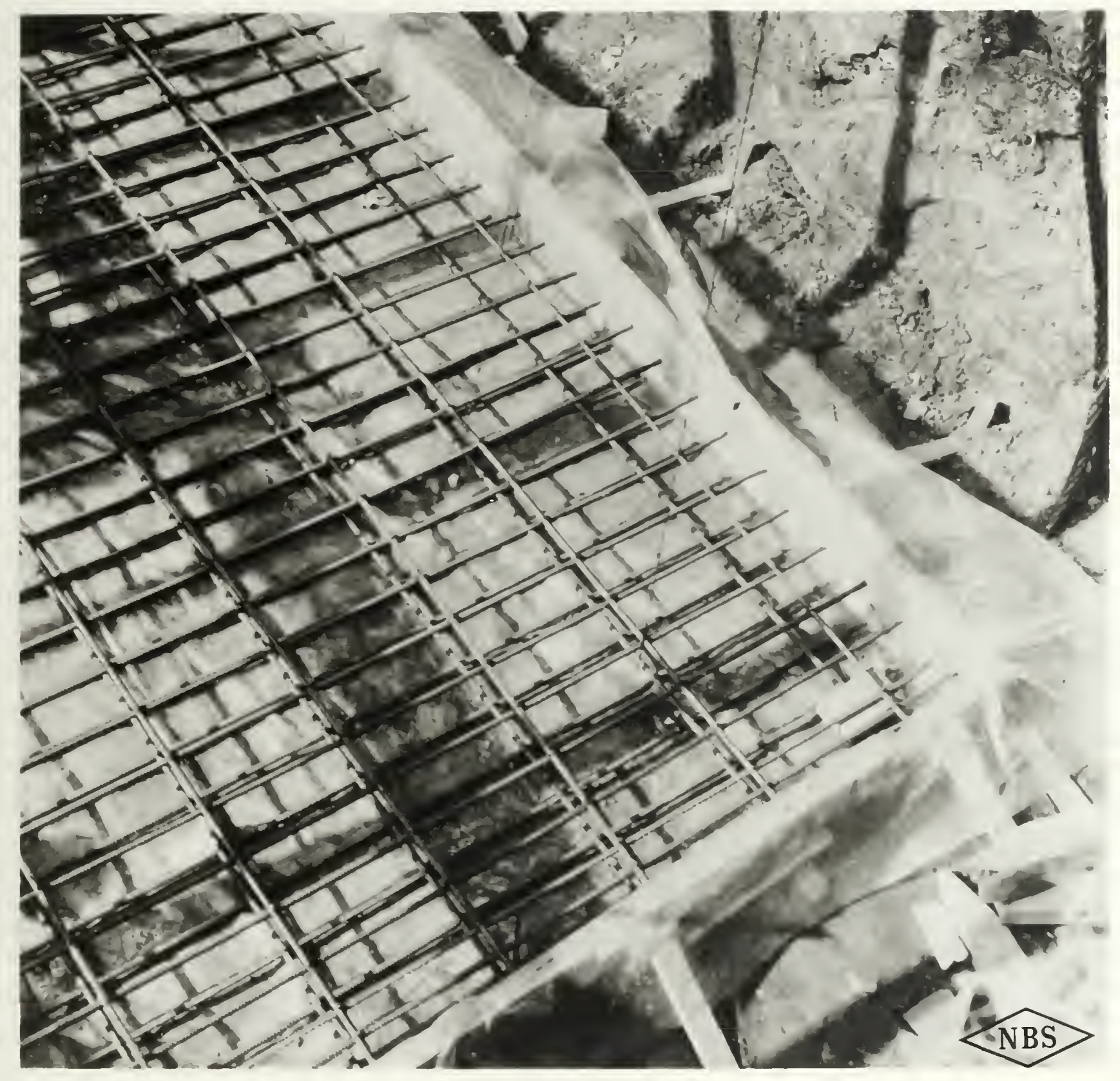

Figure 1 



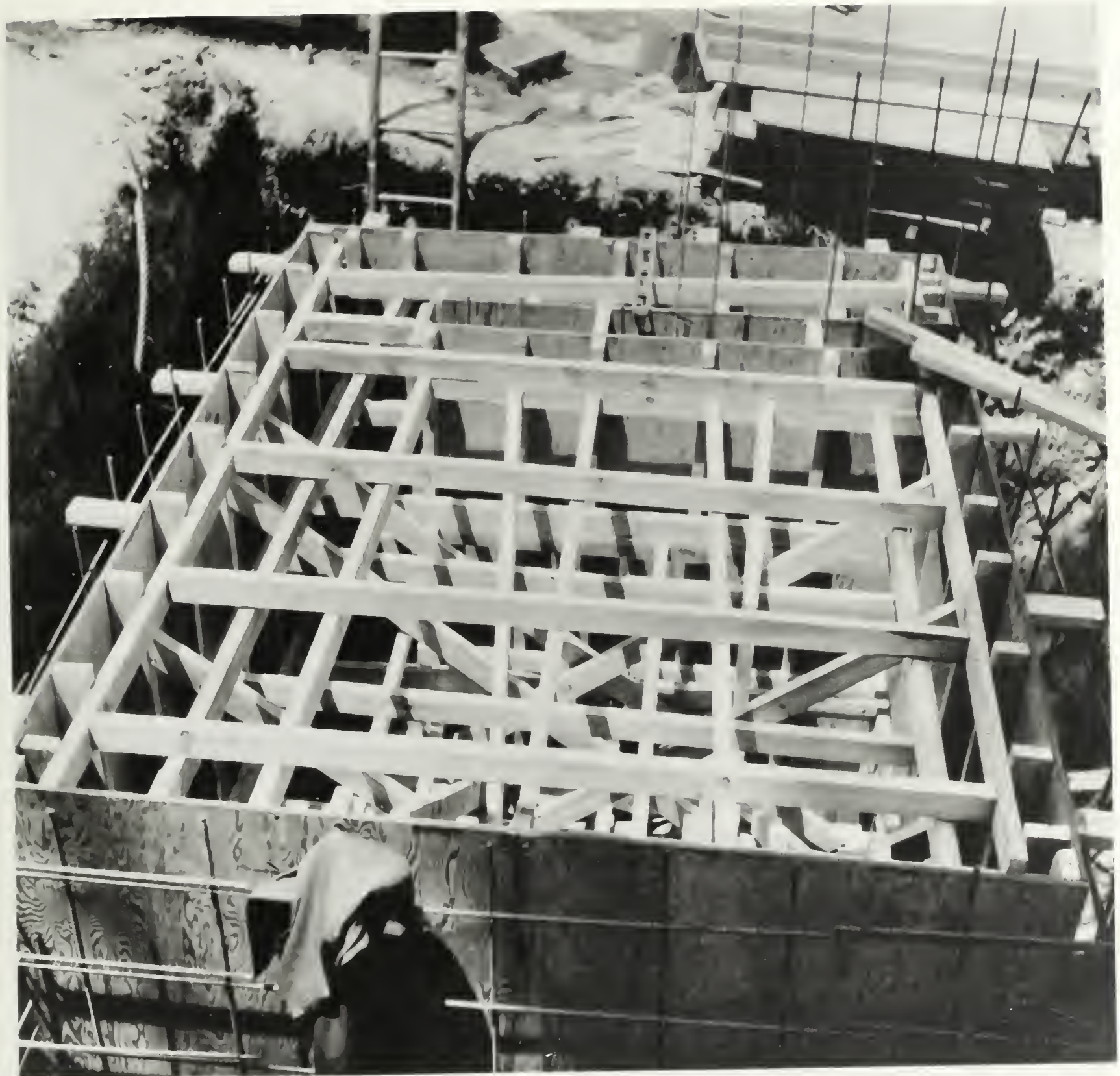

Figure 2 


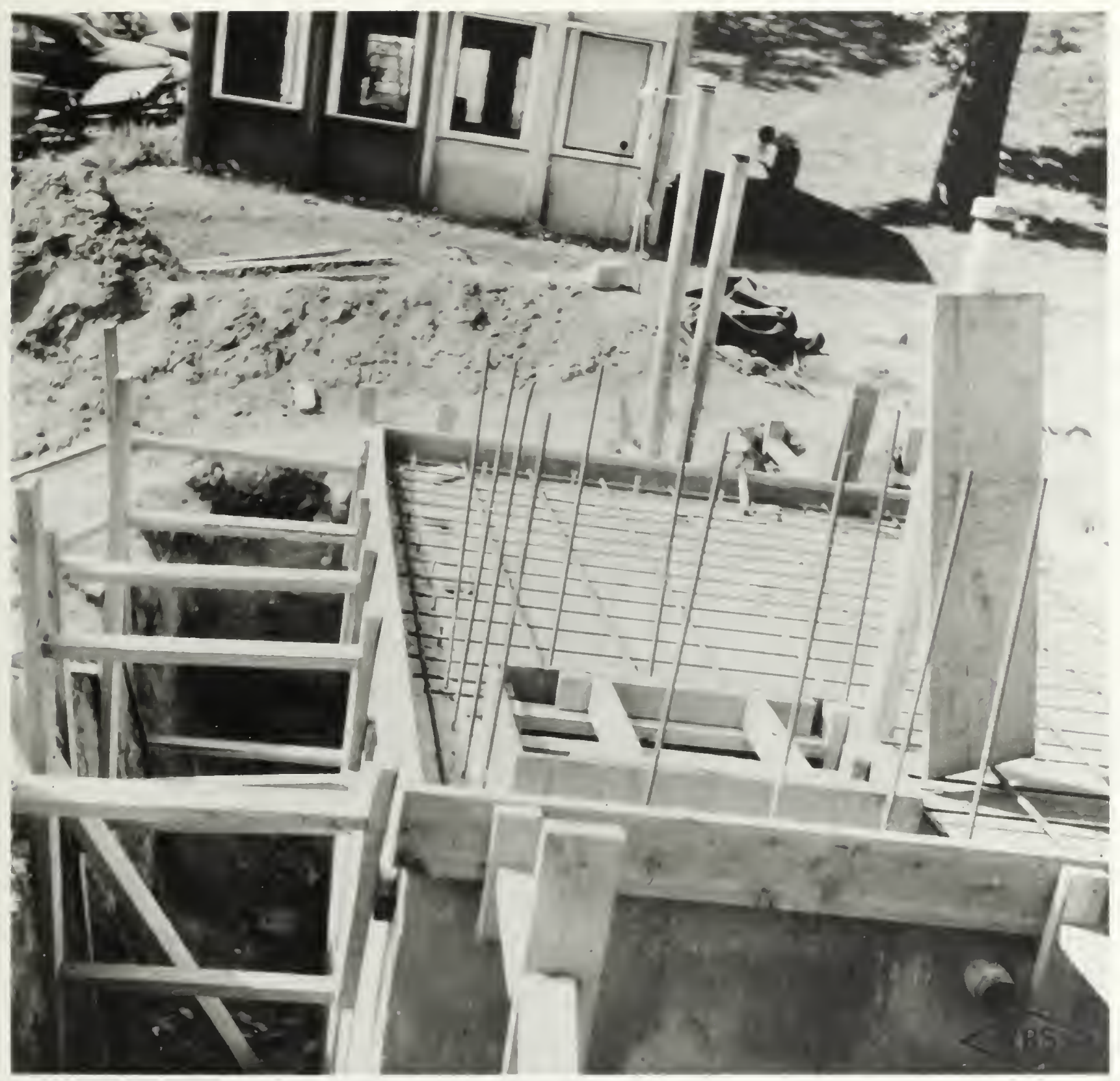

Figure 3 


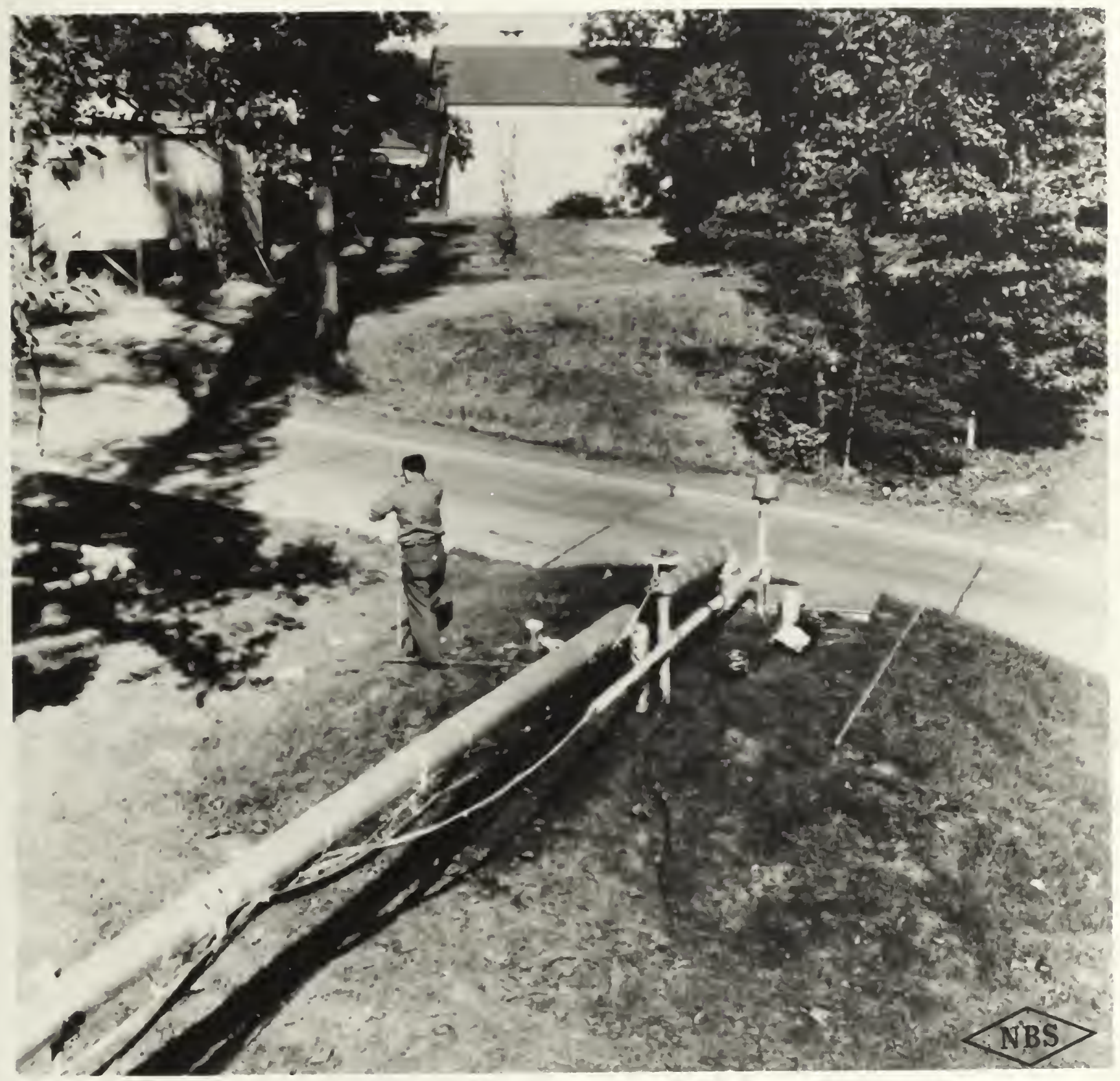

Figure 4 


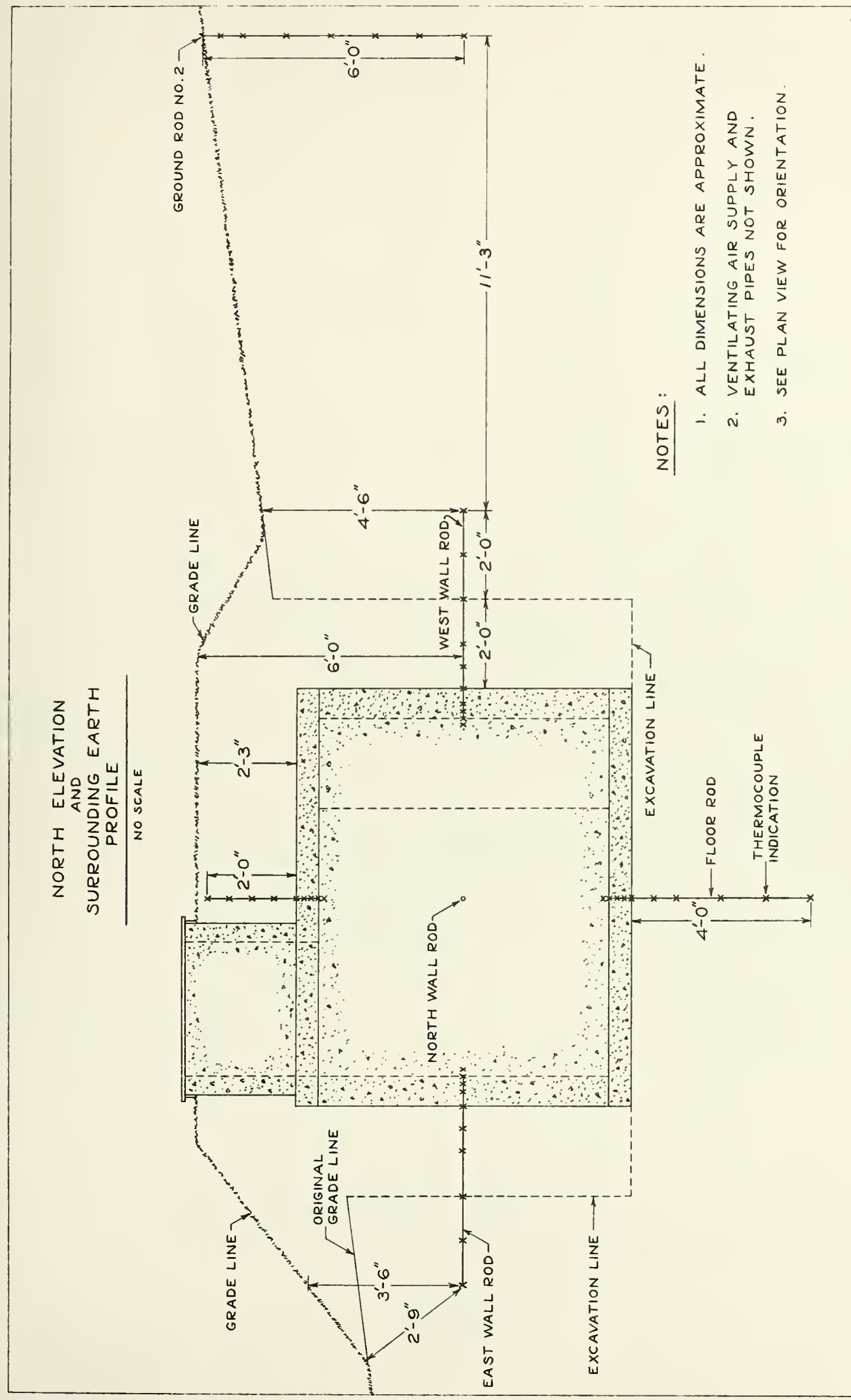

$\frac{n}{4}$ 


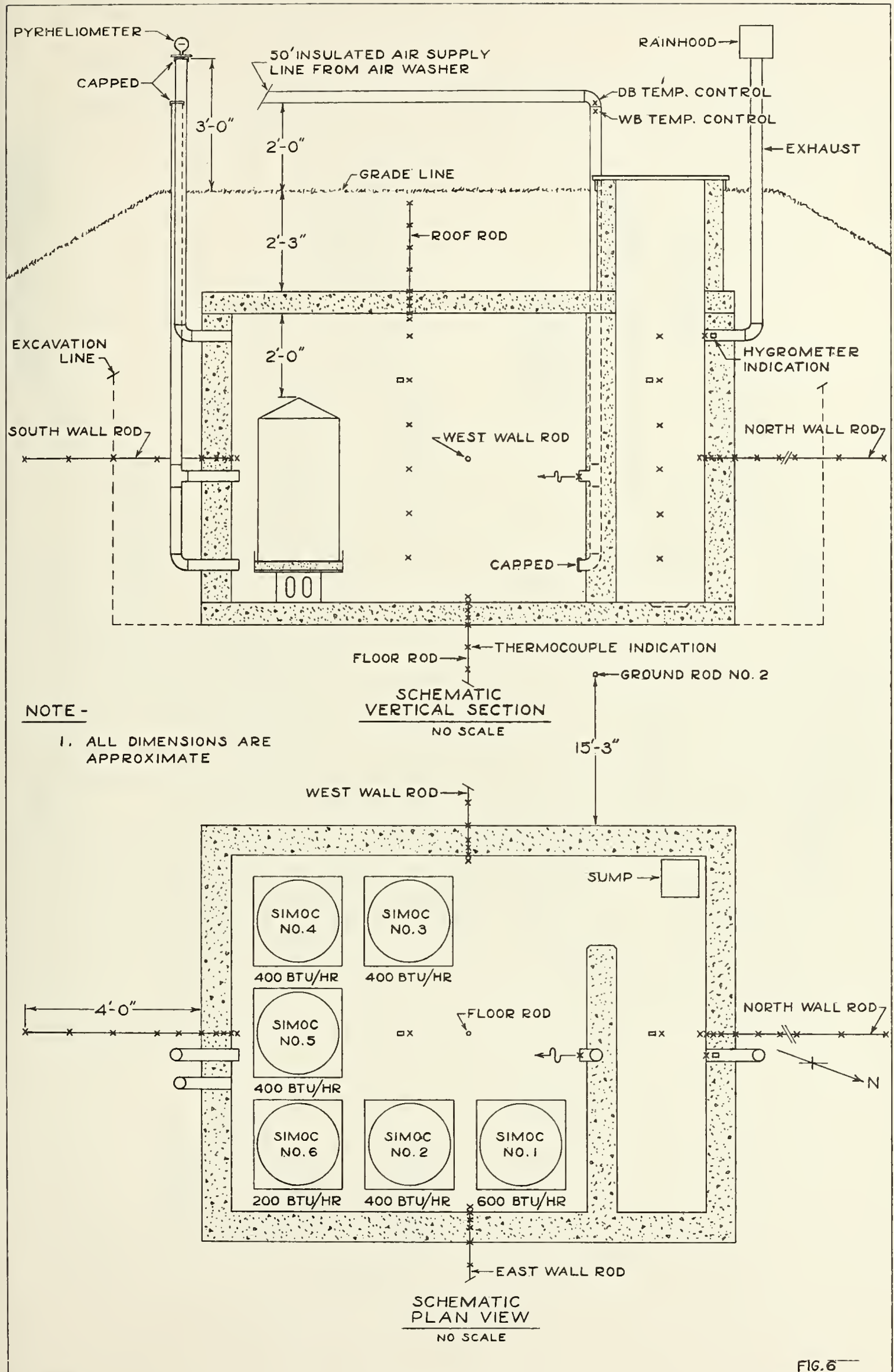




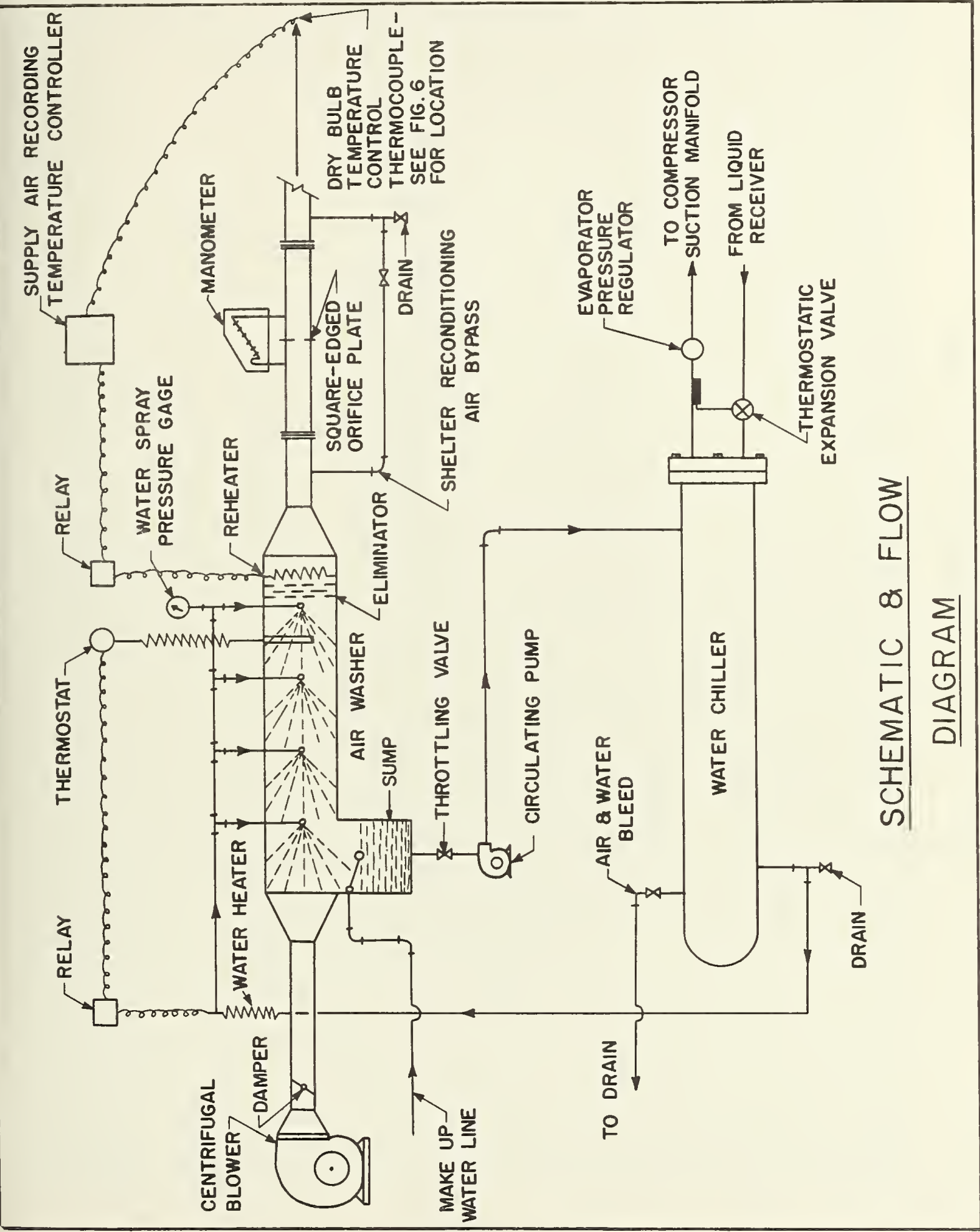

Figure 7 



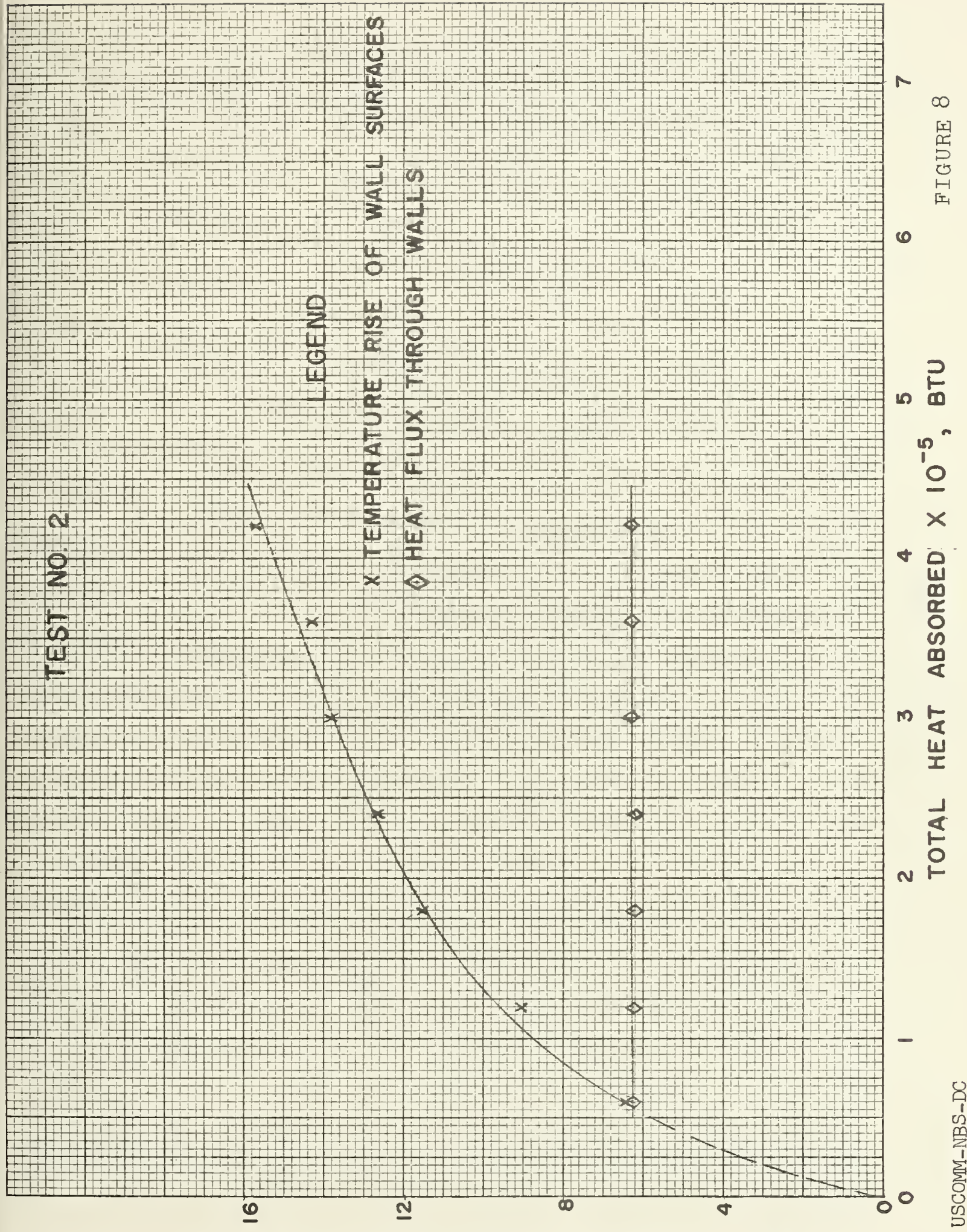

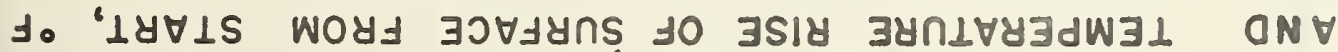 ( $\perp$ ) $\forall H / \cap \perp \theta^{\prime} S 77 \forall M$ HOกO४H $\perp$ Xก」 $\perp \forall 3 H$}





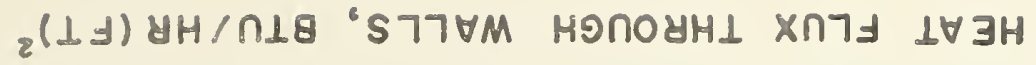

$\infty \quad \infty \quad \infty \quad \infty$

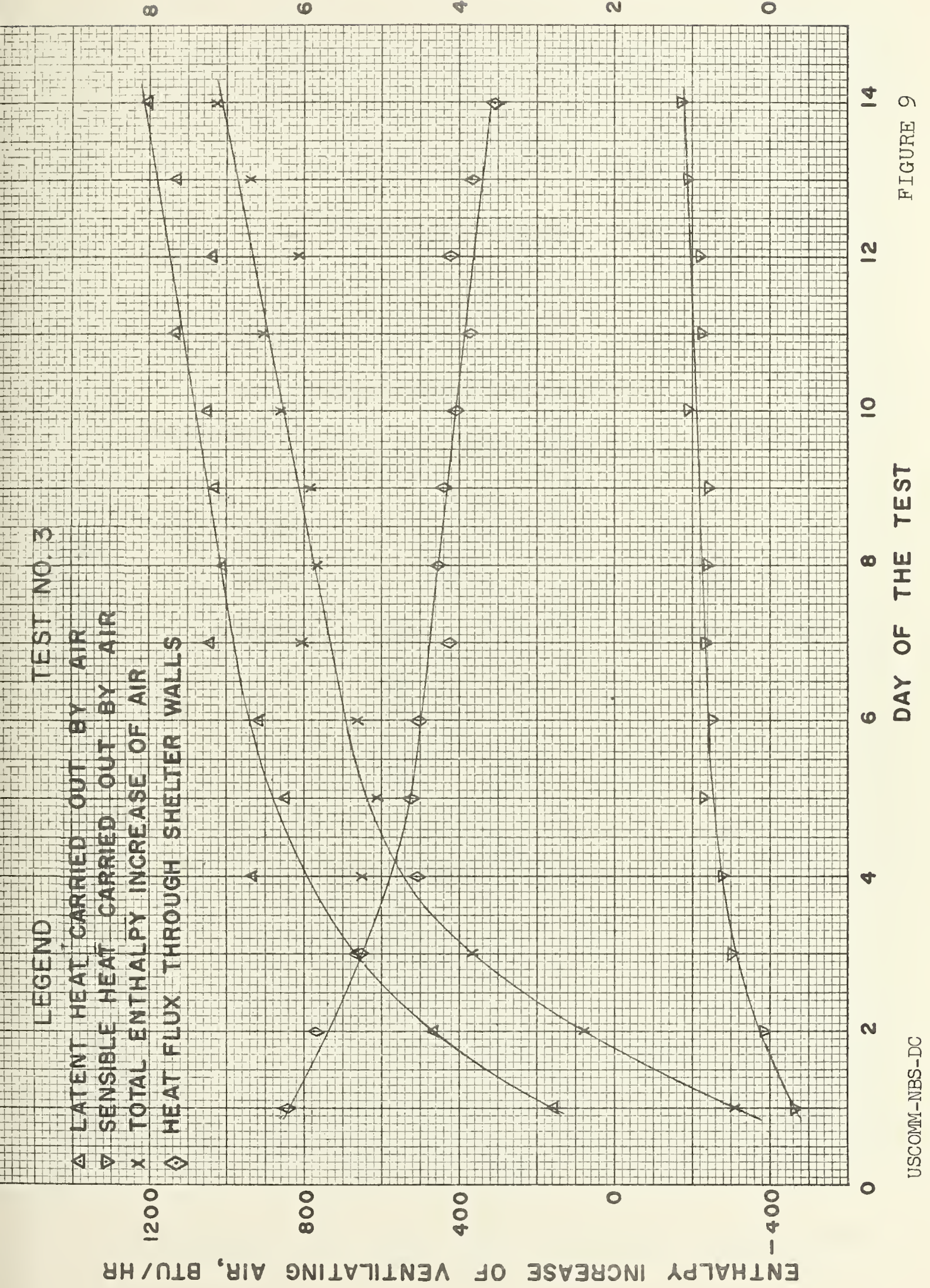





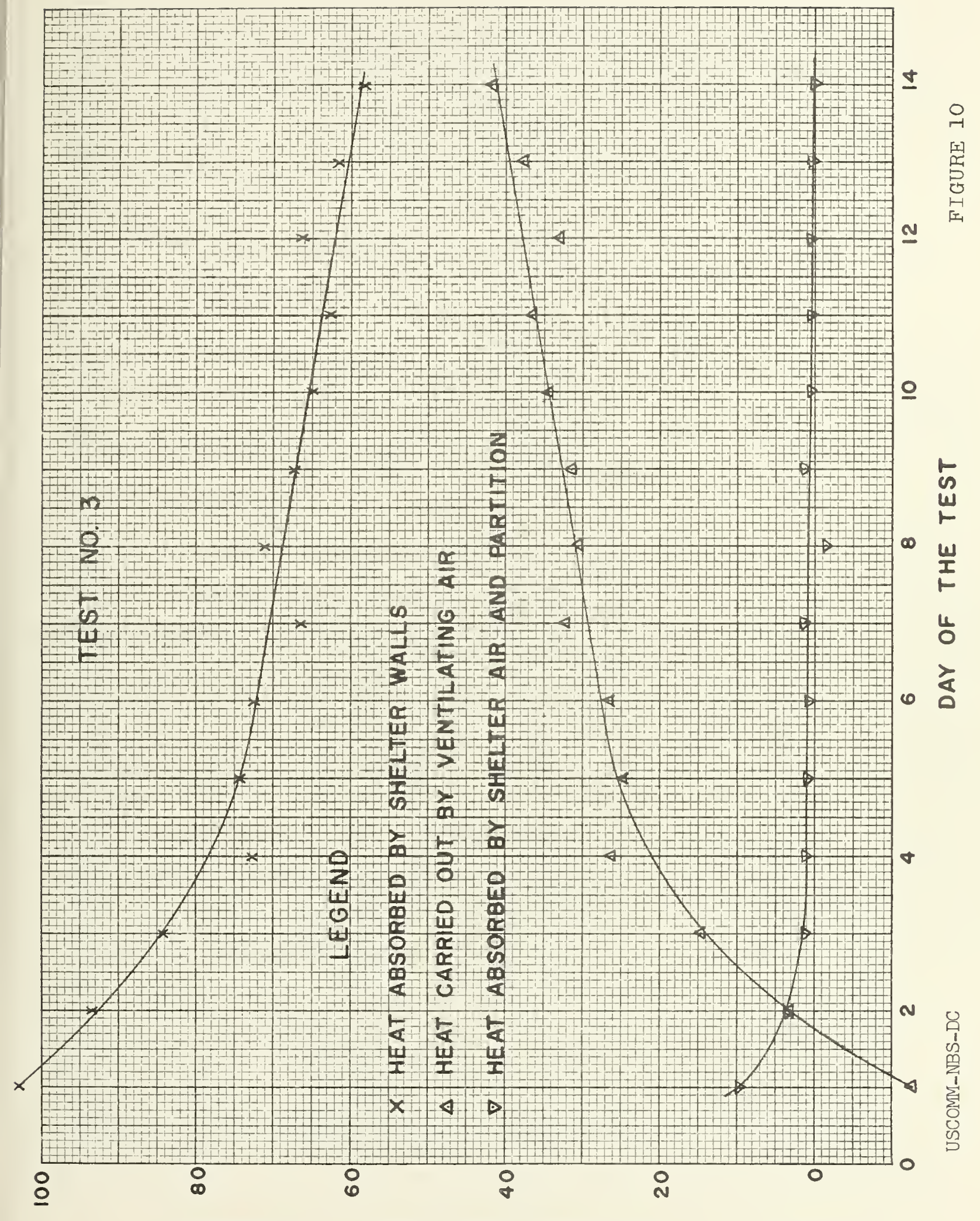

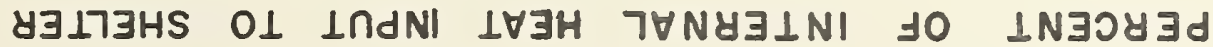





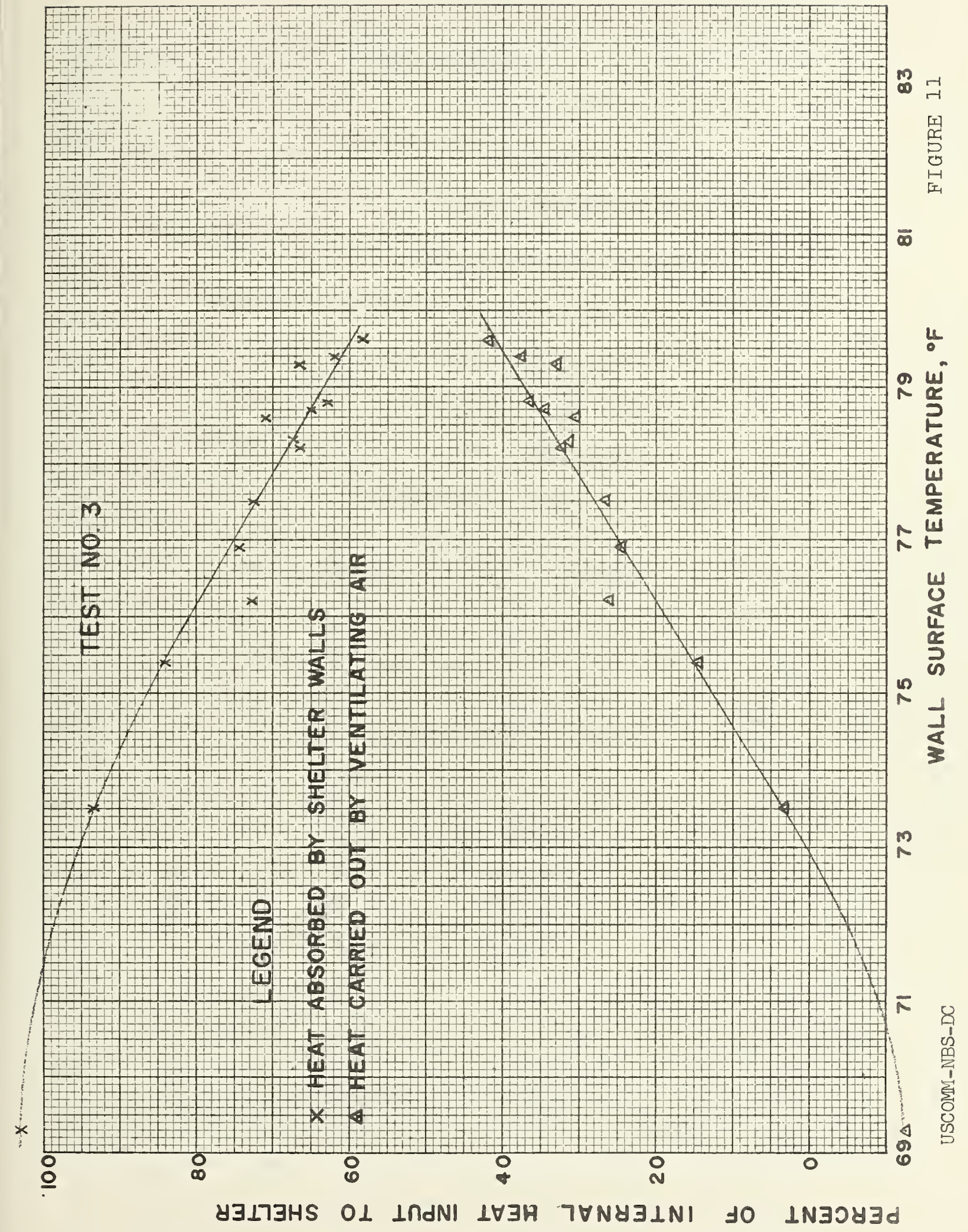





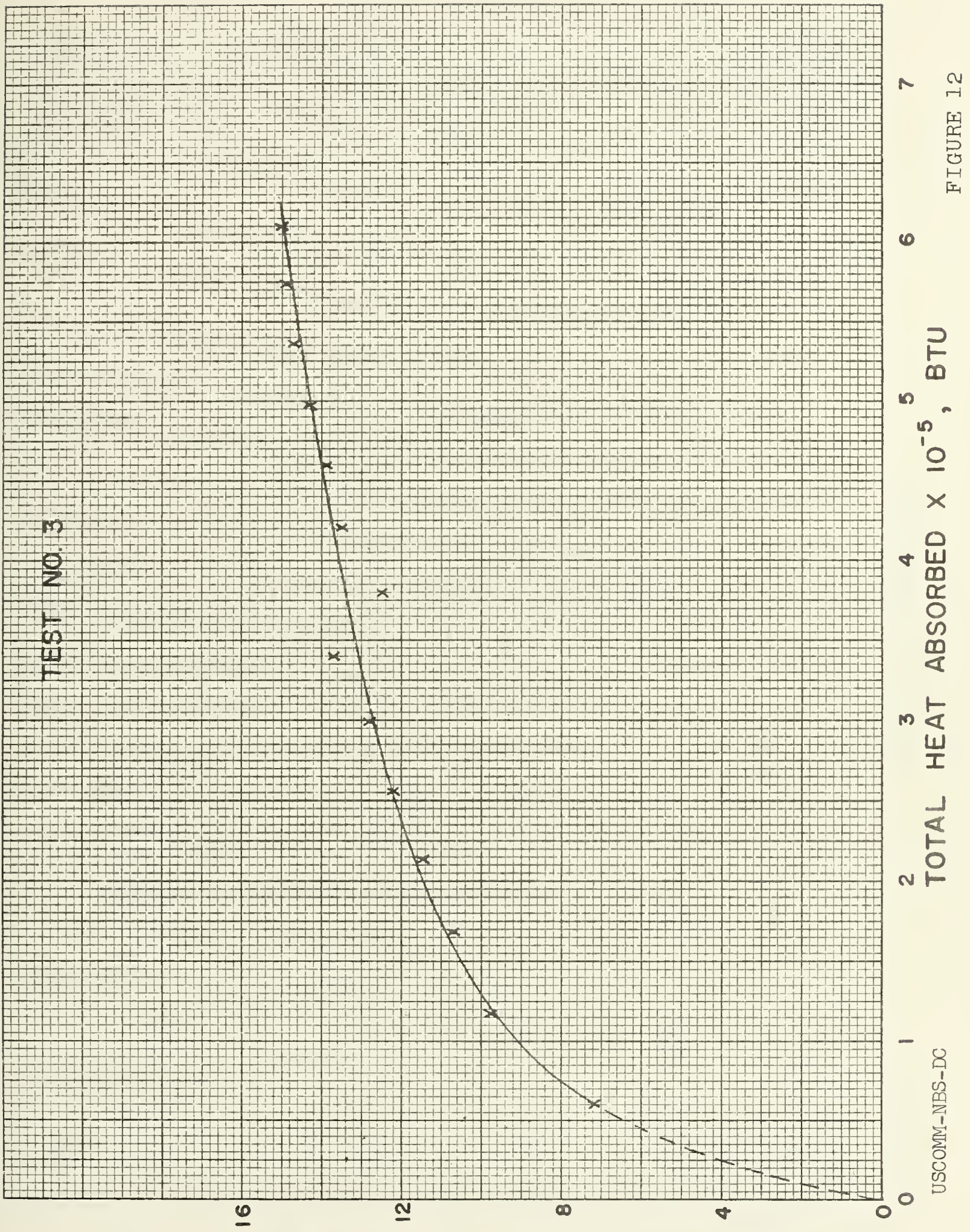

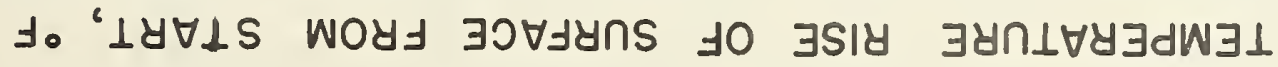



2(1

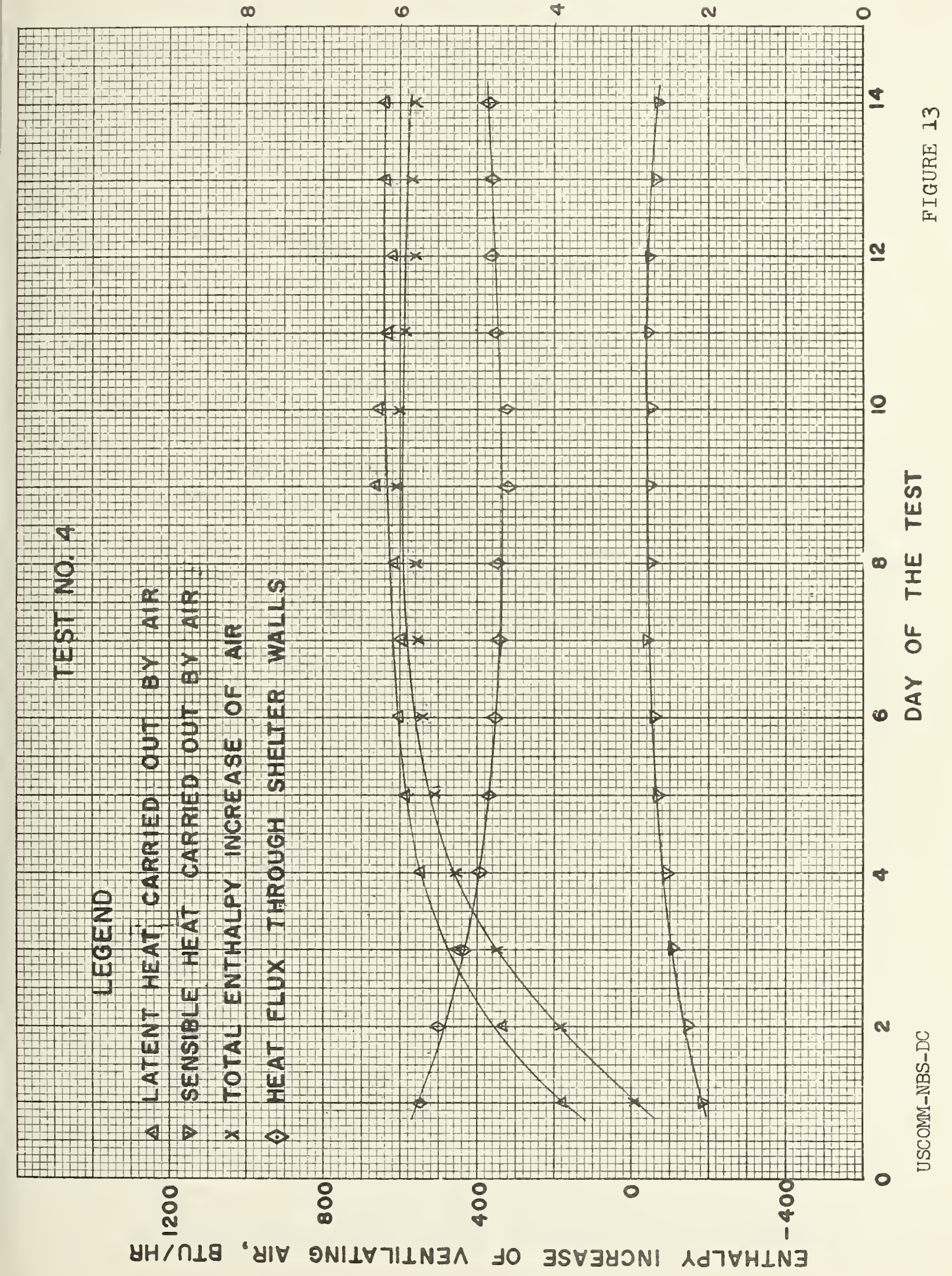






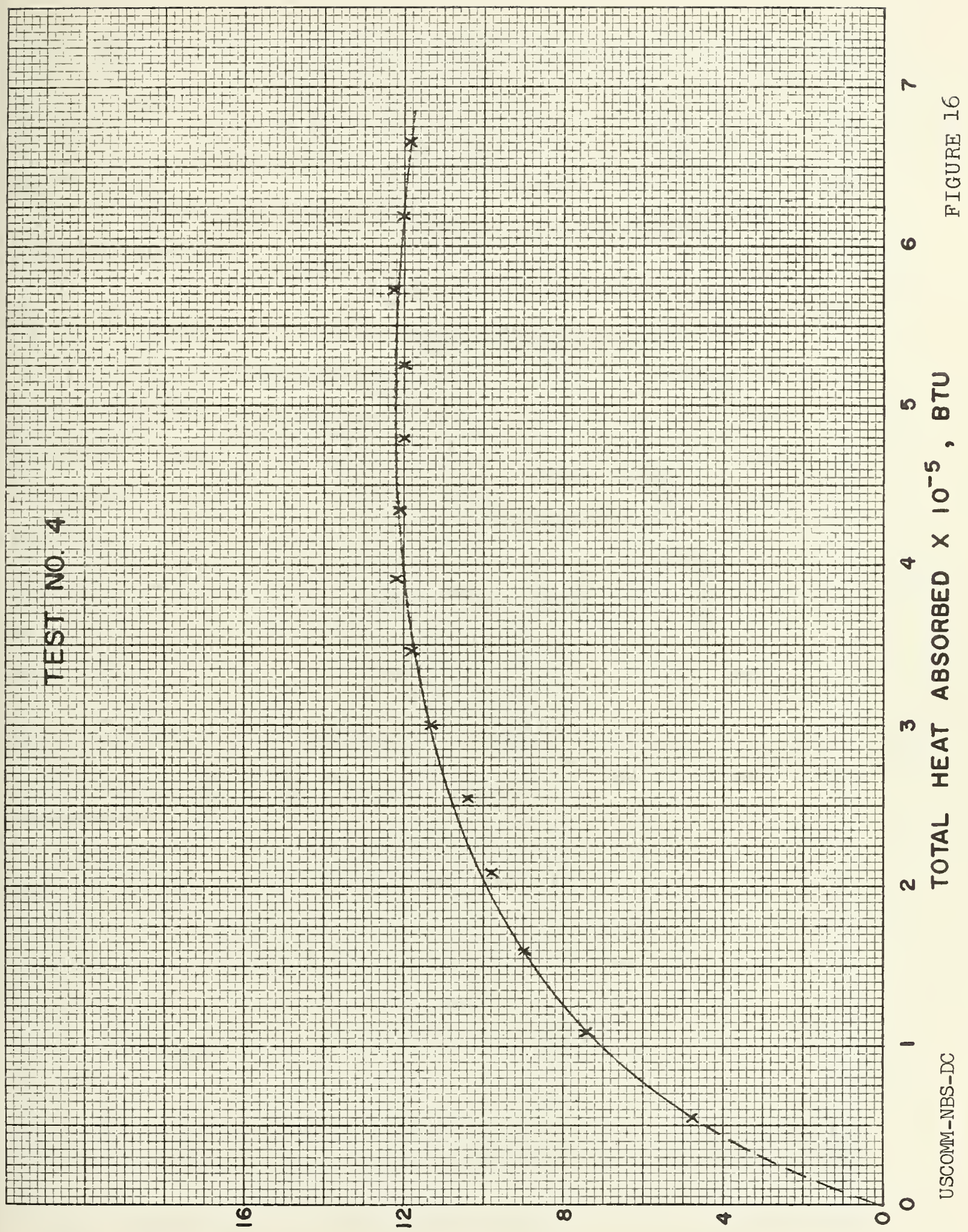

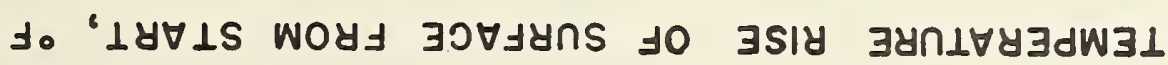




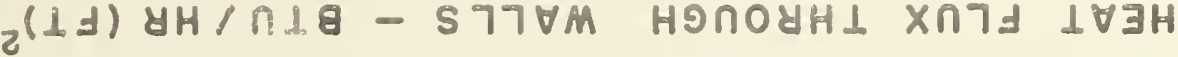

$\bullet$

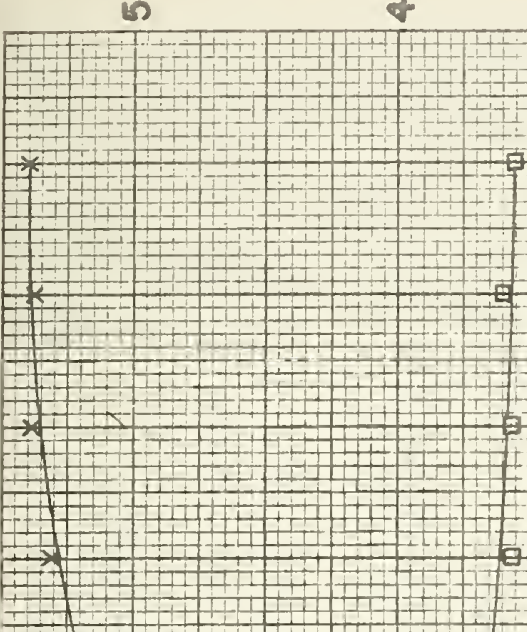

m

a

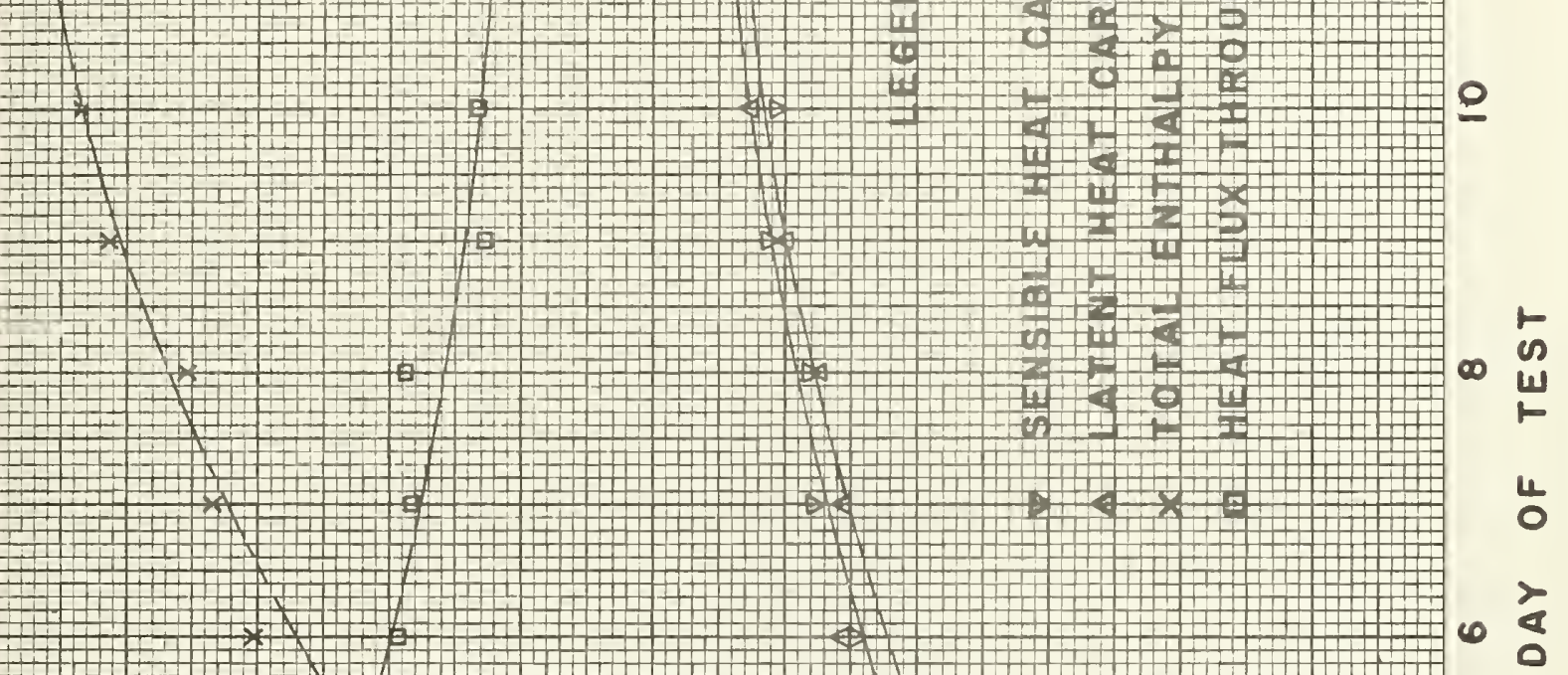

\begin{tabular}{|l|l|l|l|l|l|}
\hline \\
\hline
\end{tabular}

$$
\begin{array}{r}
5 \\
\pm \quad w \\
\frac{1}{2} \\
\frac{0}{4}
\end{array}
$$

E

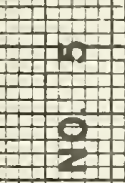

$+1$

(3)

if

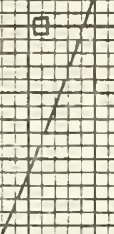

$+$
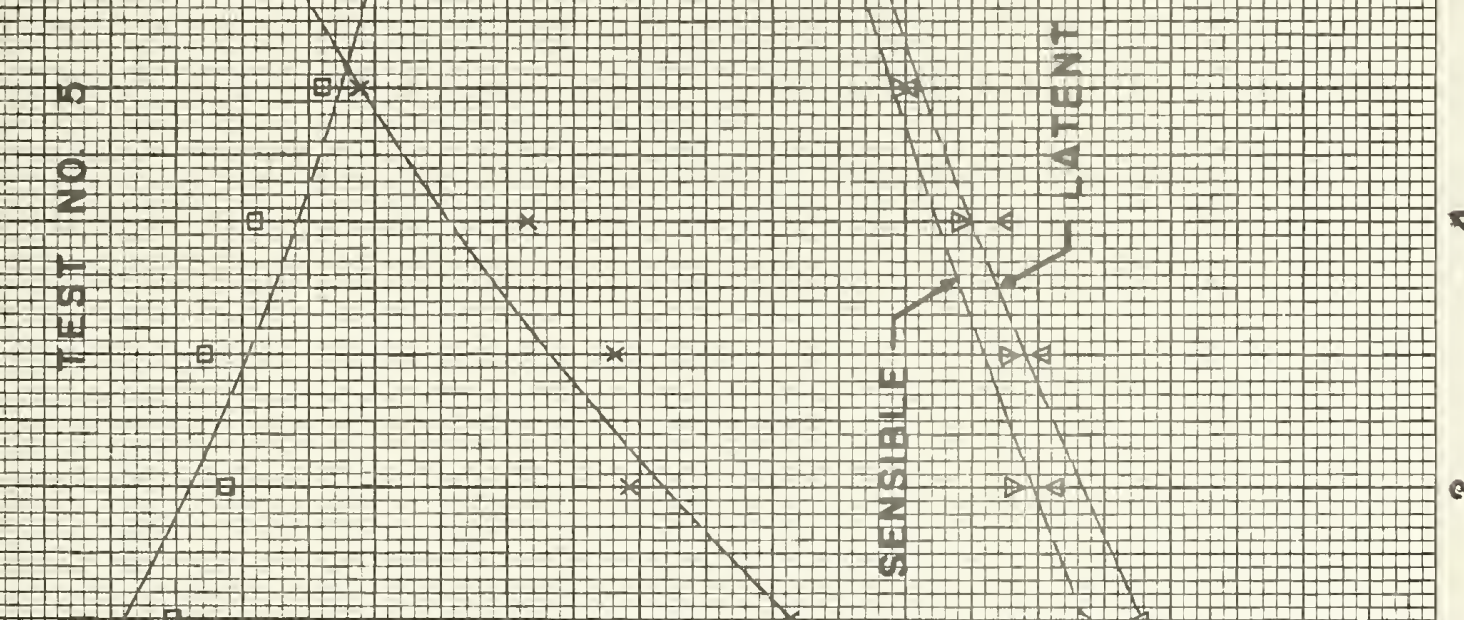

$$
\text { \# }
$$

\begin{tabular}{l|l|l|}
\hline प1 \\
H
\end{tabular}

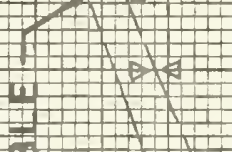

ma

?

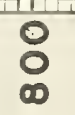

8

8

0
0
N

o 


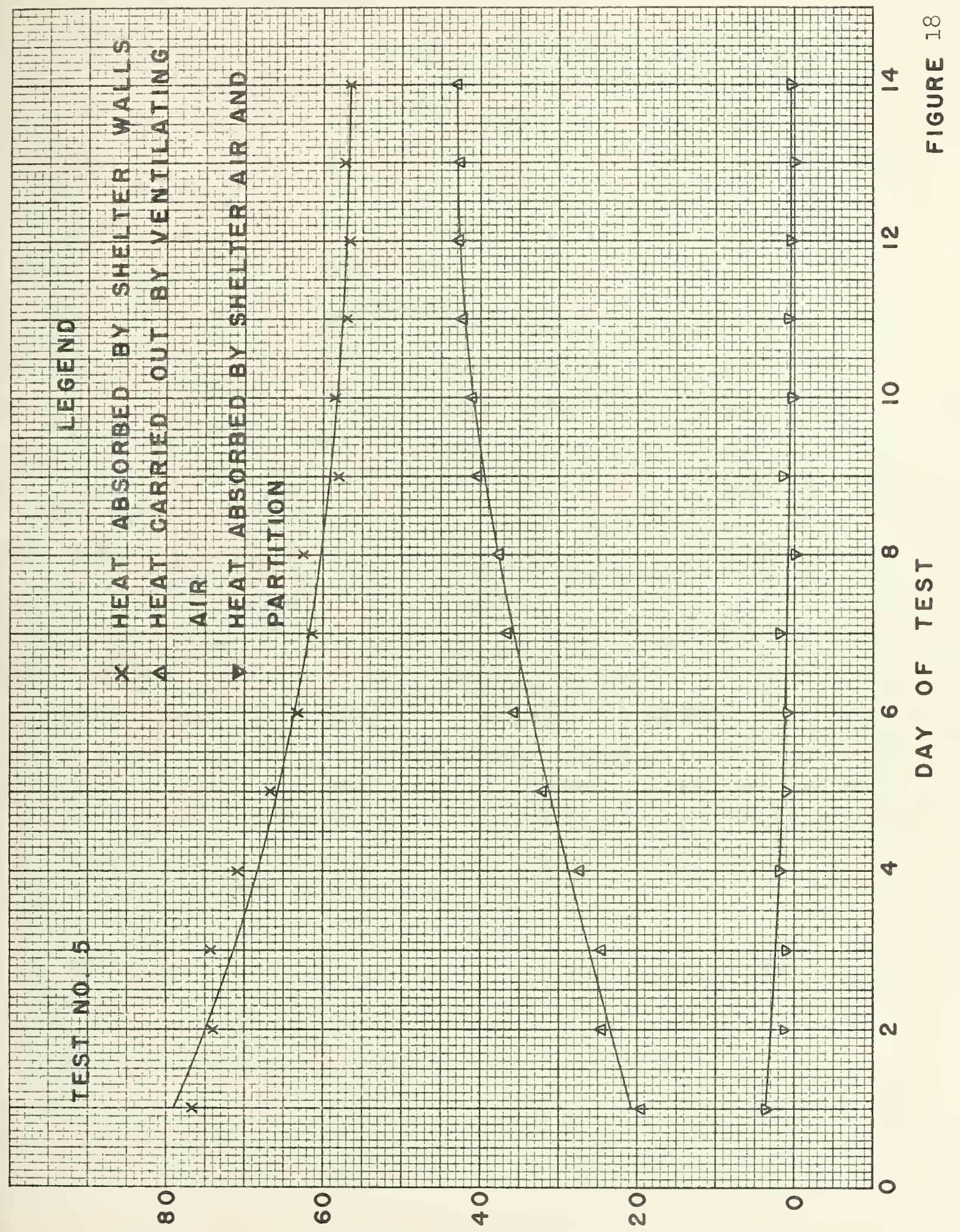

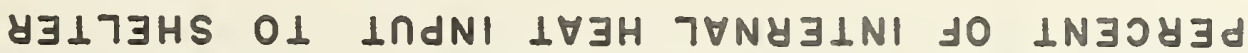





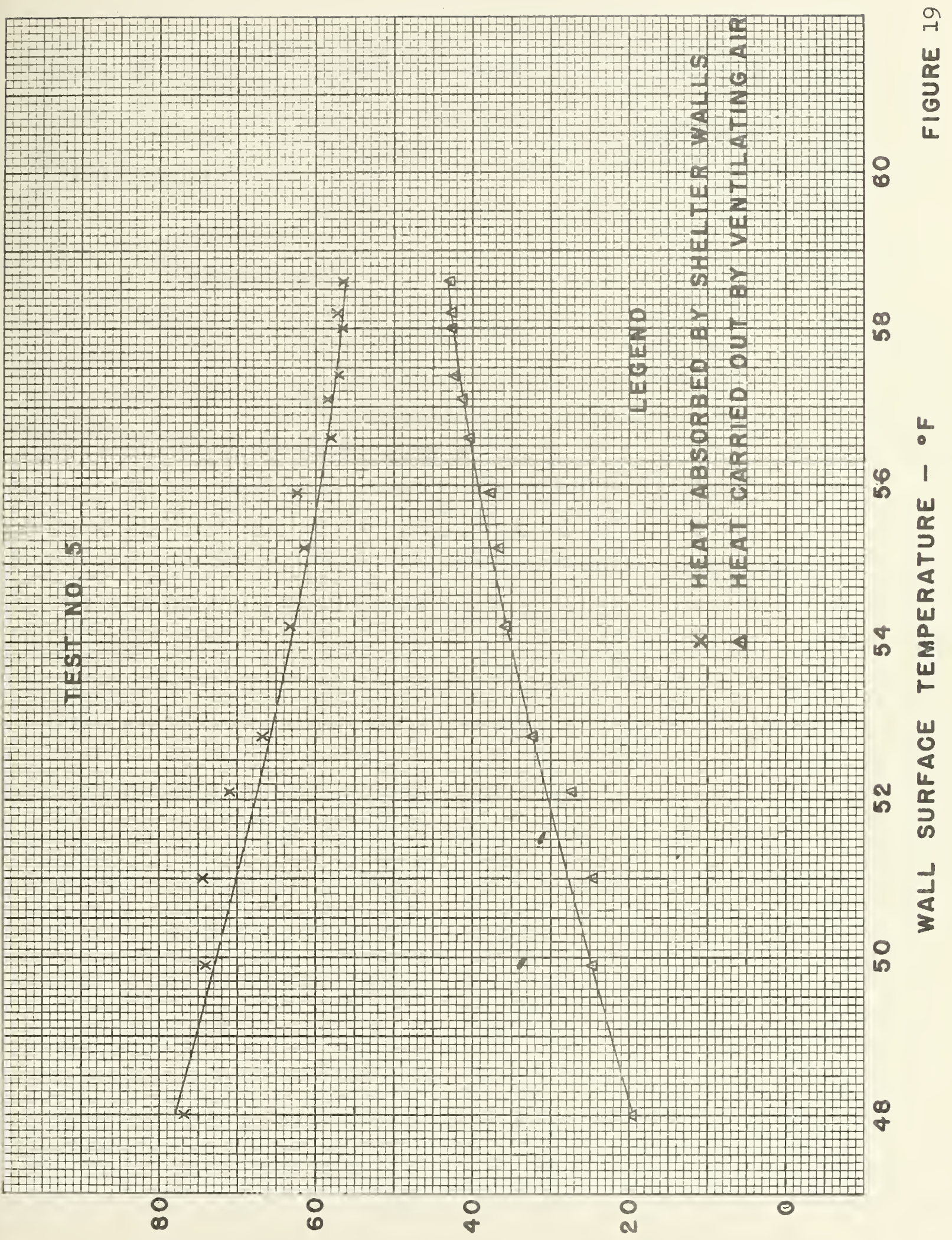

$\forall \exists \perp 7 \exists H S O \perp \perp \cap d N I \perp \forall 3 H$ TVNYIINI 



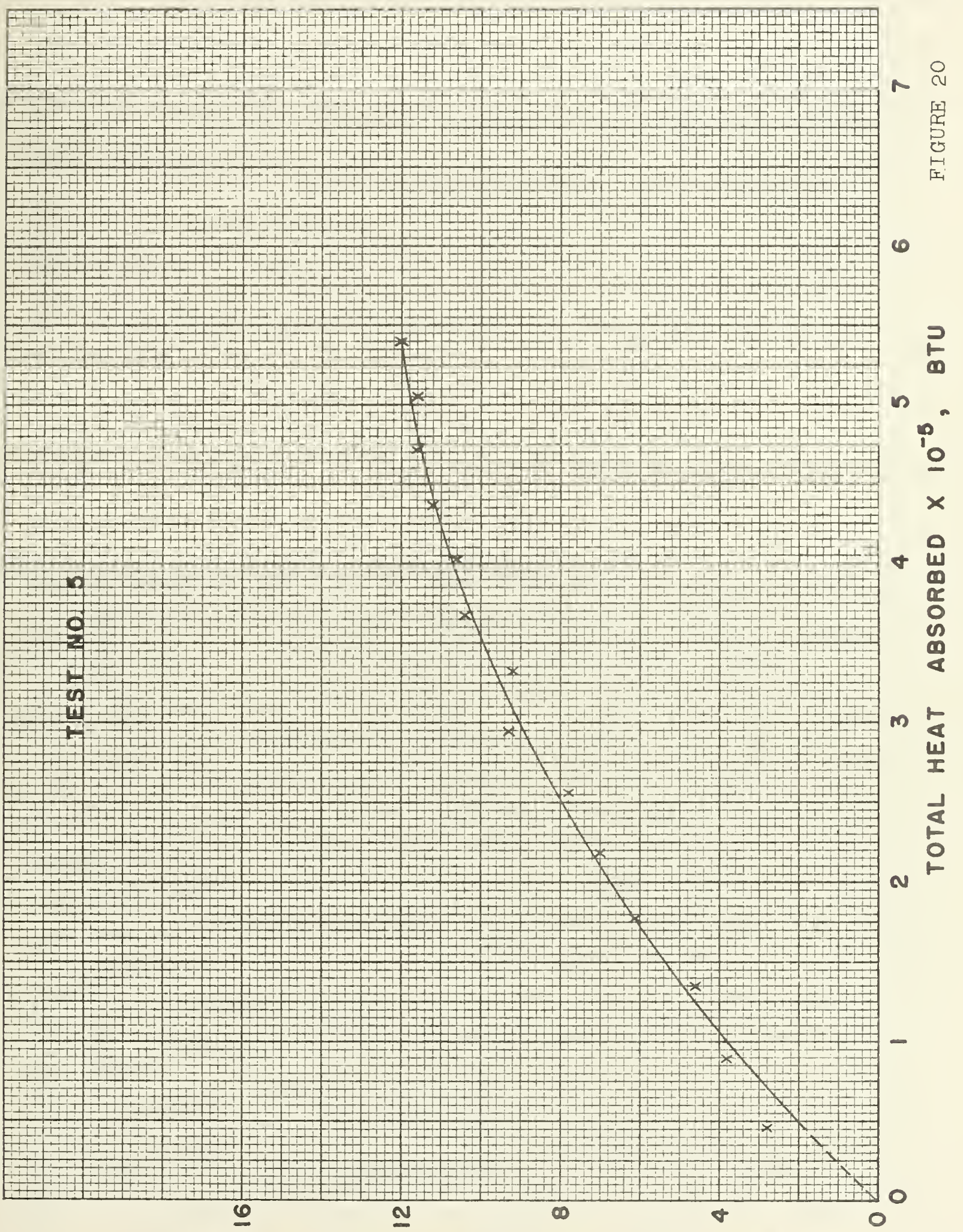

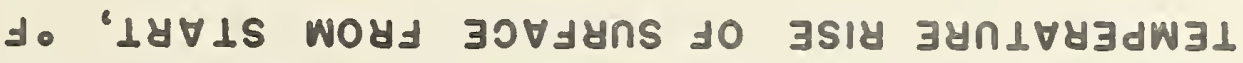




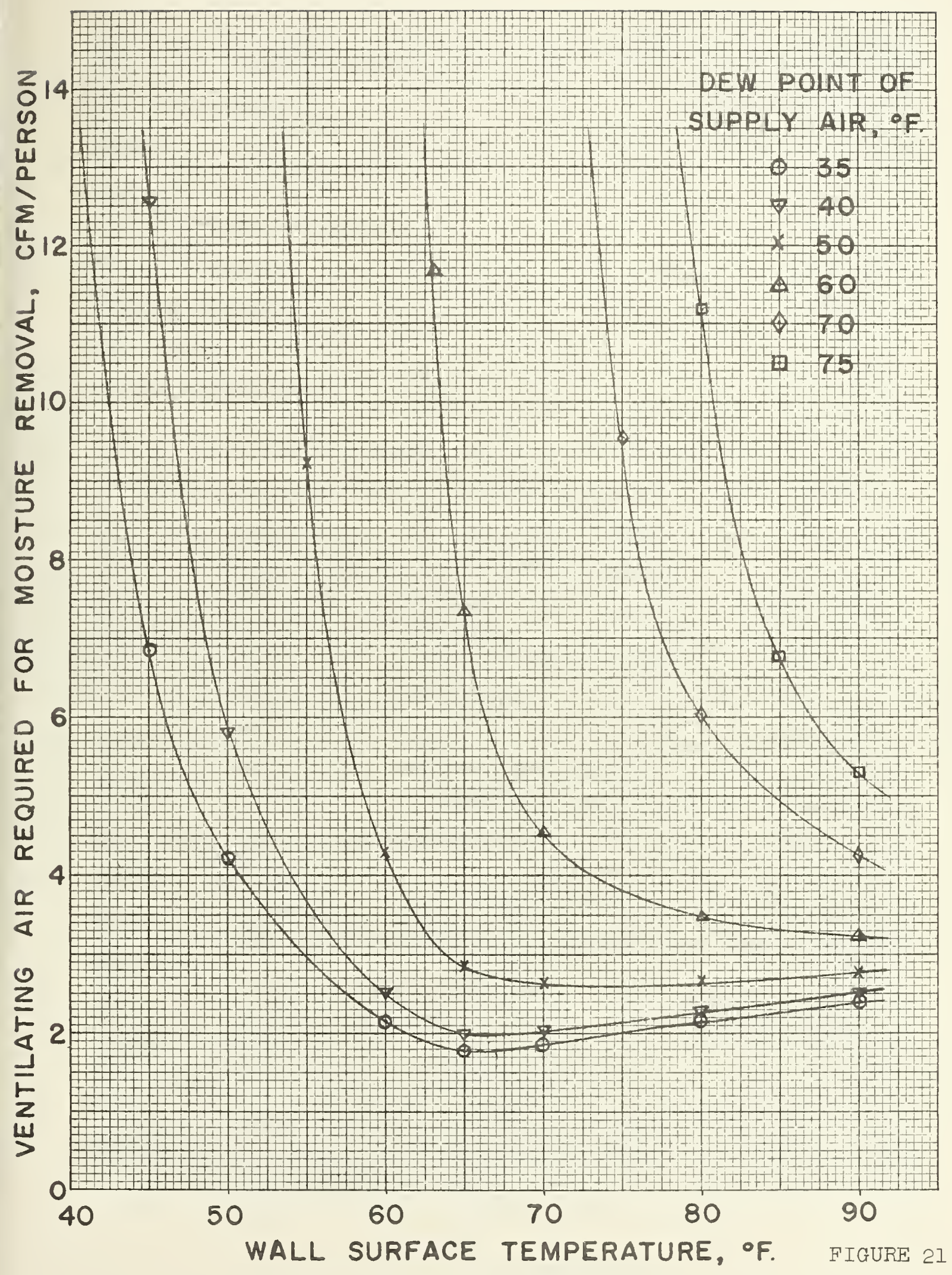





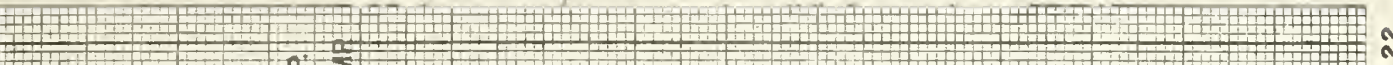

ก

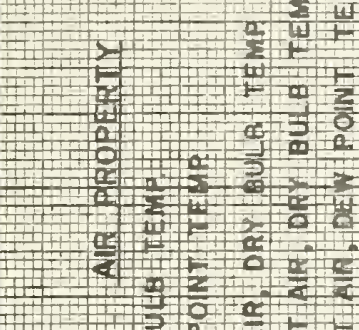

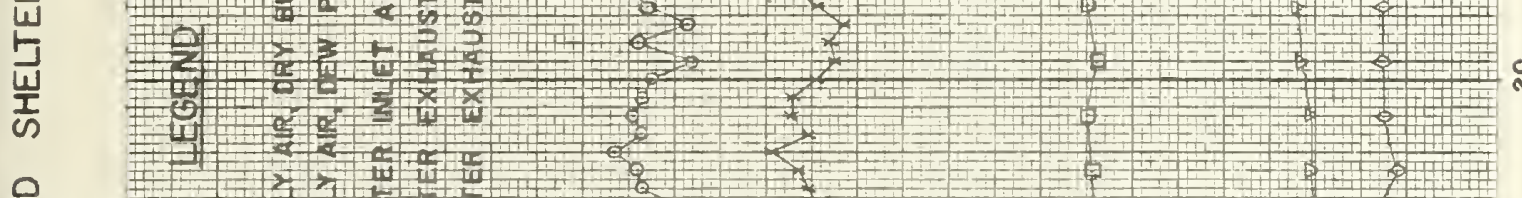

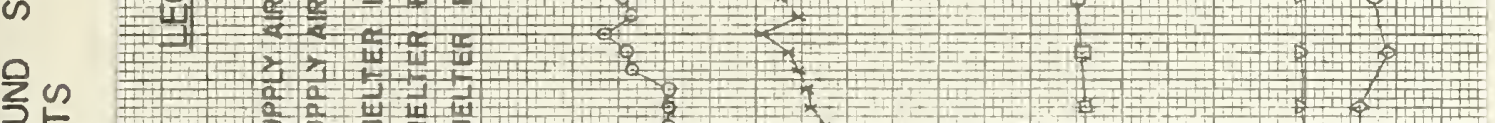

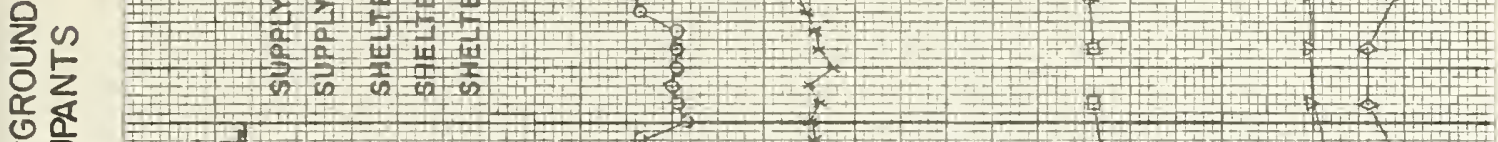

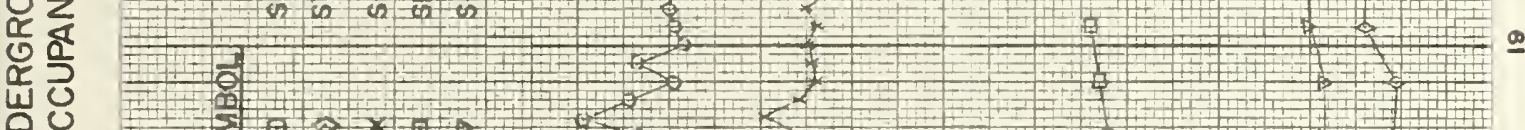

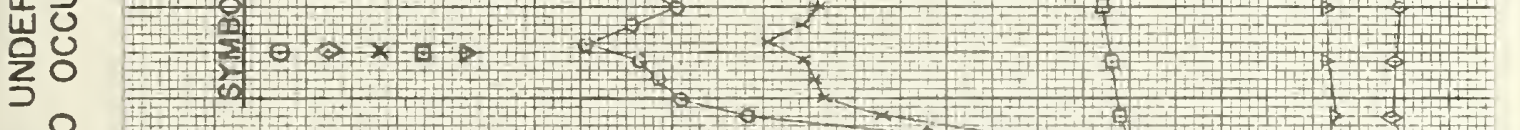

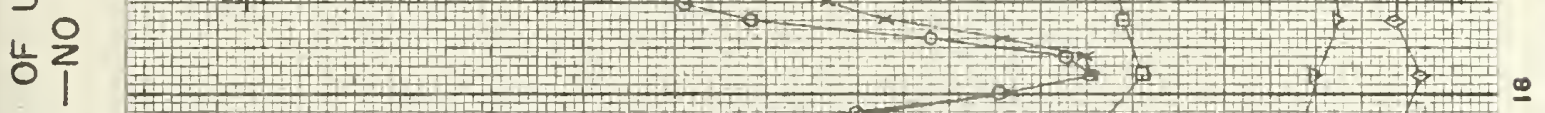

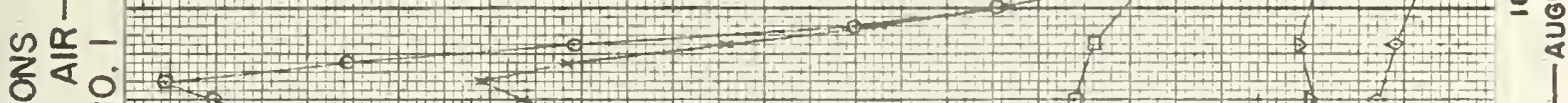

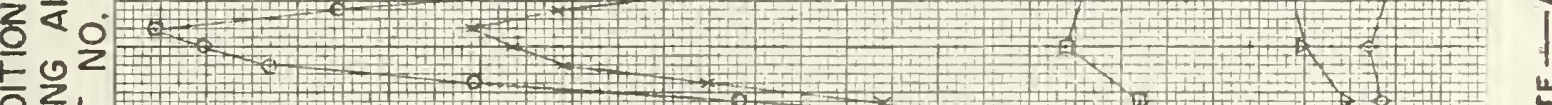

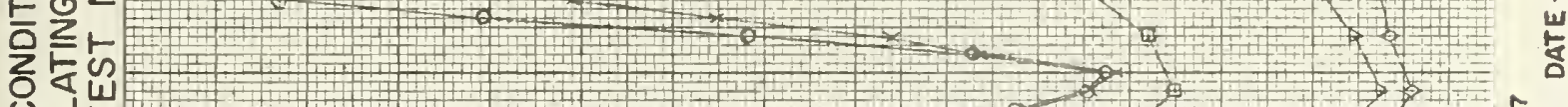

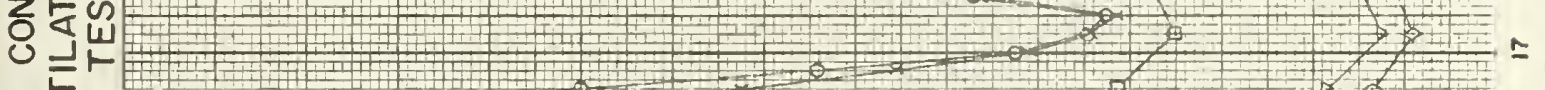

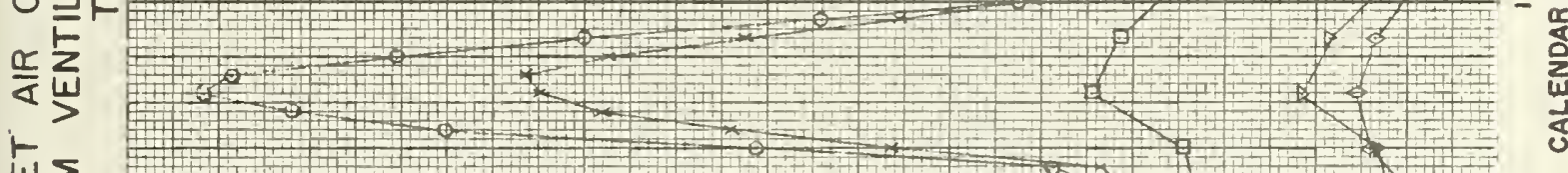

ヒ匕匕U

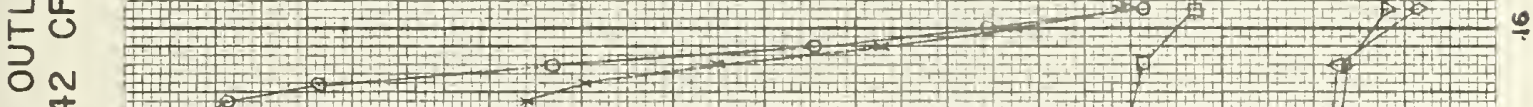

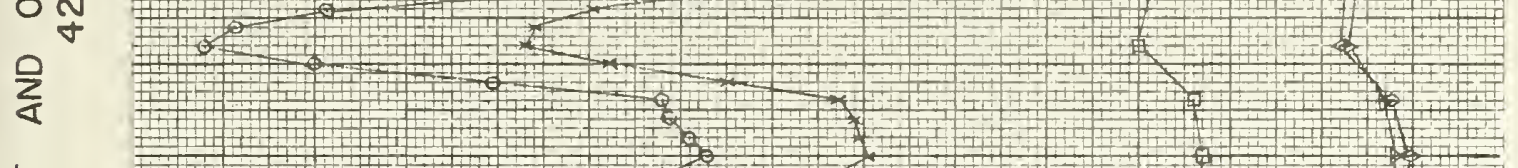

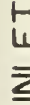
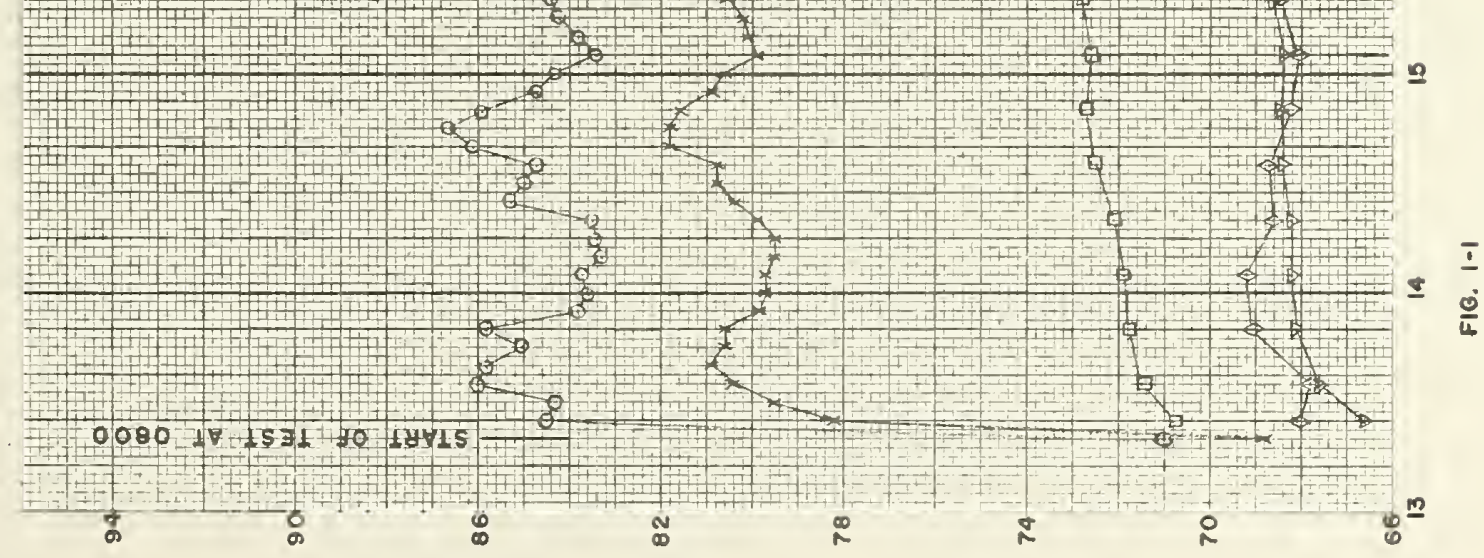



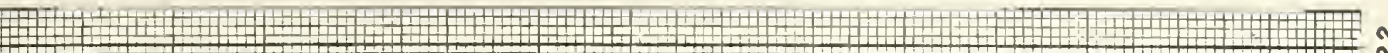

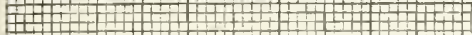

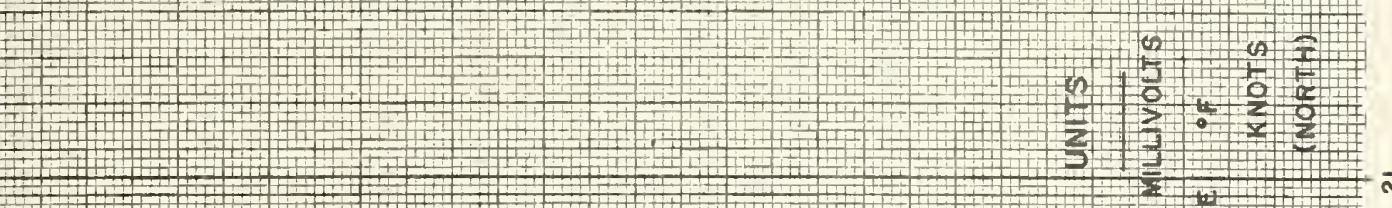
\begin{tabular}{|c|c|c|c|c|c|c|}
\hline \\
\hline
\end{tabular}

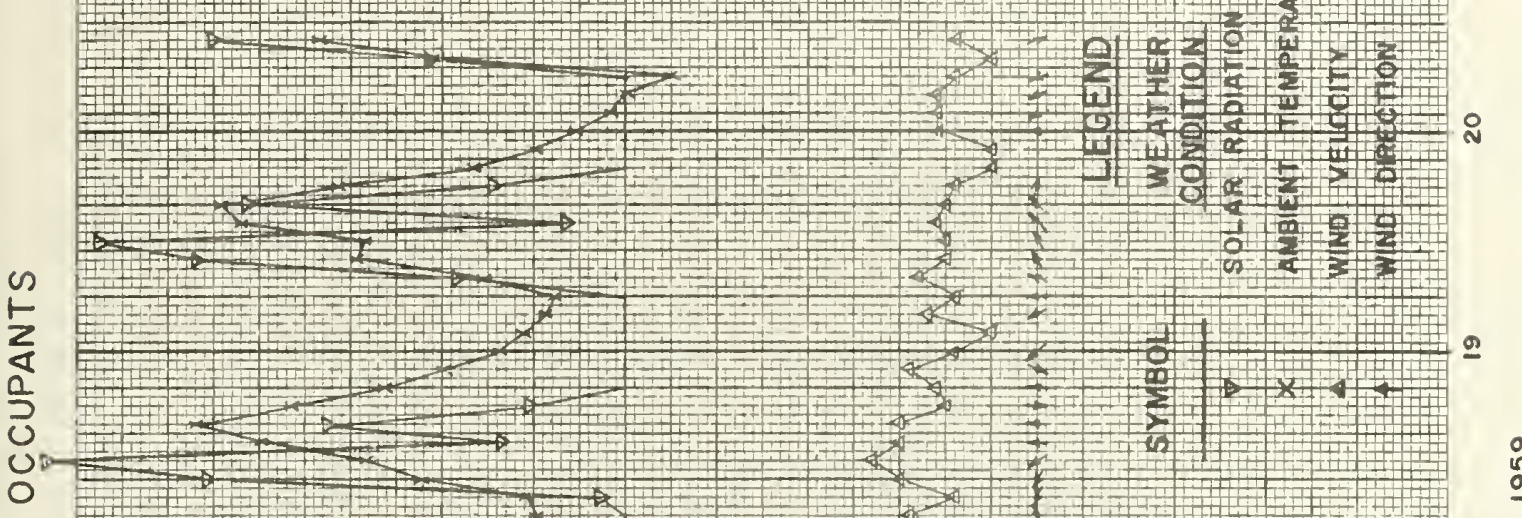

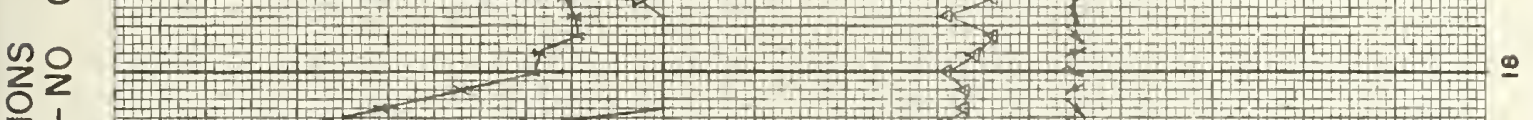

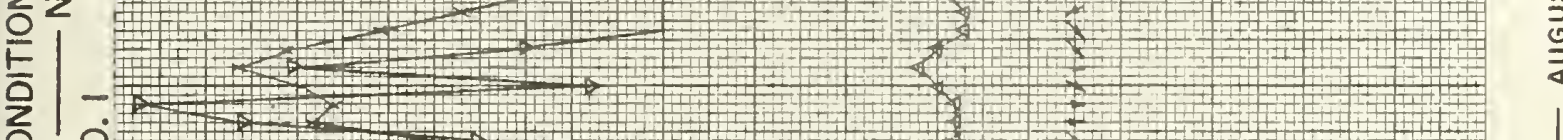

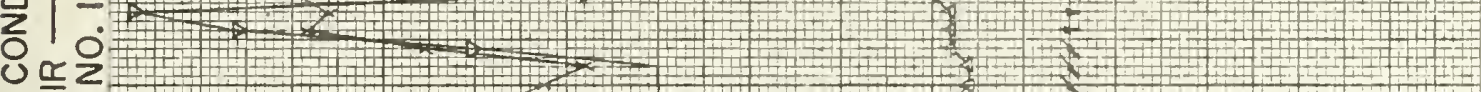

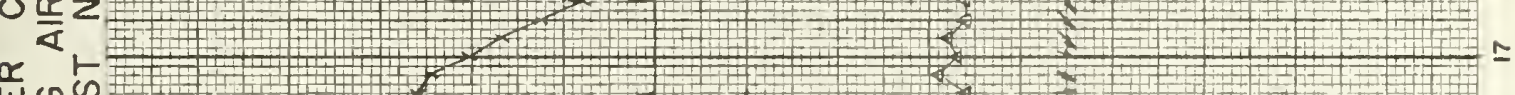

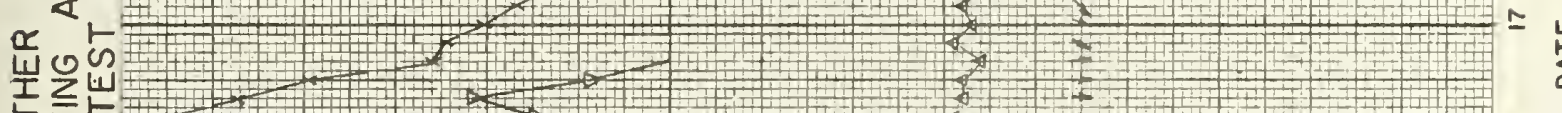

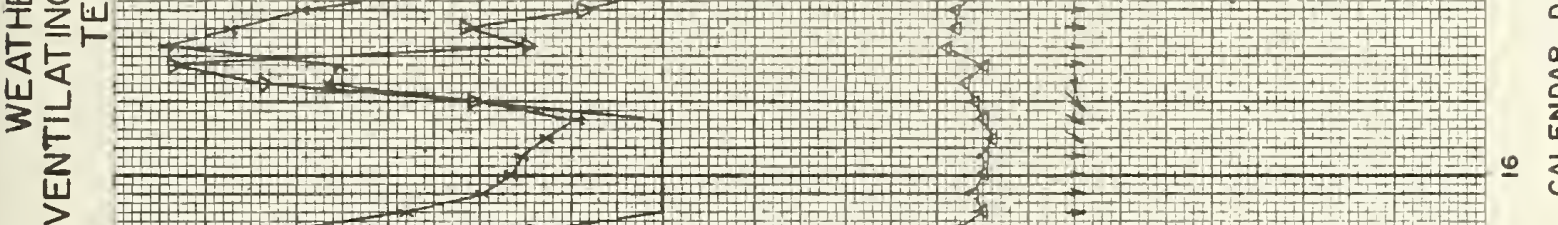
ڤి

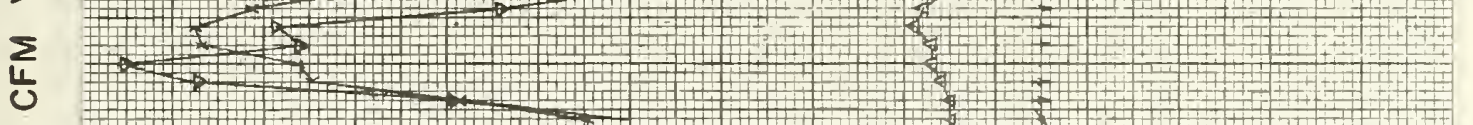

$\mathrm{N}$<smiles>CCCC1CCCCC1</smiles>

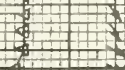





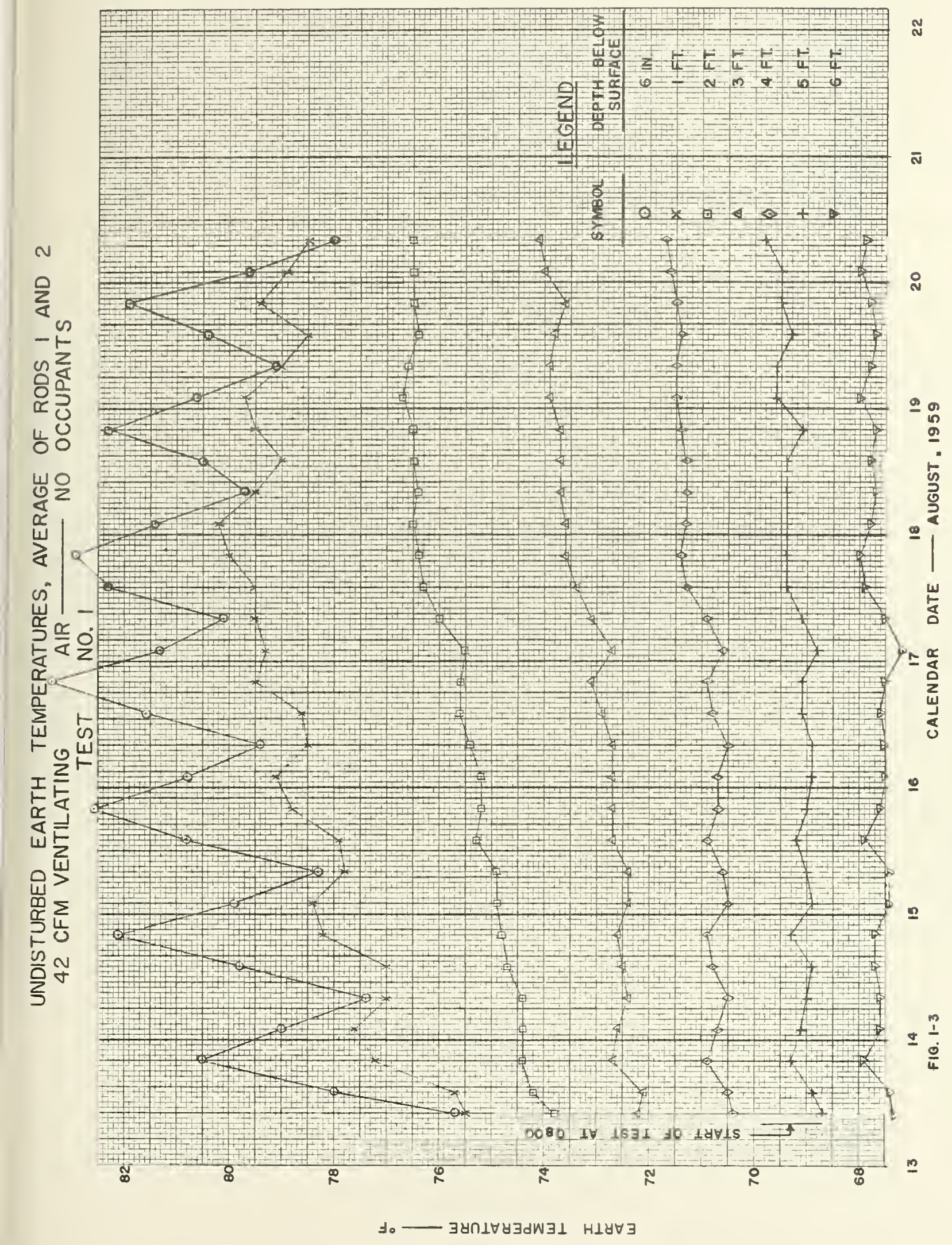





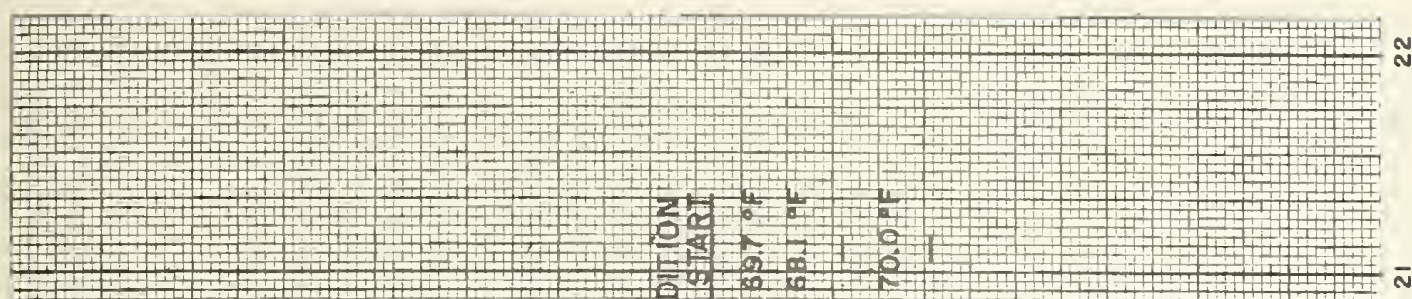

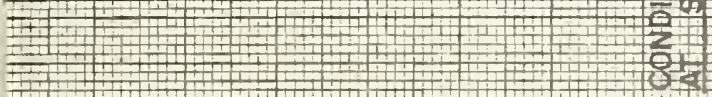

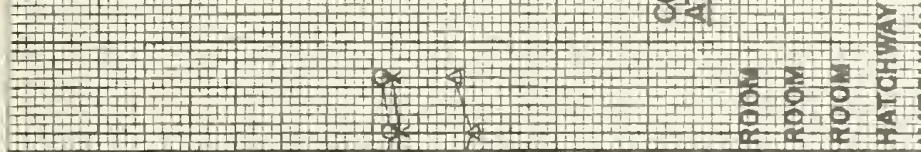

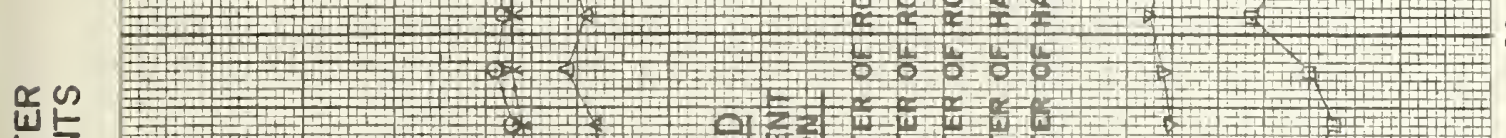

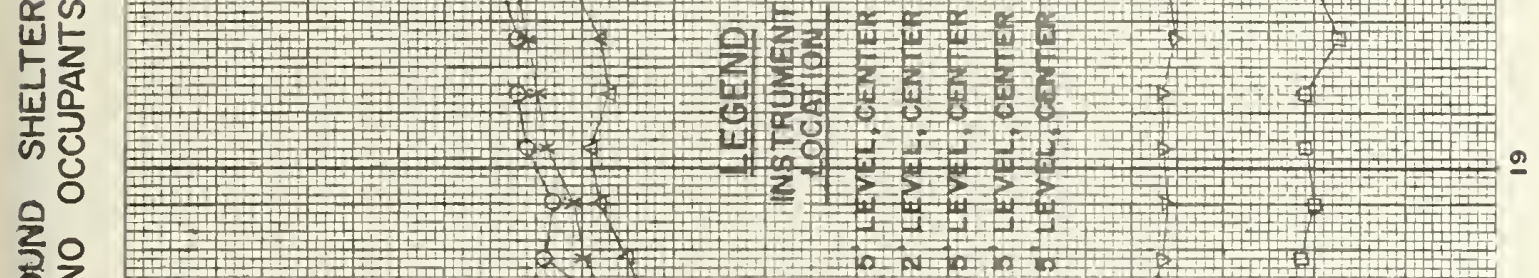

帘足

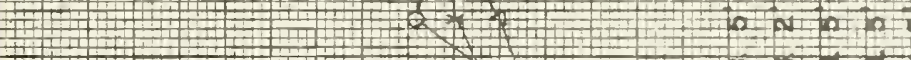

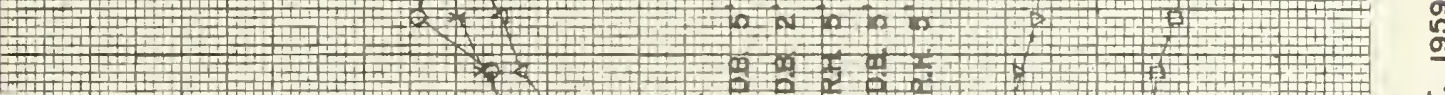

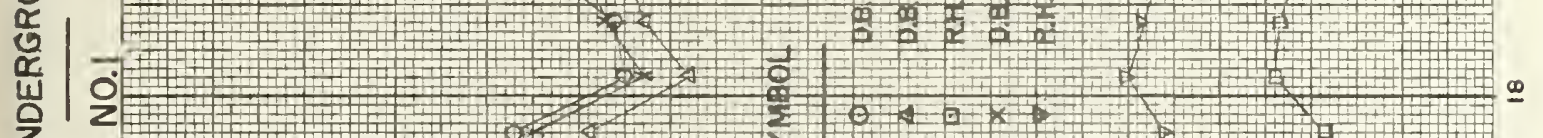

焉的

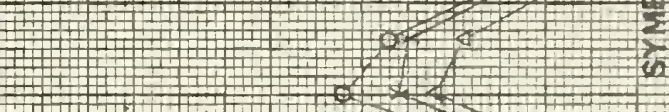

岁出

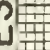

残平

1
1
1

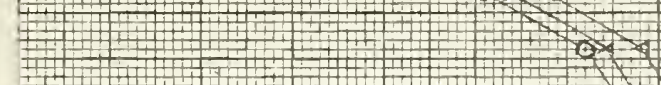

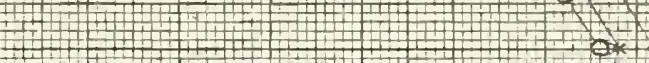

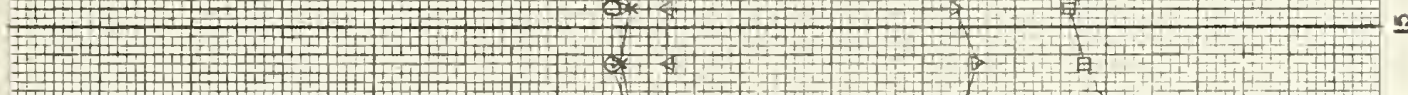

\begin{tabular}{|c|c|c|c|}
\hline & & & \\
\hline
\end{tabular}

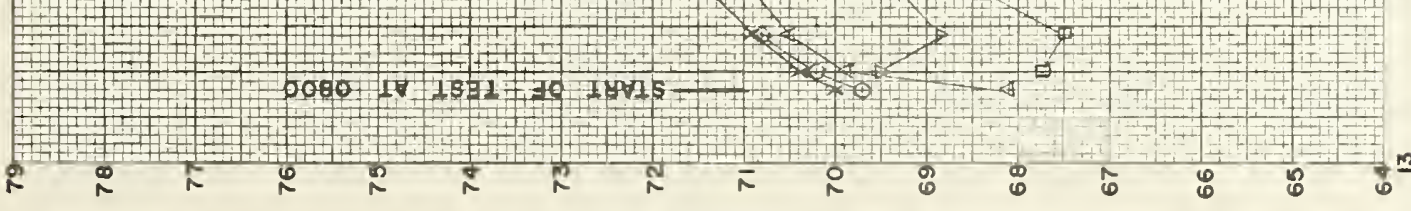

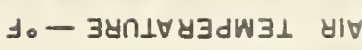

\& $\stackrel{0}{2} \stackrel{\infty}{\sim}$ 



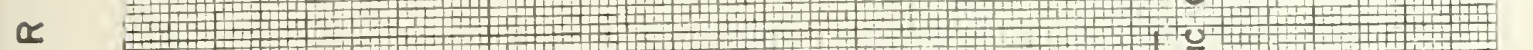

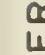

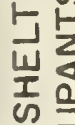

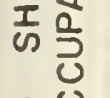

잉

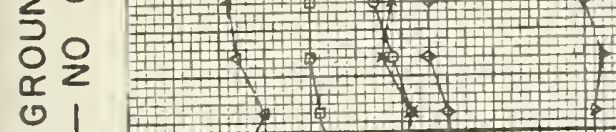

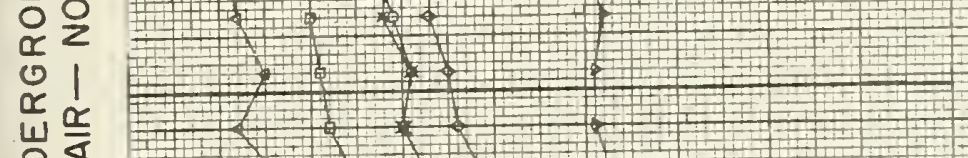

之

$\sum 0$

岁焉



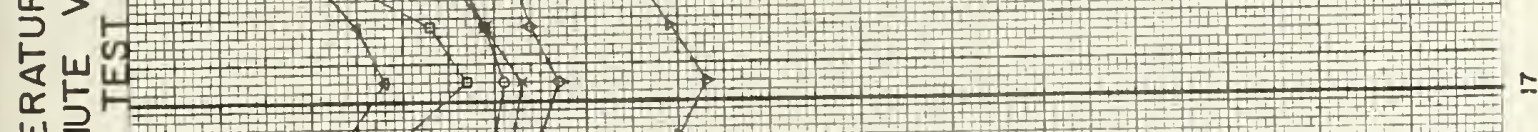

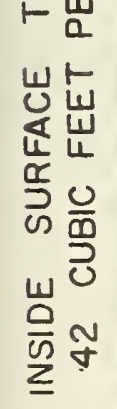

(1) $+1$ +

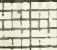
$\frac{1}{4+2}$
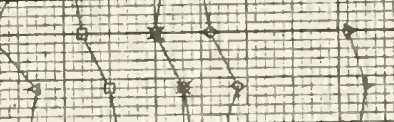

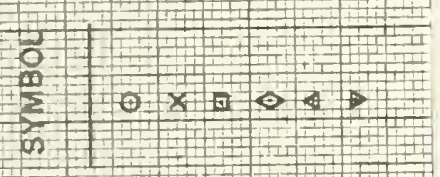
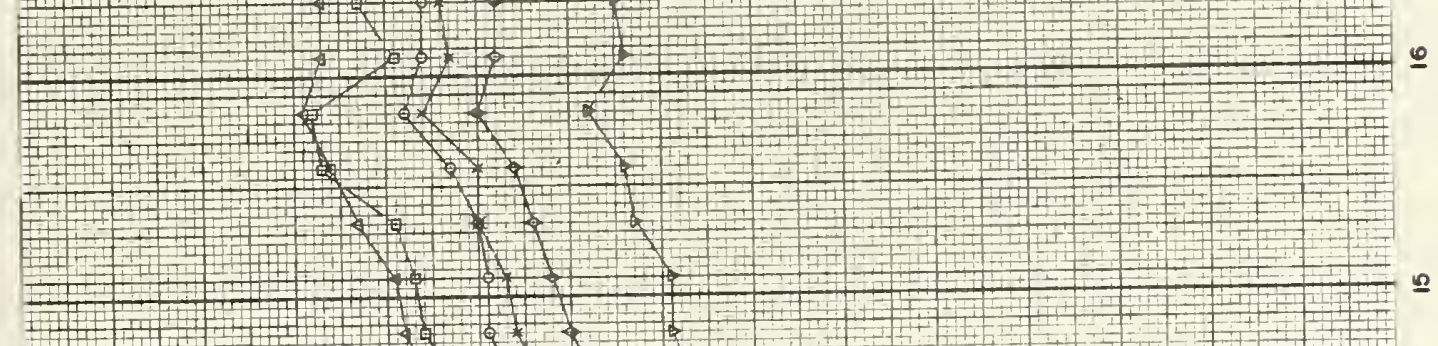

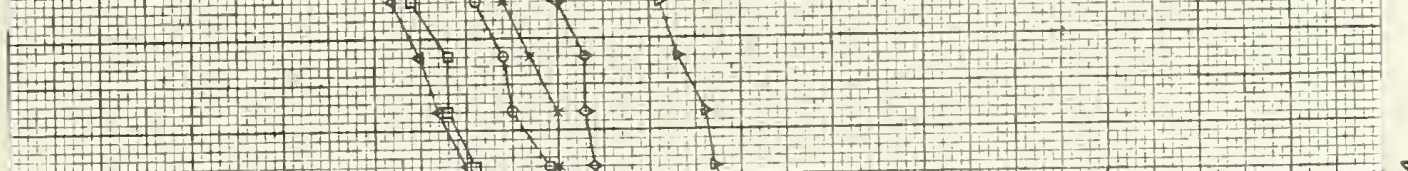

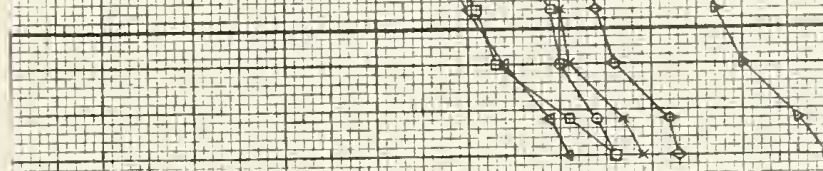

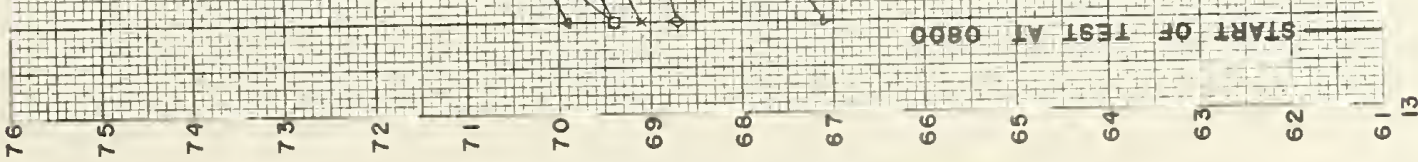





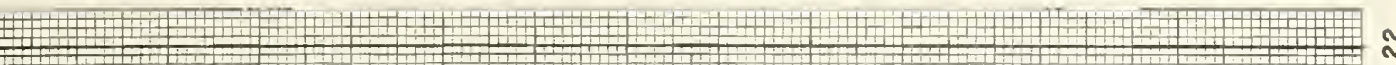

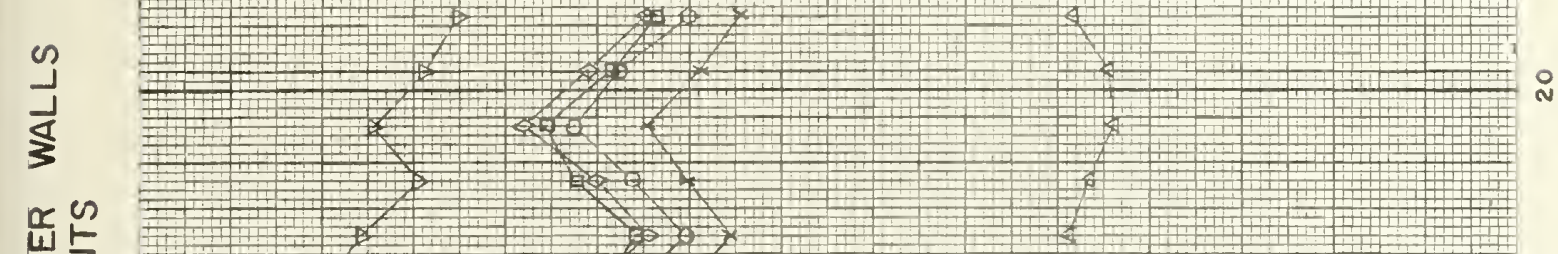

出占

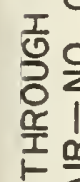

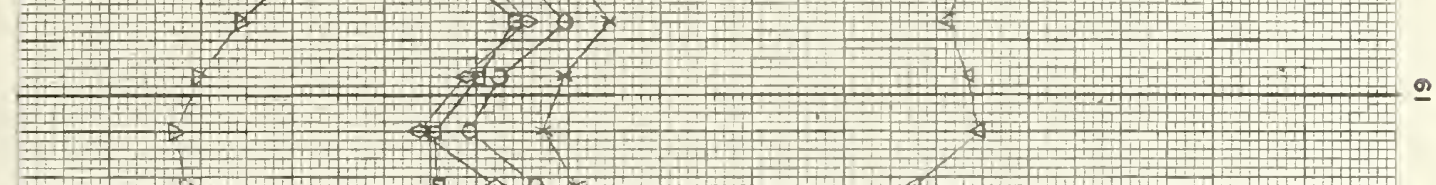

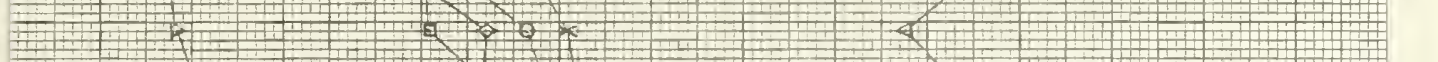

을

$+2+2+2$

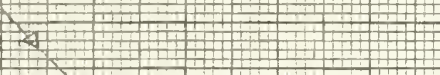

w

$\frac{1}{12}$

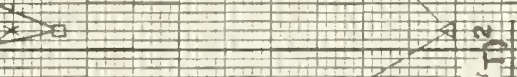

w

$x$

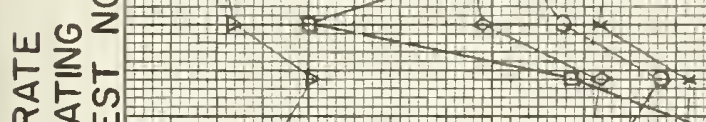

员

W

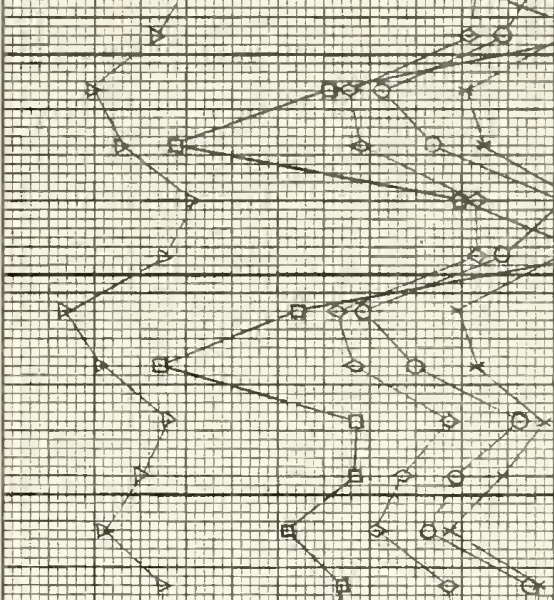

4
$\times 15$

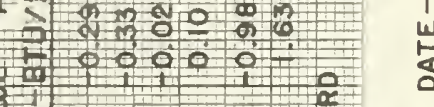

$\frac{5}{5}$

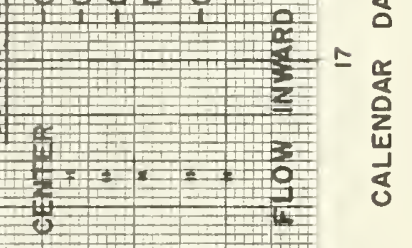

迹

$\sum 0$

$\mathscr{F}$

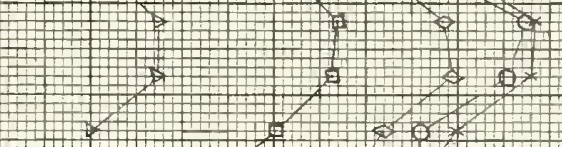

$+$
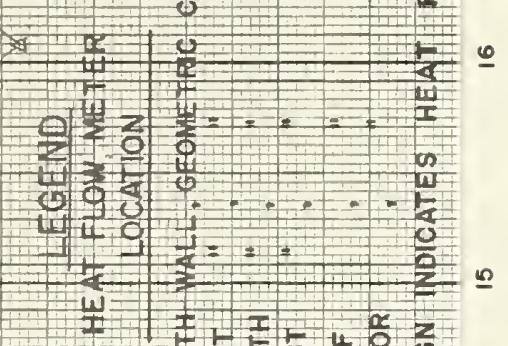

$\frac{y+\cdots+\ldots}{\delta}$

$\propto 5$

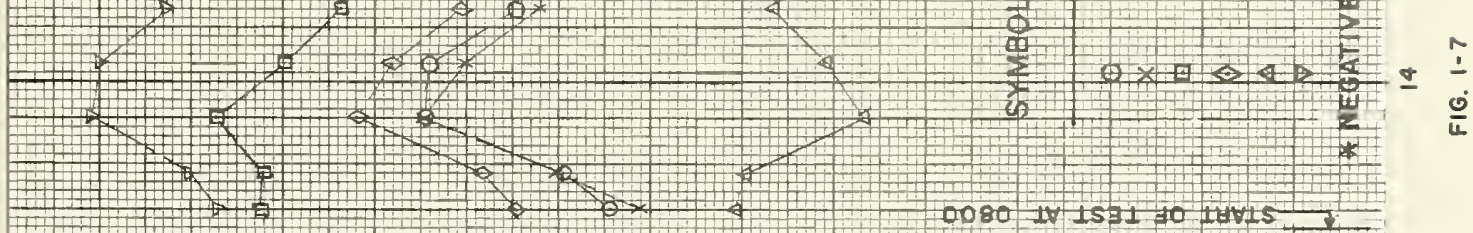

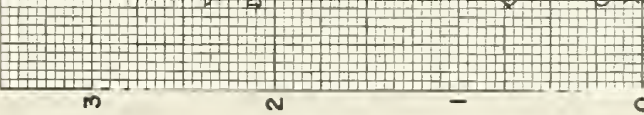

0000 IV ISII jo IVtVIS T

N

i 

TEMPERATURES IN SHELTER WALLS AND SURROUNDING EARTH AT START OF TEST I, AUG.13, 1959-TIME 0800

82

80

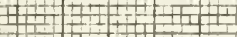

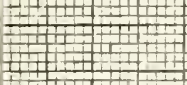

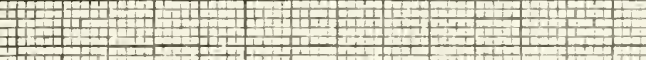

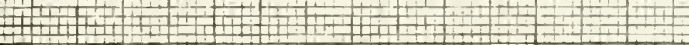

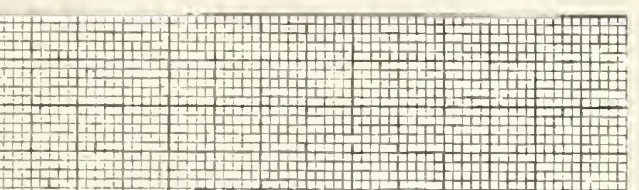
\begin{tabular}{|l|l|l|}
\hline 14 \\
\hline
\end{tabular}

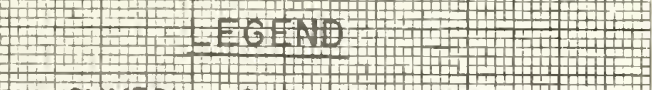

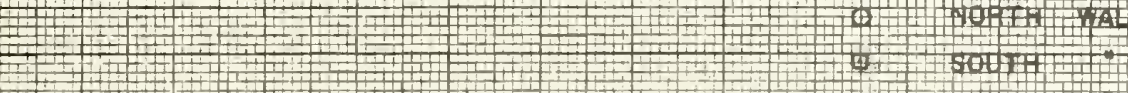
SYMEOL- SHELIEA COMDONENI

6

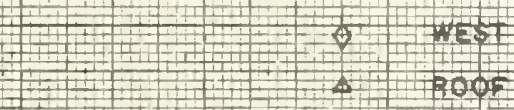

|

72

4

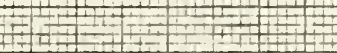

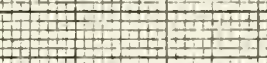
$\frac{1+1+1}{1+1+1+1}$

$\frac{+4}{+1+1}$

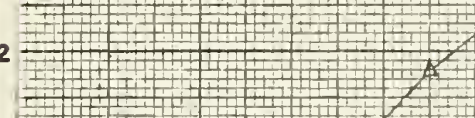

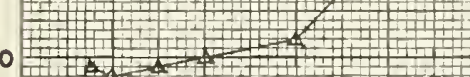

70 $+2$

$+2$

68

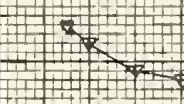

66

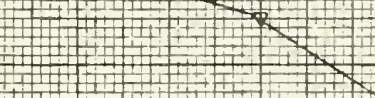

$+1$

s

64

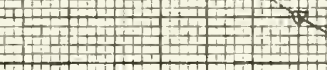

$+7$

सा+

$+$

62

\#
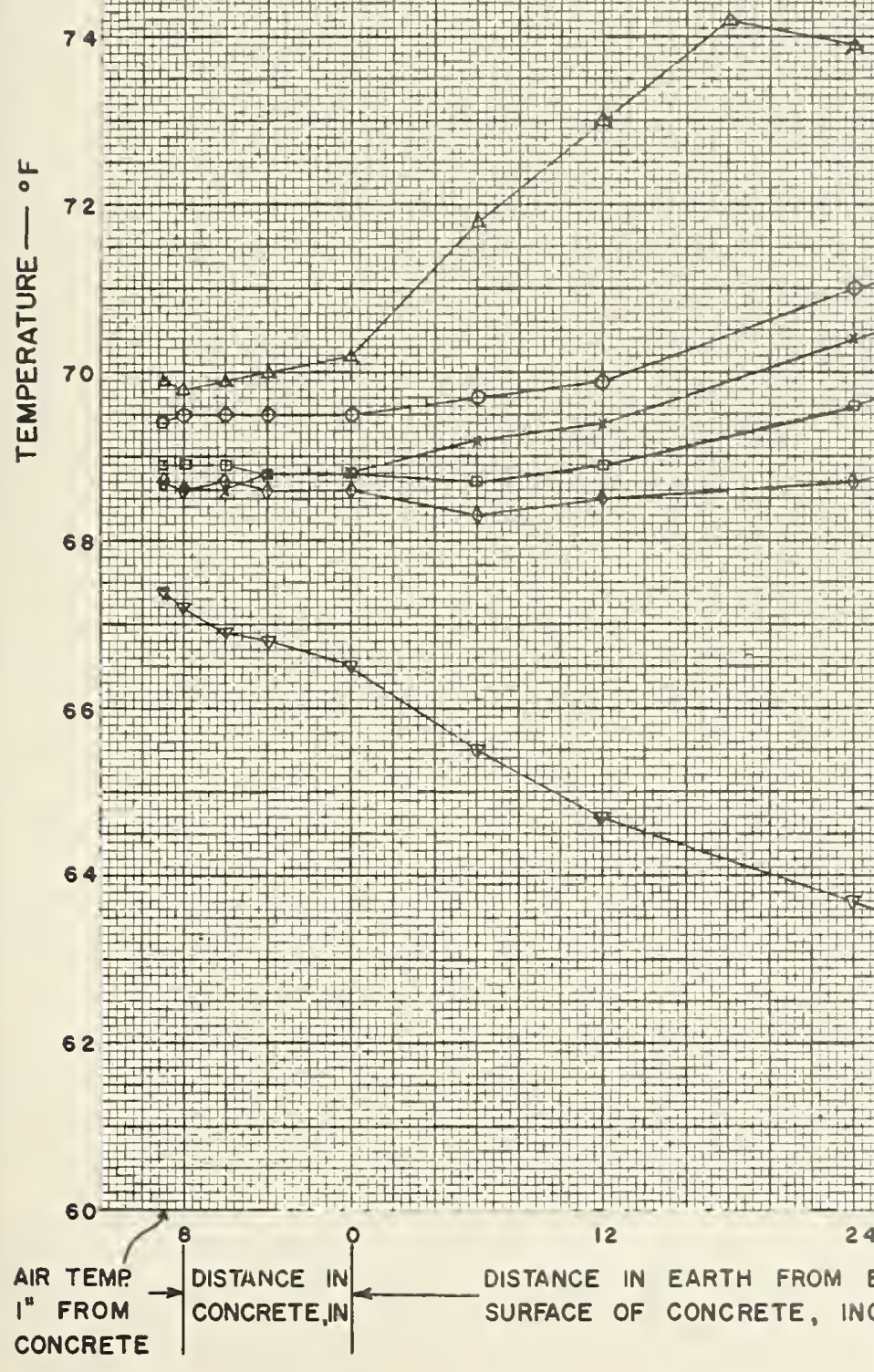

$$
+4+1+1
$$


TEMPERATURES IN SHELTER WALLS AND SURROUNDING EARTH AT END OF TEST I, AUG.20, 1959-TIME 1000

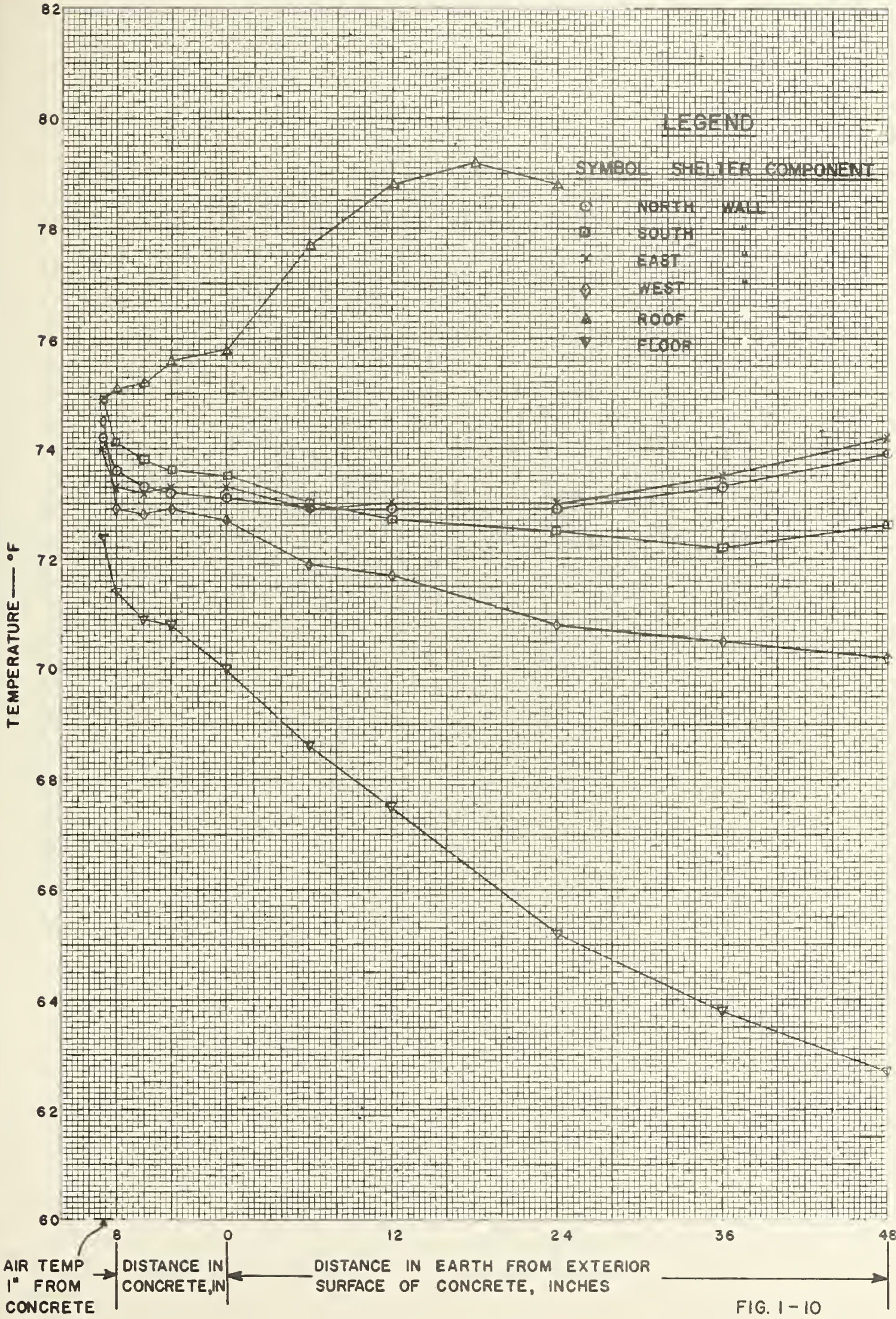




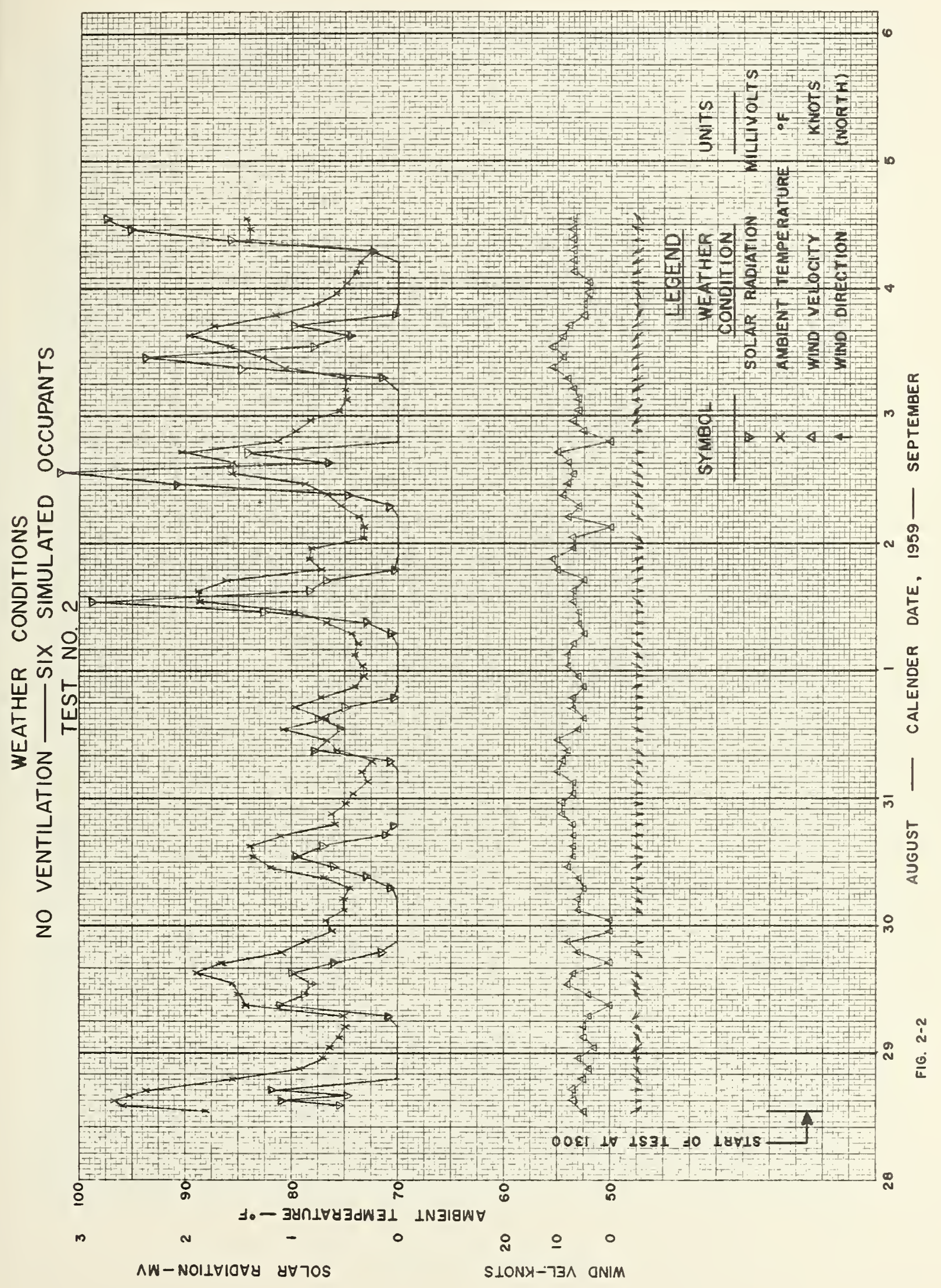





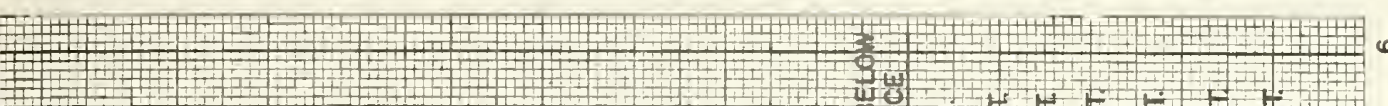

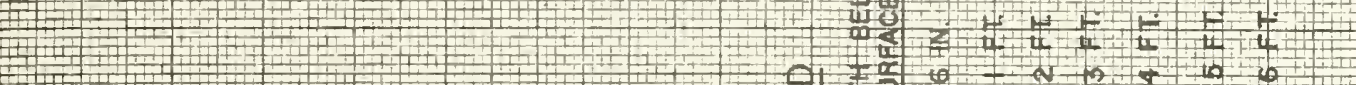

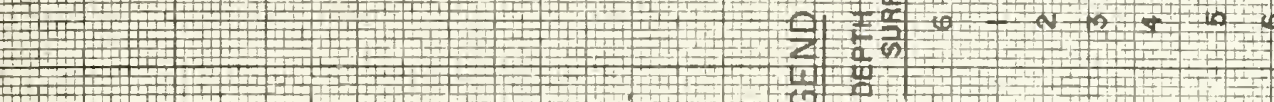

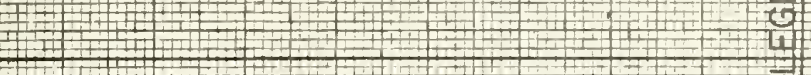

金赵

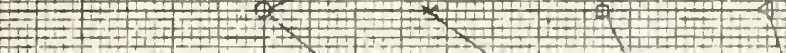

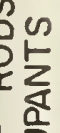

แᄂ

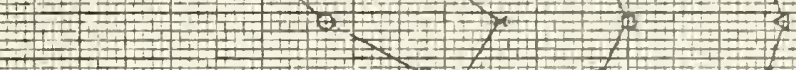

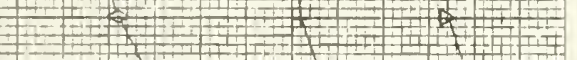

닝

品

㱐要

造

㟧 $\frac{2}{\omega}$

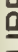

गे

这

178

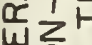

(12

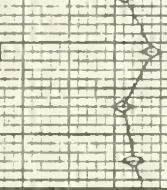

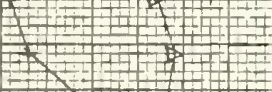

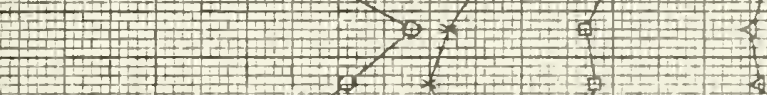

$+$

+20

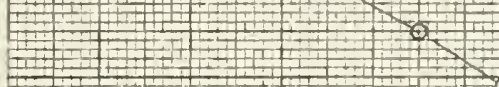

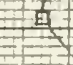

$+\frac{1}{2+1}$

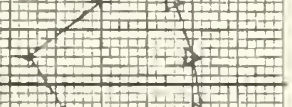

$\frac{\frac{c}{u}}{\frac{0}{2}}$

嵌

$\sum_{W}$

点

政

䑩

wo

0

岩

穴

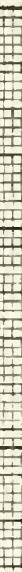

$+1$

$+2$

$+\quad+\quad+1$

$\frac{1}{2+1}$
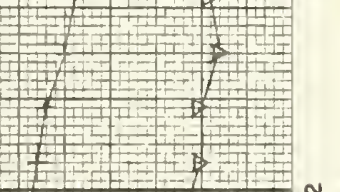

a

ֻ

崩
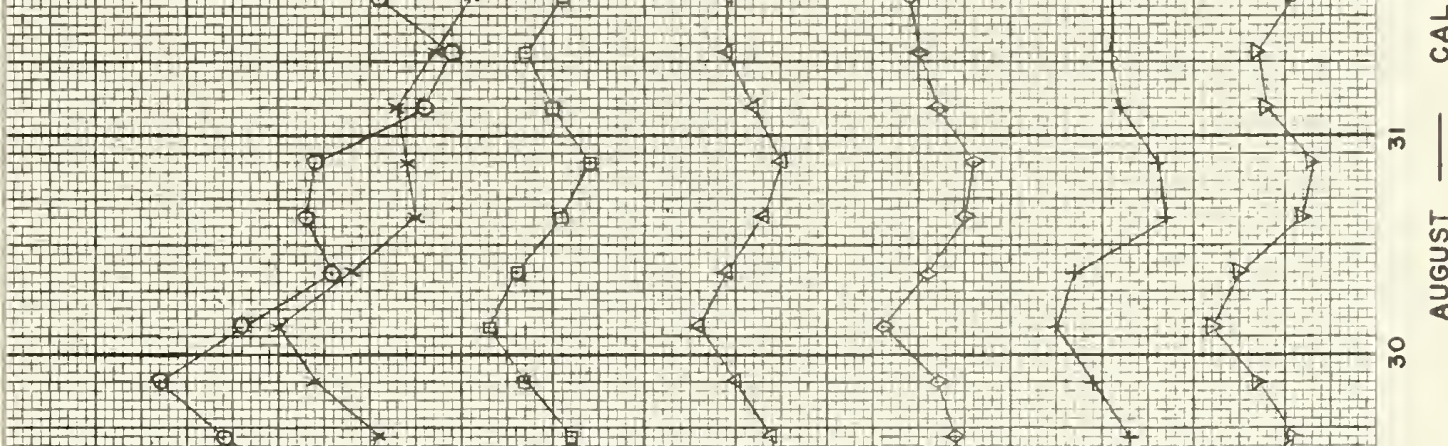

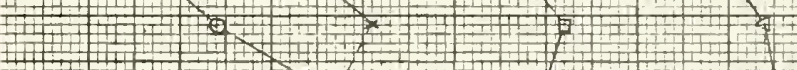

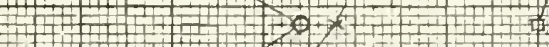

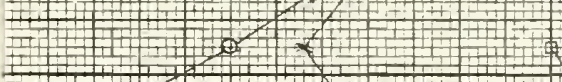

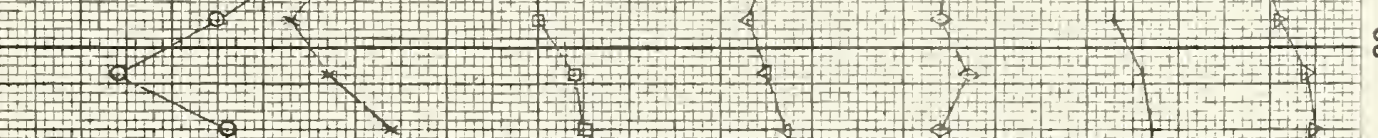

$+4+2+1+2+2$

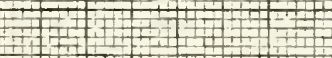

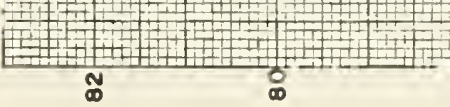

$002+\forall+15: \pm 0$

$19+15-\frac{1+1+\frac{1}{4}}{4}$

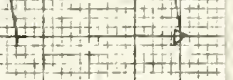

尔 




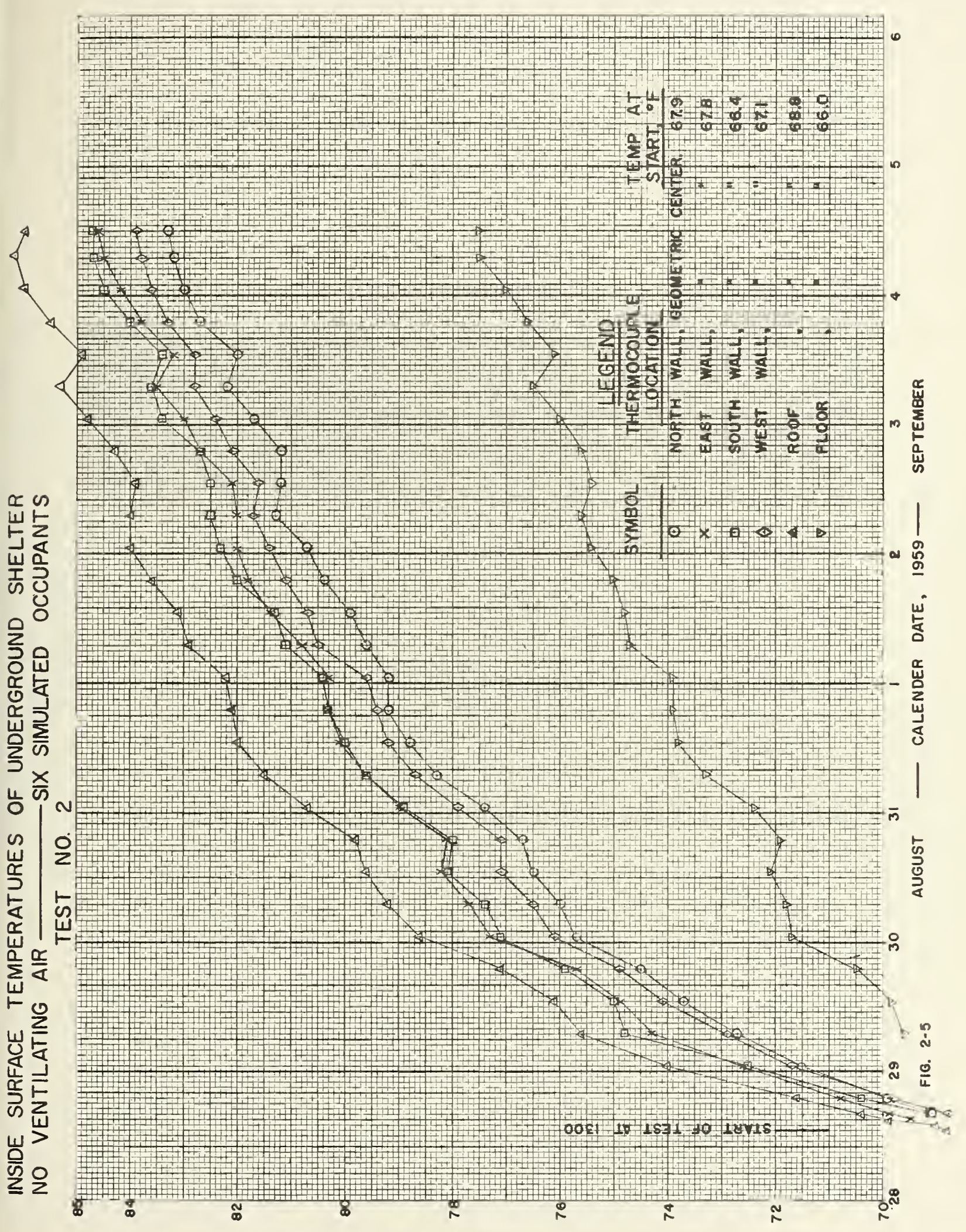





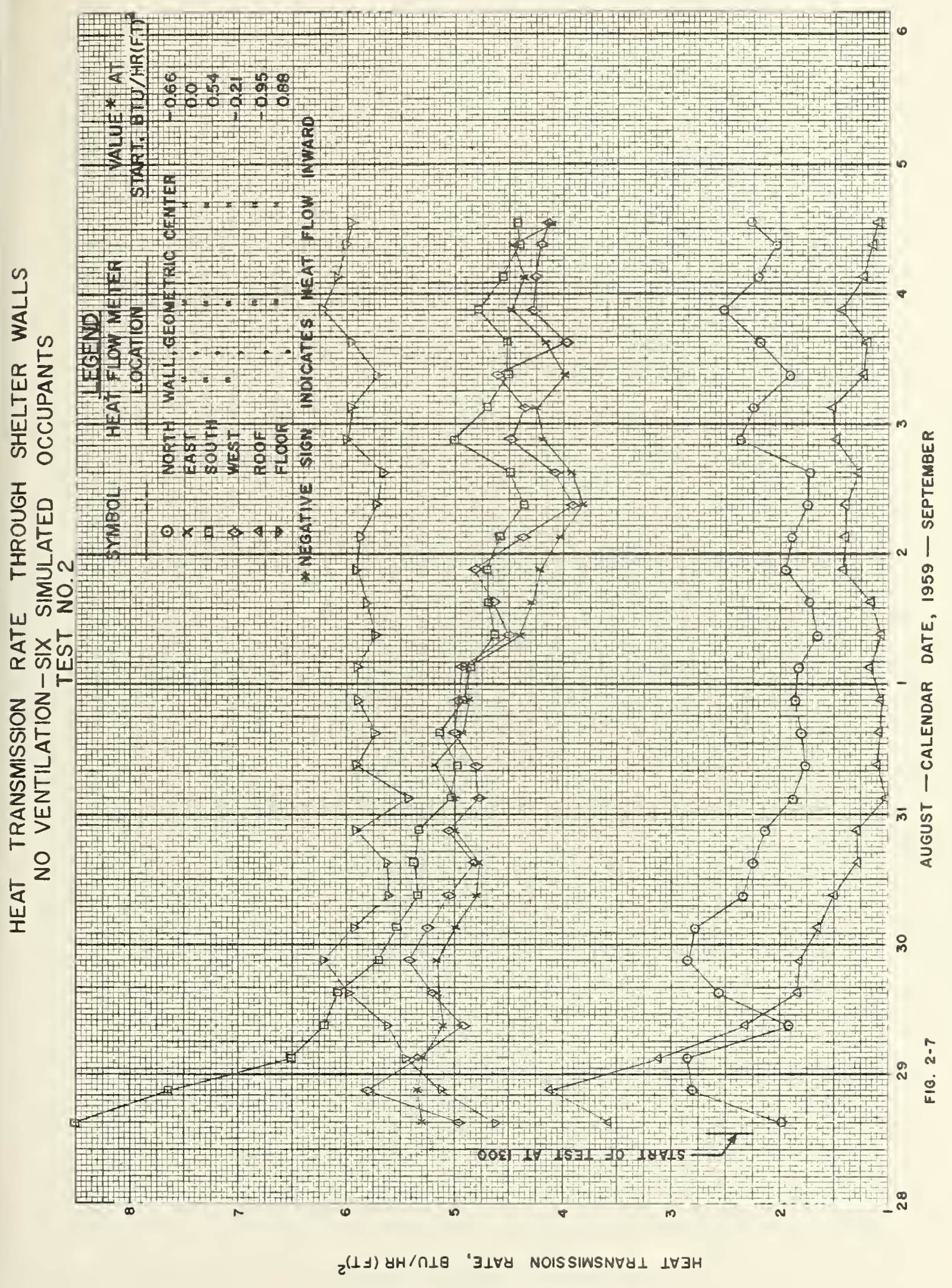



TEMPERATURES IN SHELTER WALLS AND SURROUNDING EARTH AT START OF TEST 2, AUG. 28, 1959-TIME 1300

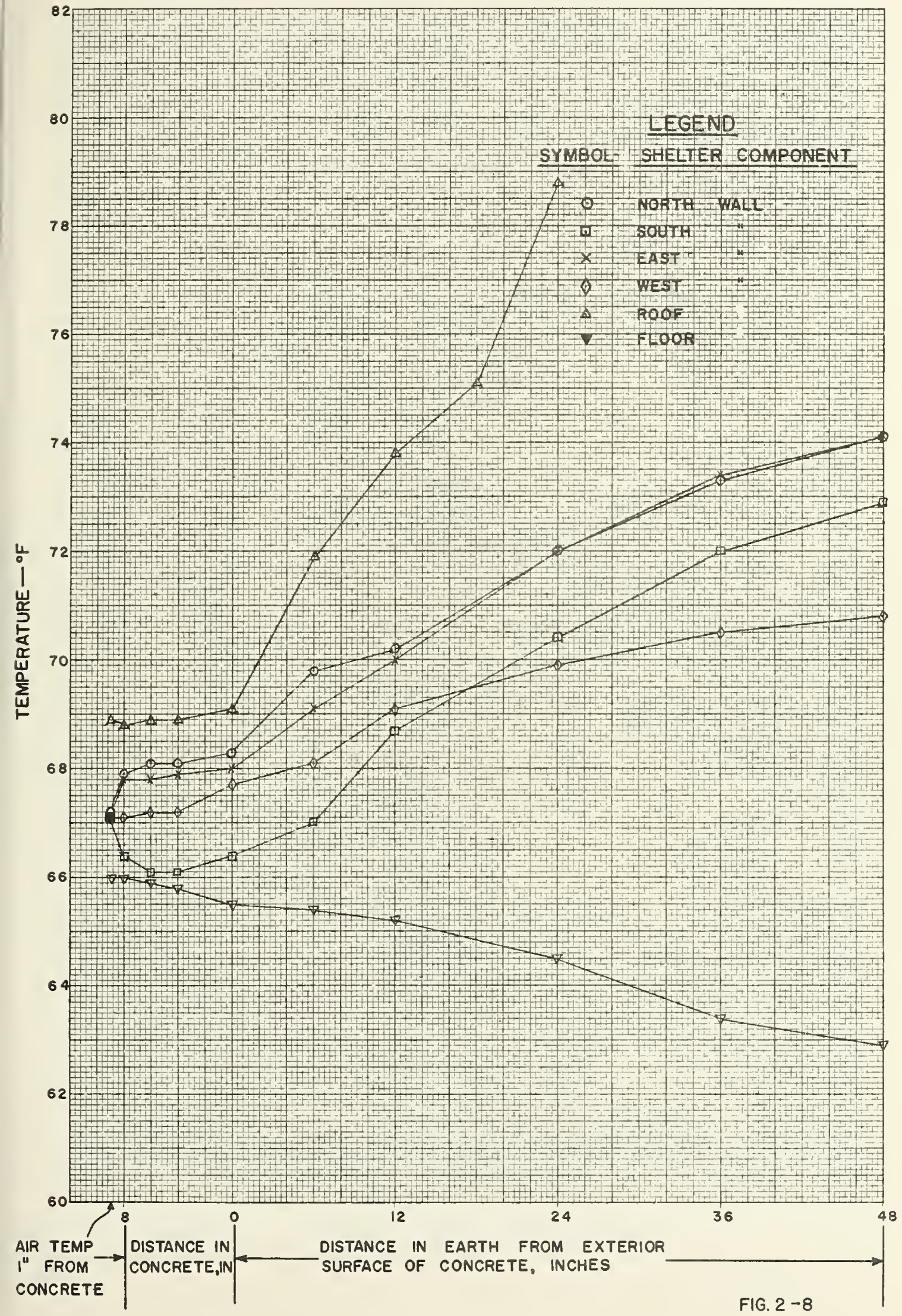



TEMPERATURES IN SHELTER WALLS AND SURROUNDING EARTH

AT END OF TEST 2, SEPT. 4, 1959-TIME 1300

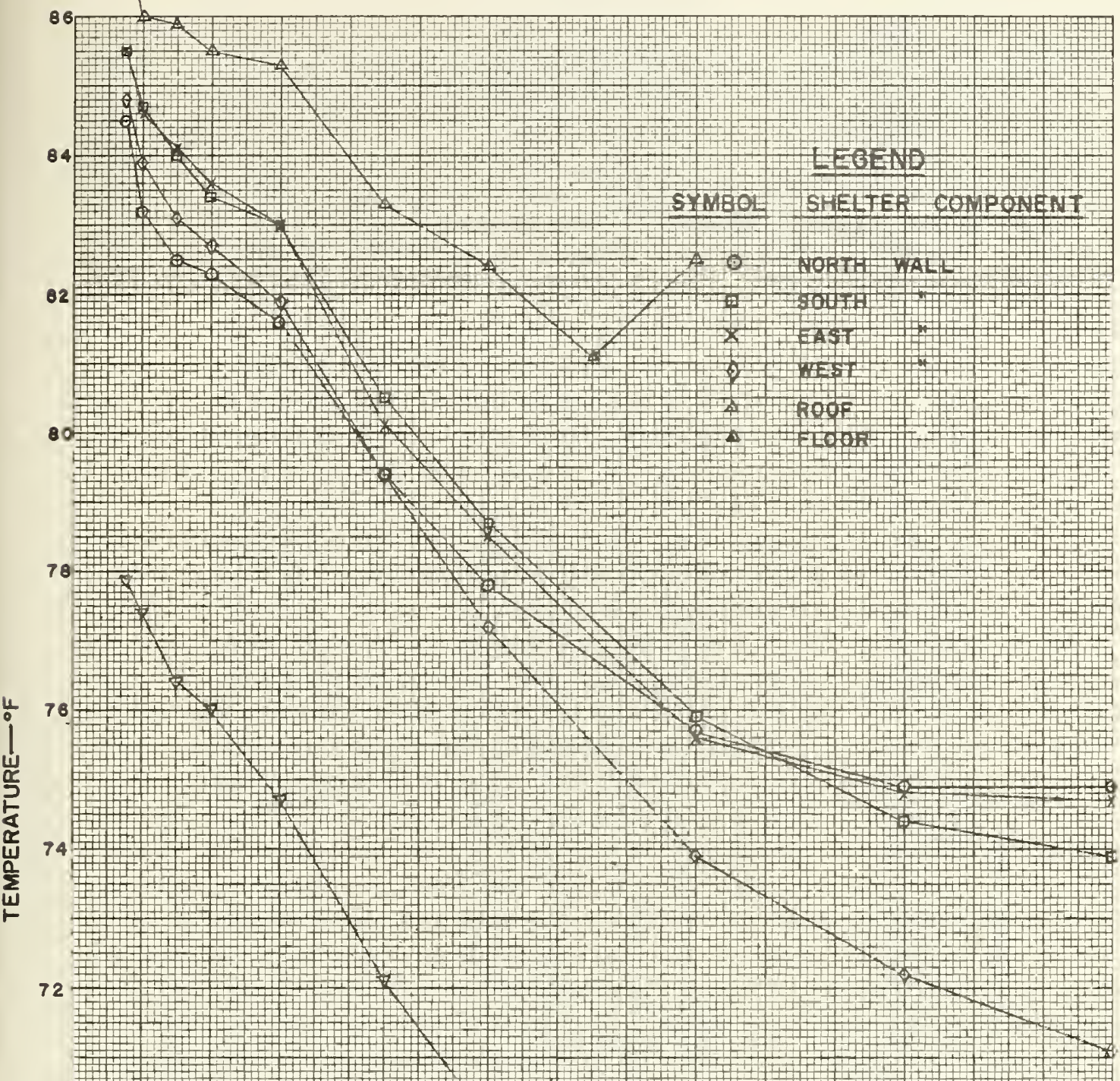

0

\begin{tabular}{|l|l|l|l}
\hline \\
\hline
\end{tabular}

+

8

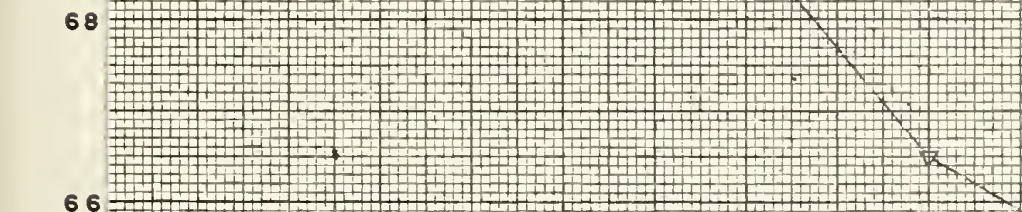

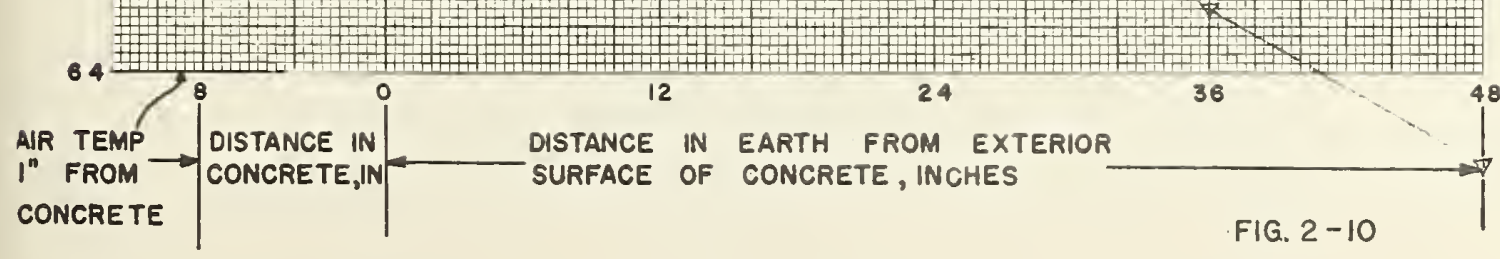





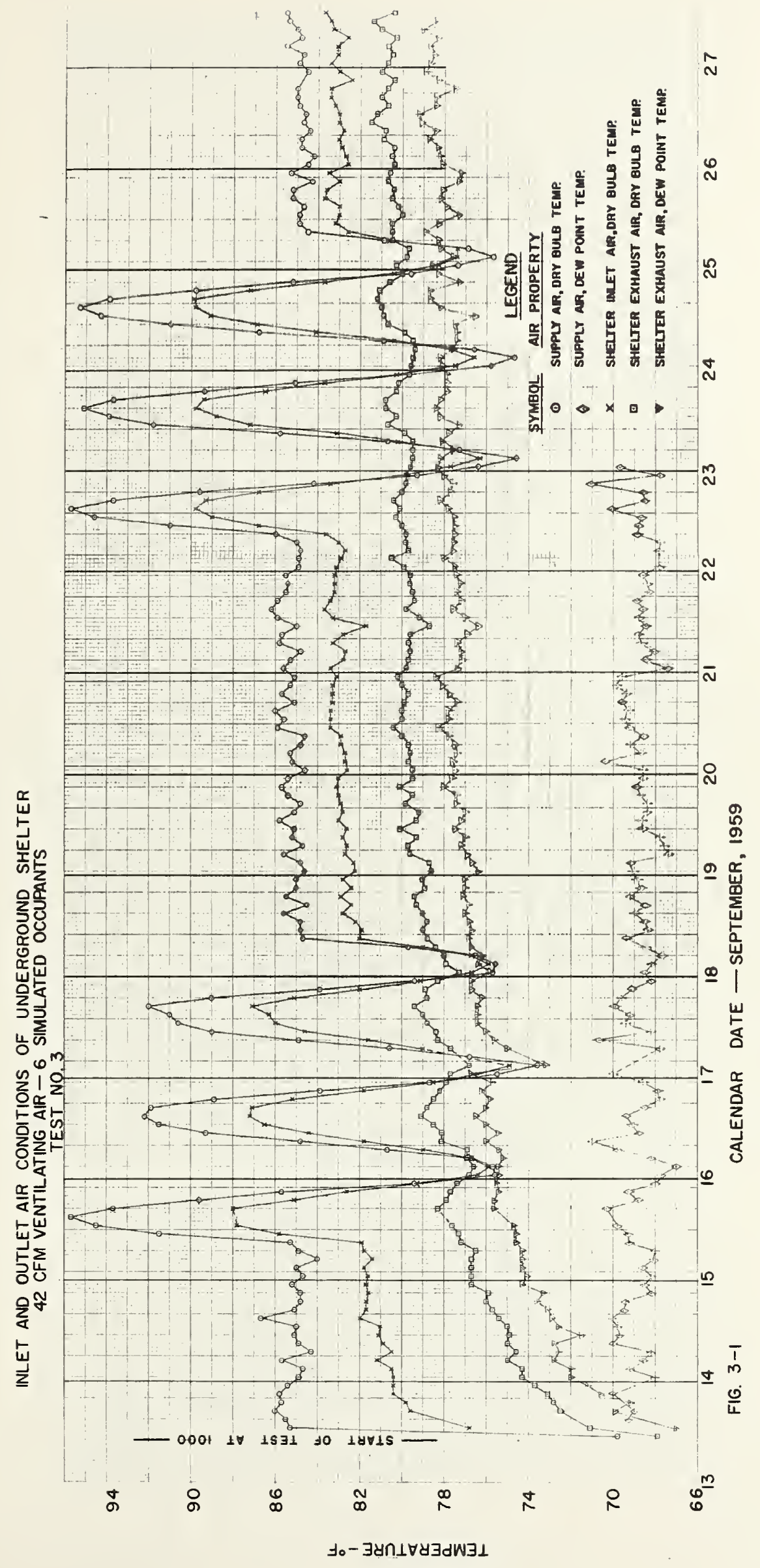





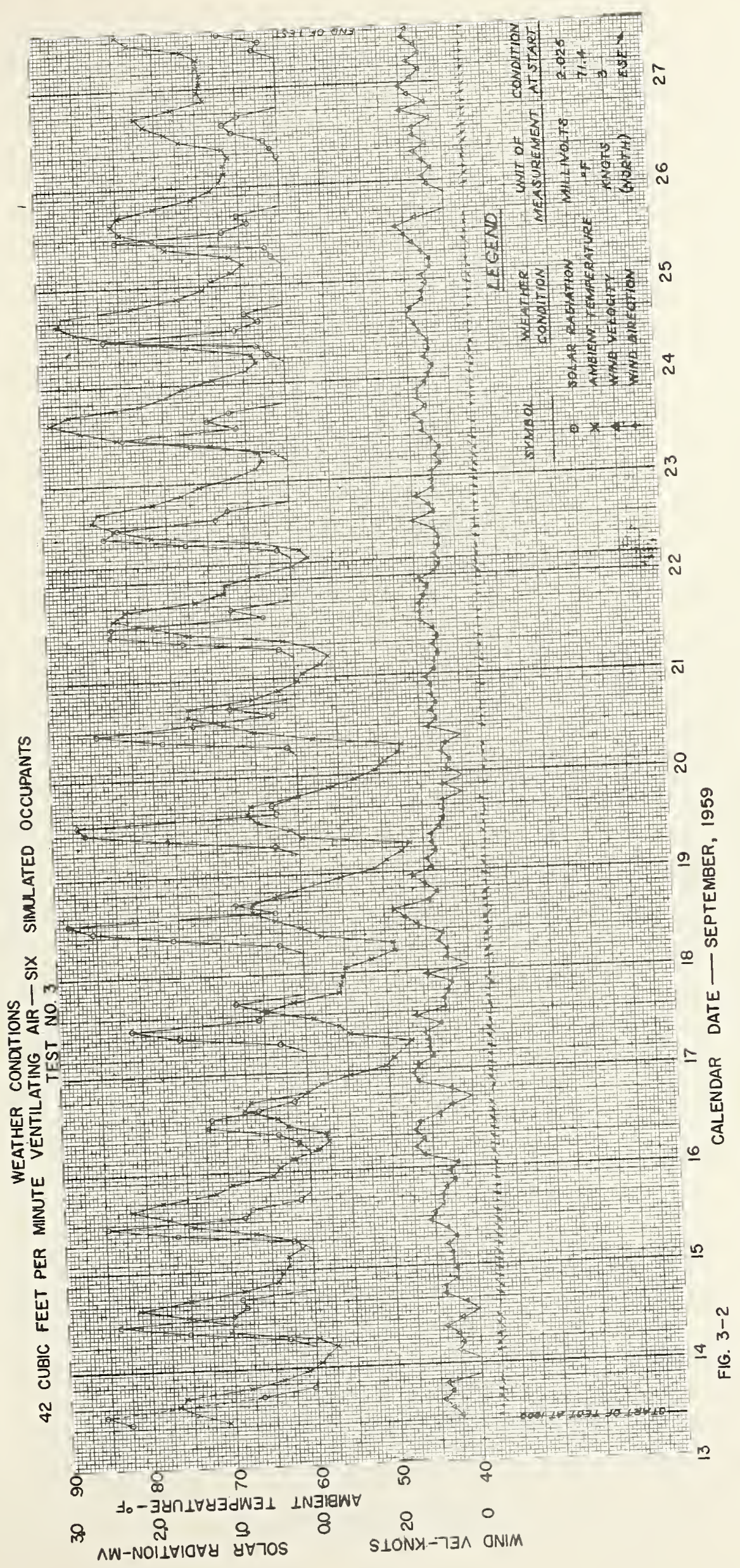





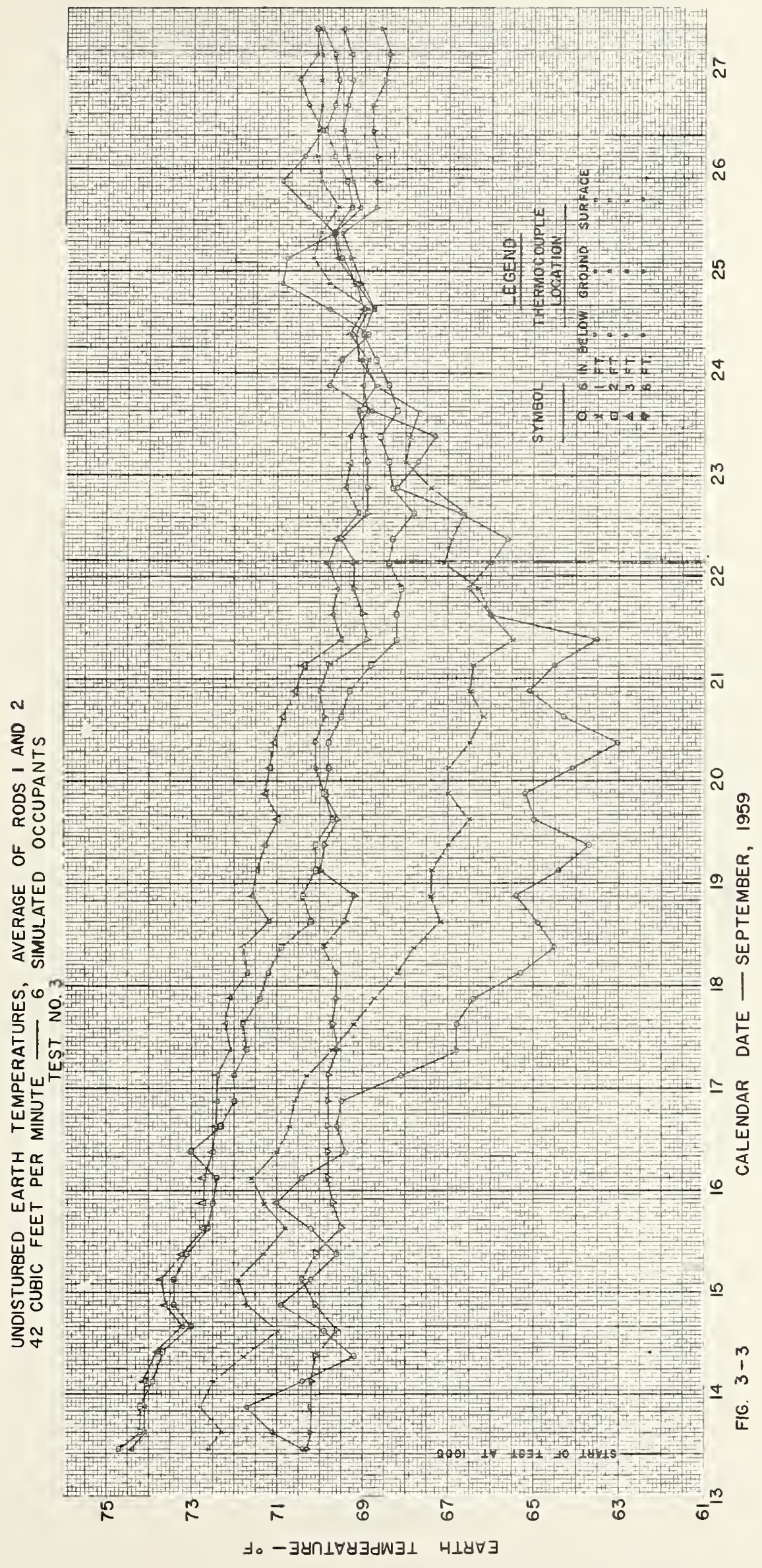





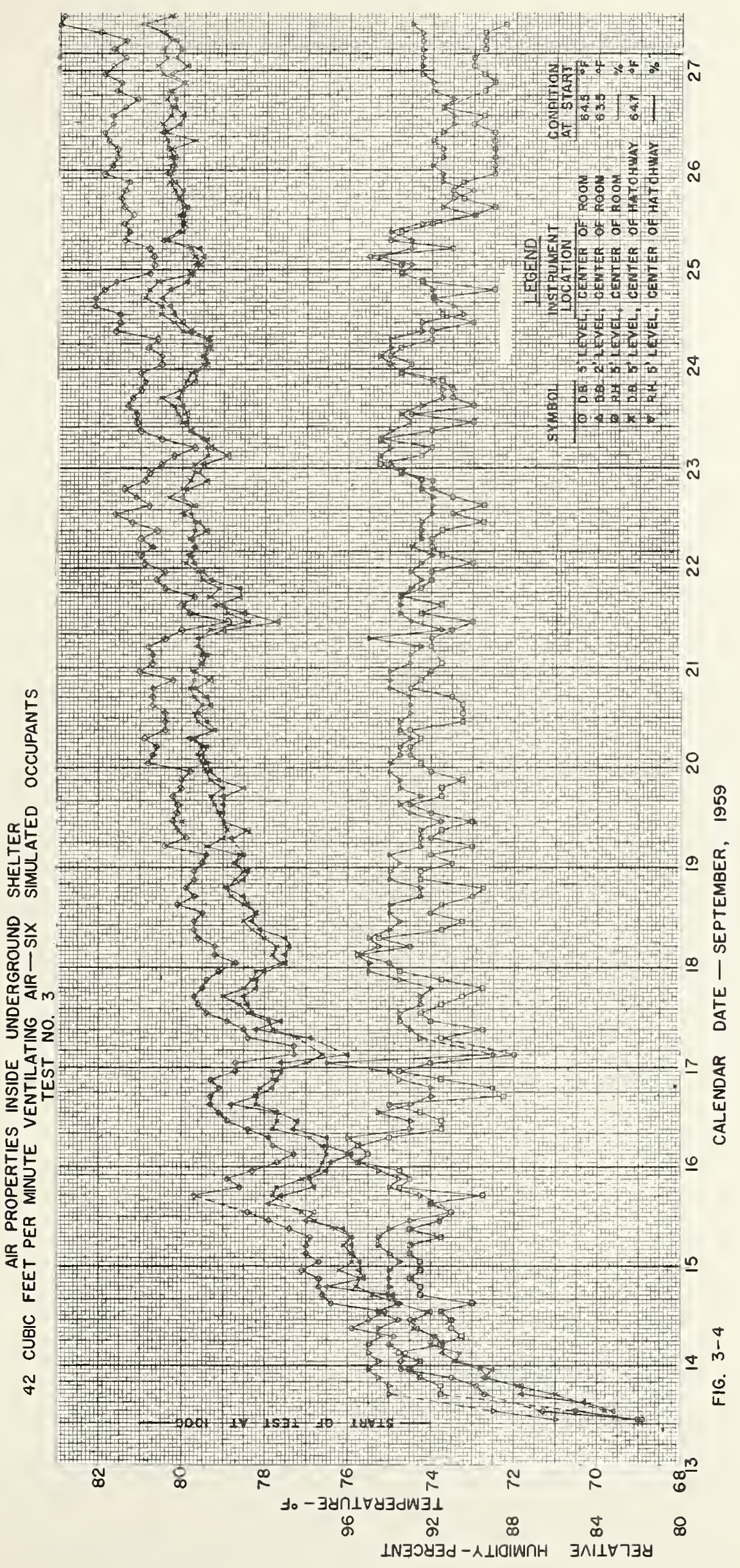





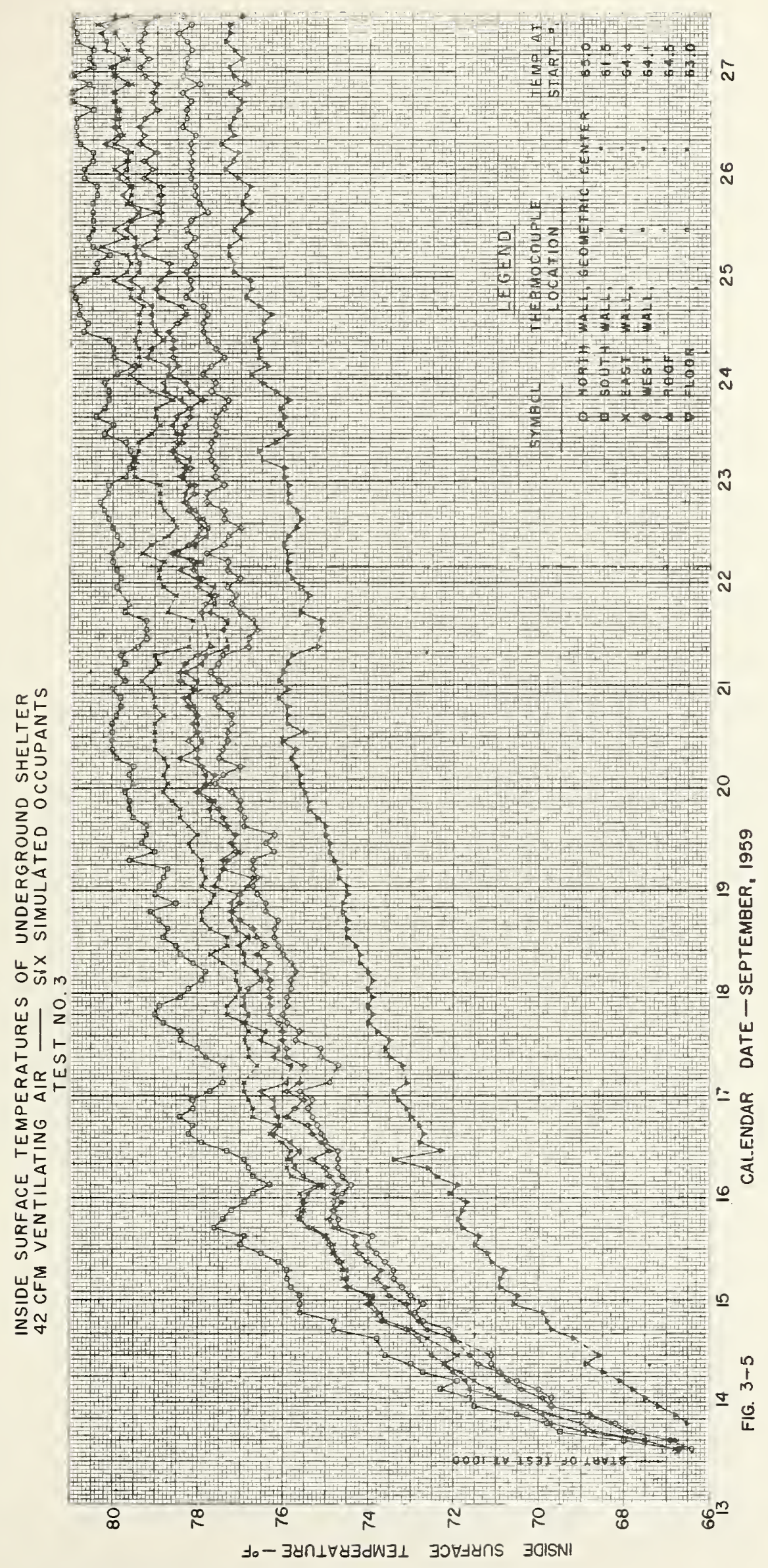





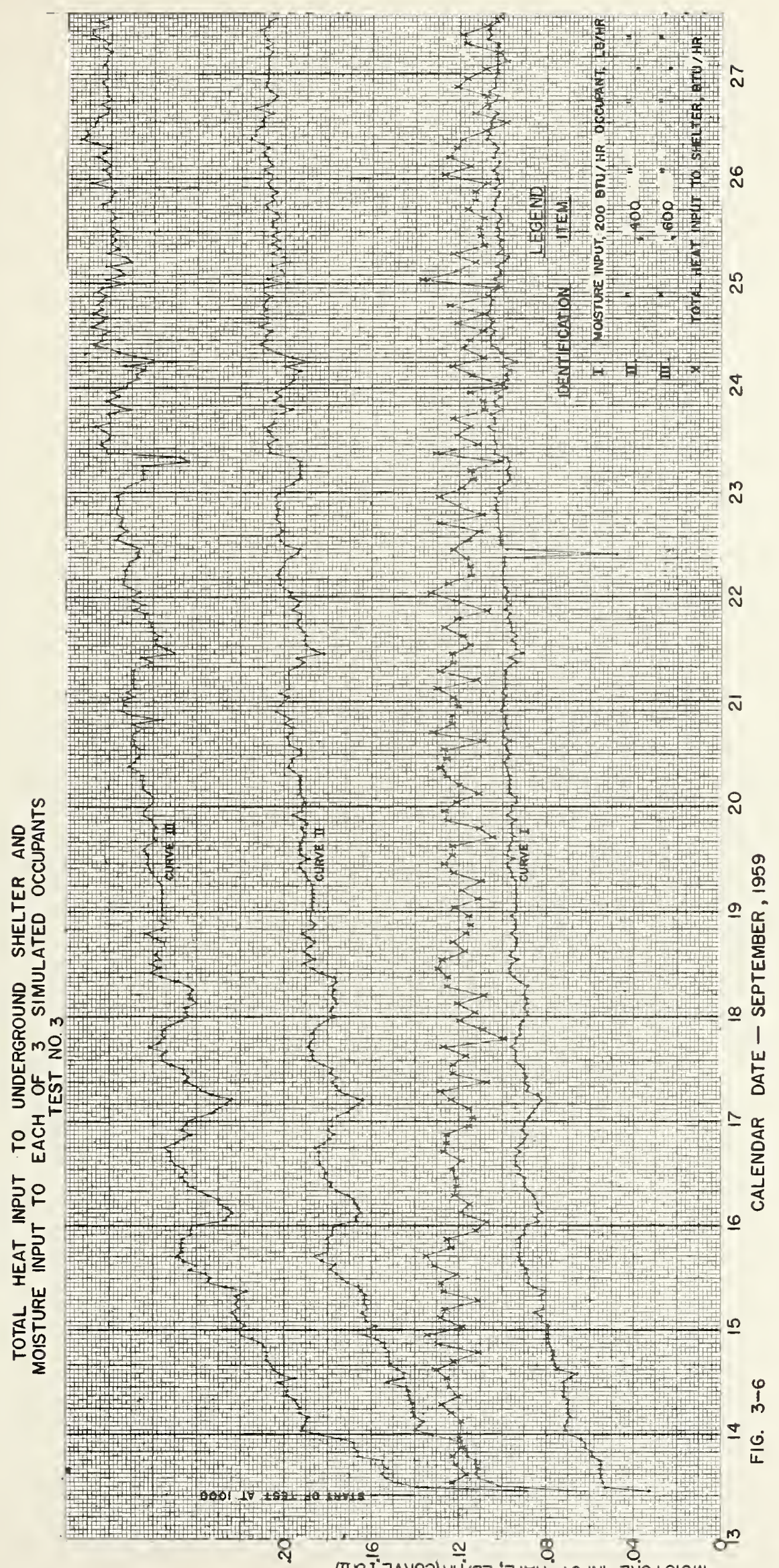

2.

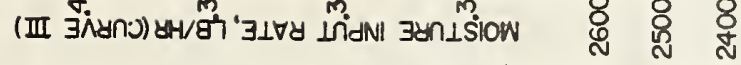

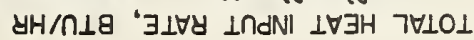





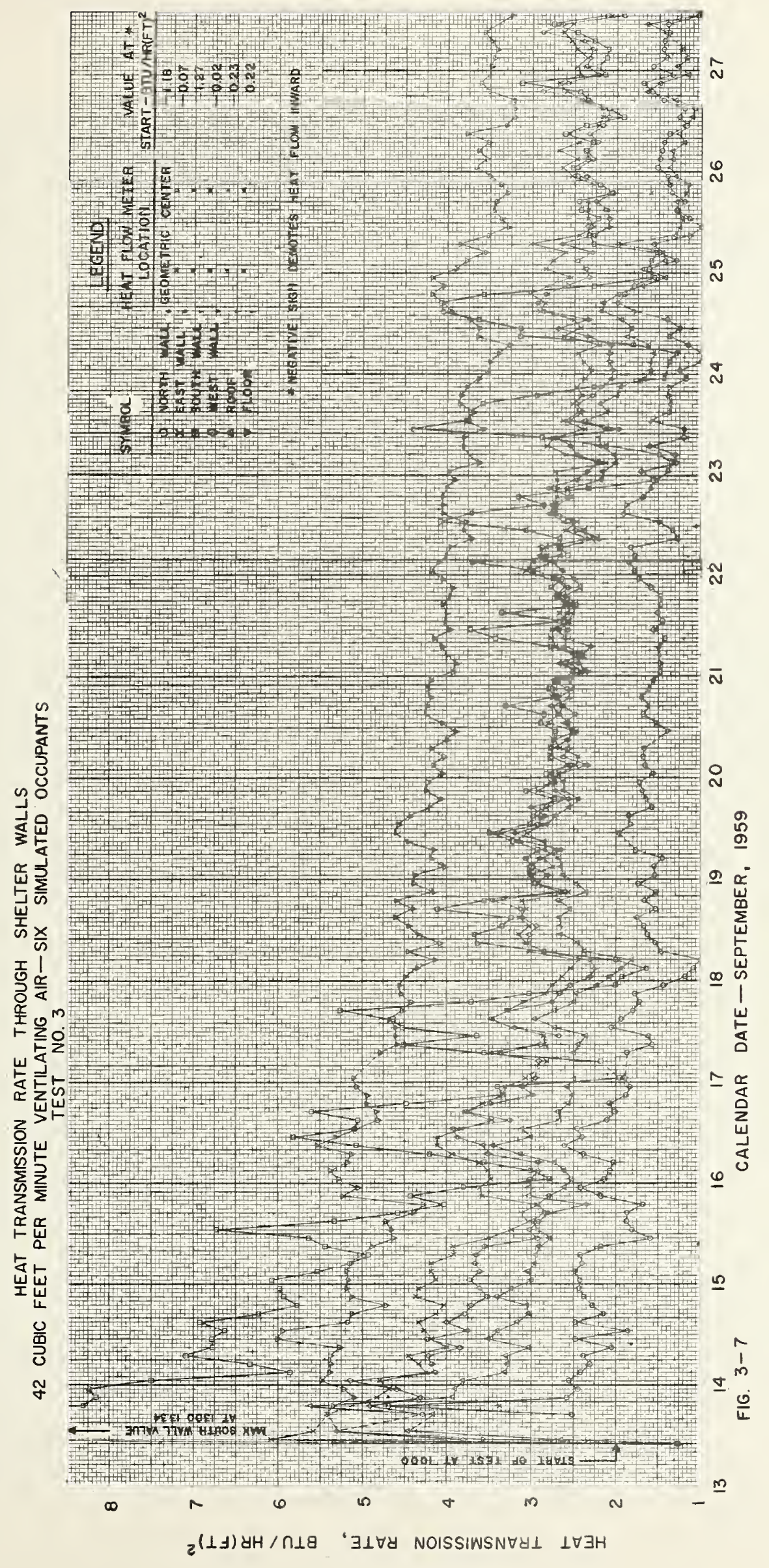



TEMPERATURES IN SHELTER WALLS AND SURROUNDING EARTH AT START OF TEST 3, SEPT. 13, 1959-TIME 1000

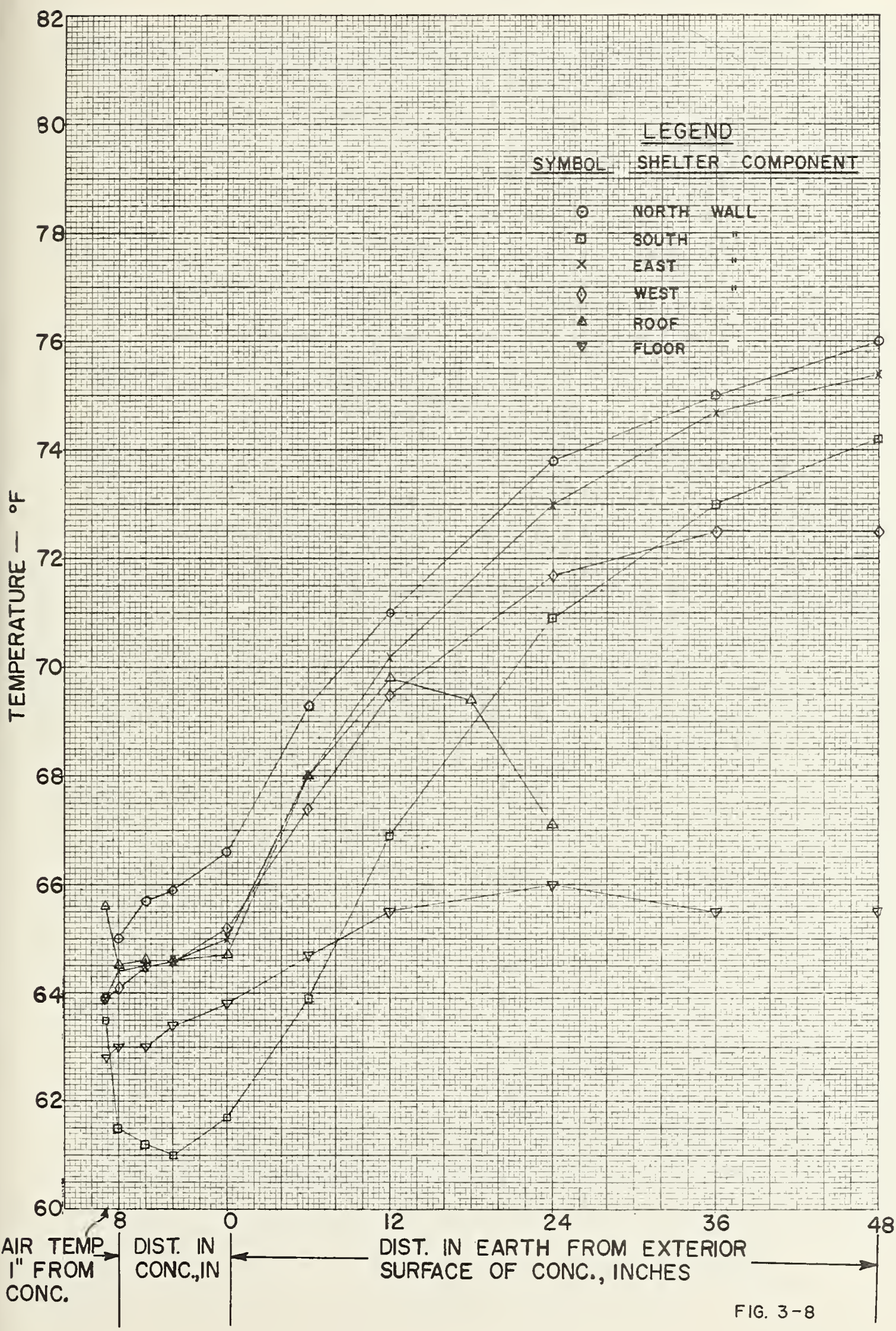



TEMPERATURES IN SHELTER WALLS AND SURROUNDING EARTH AFTER 7 DAYS OF TEST 3, SEPT. 27, 1959-TIME 1100

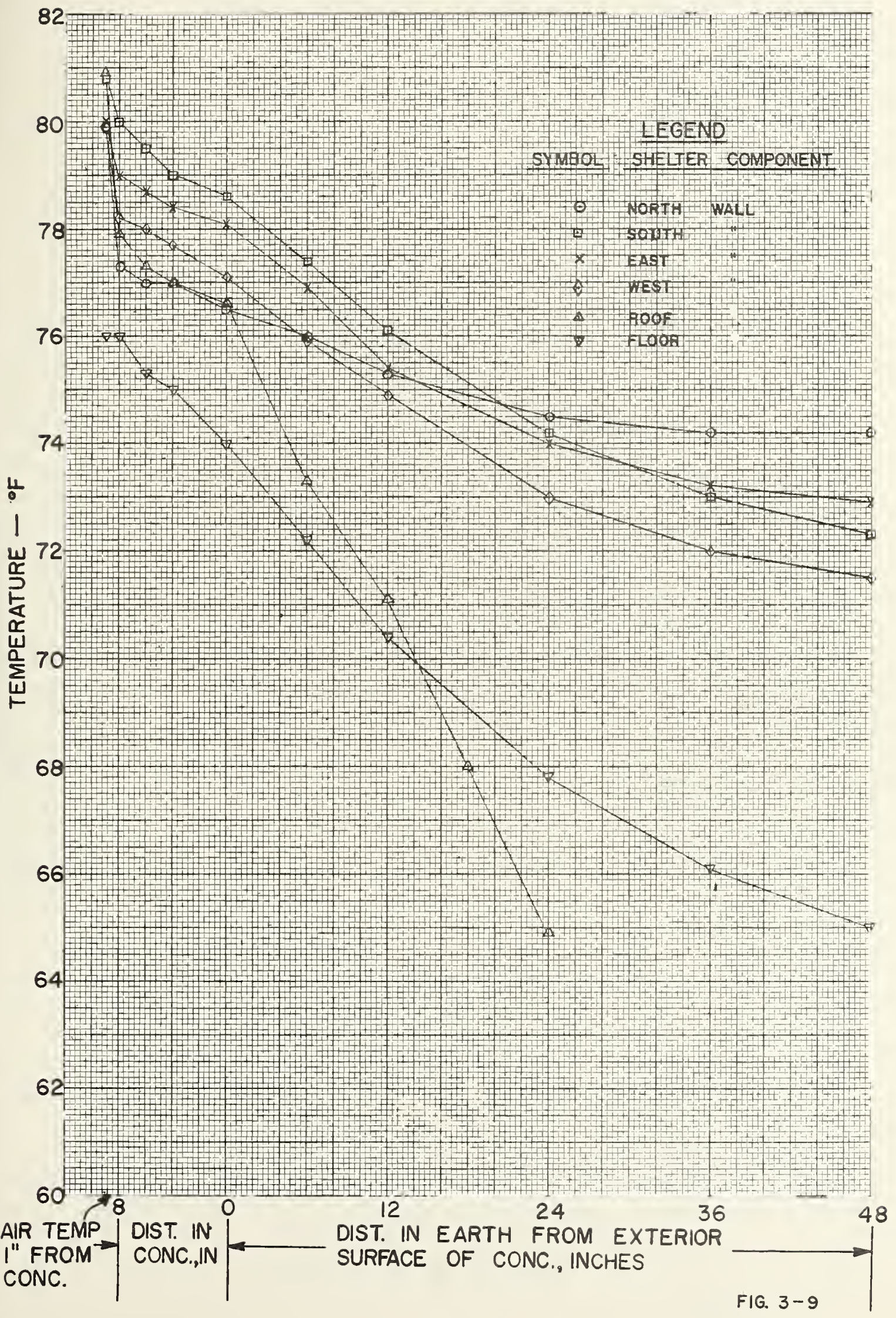



TEMPERATURES IN SHELTER WALLS AND SURROUNDING EARTH AT END OF TEST 3, SEPT. 27, 1959-TIME 1100

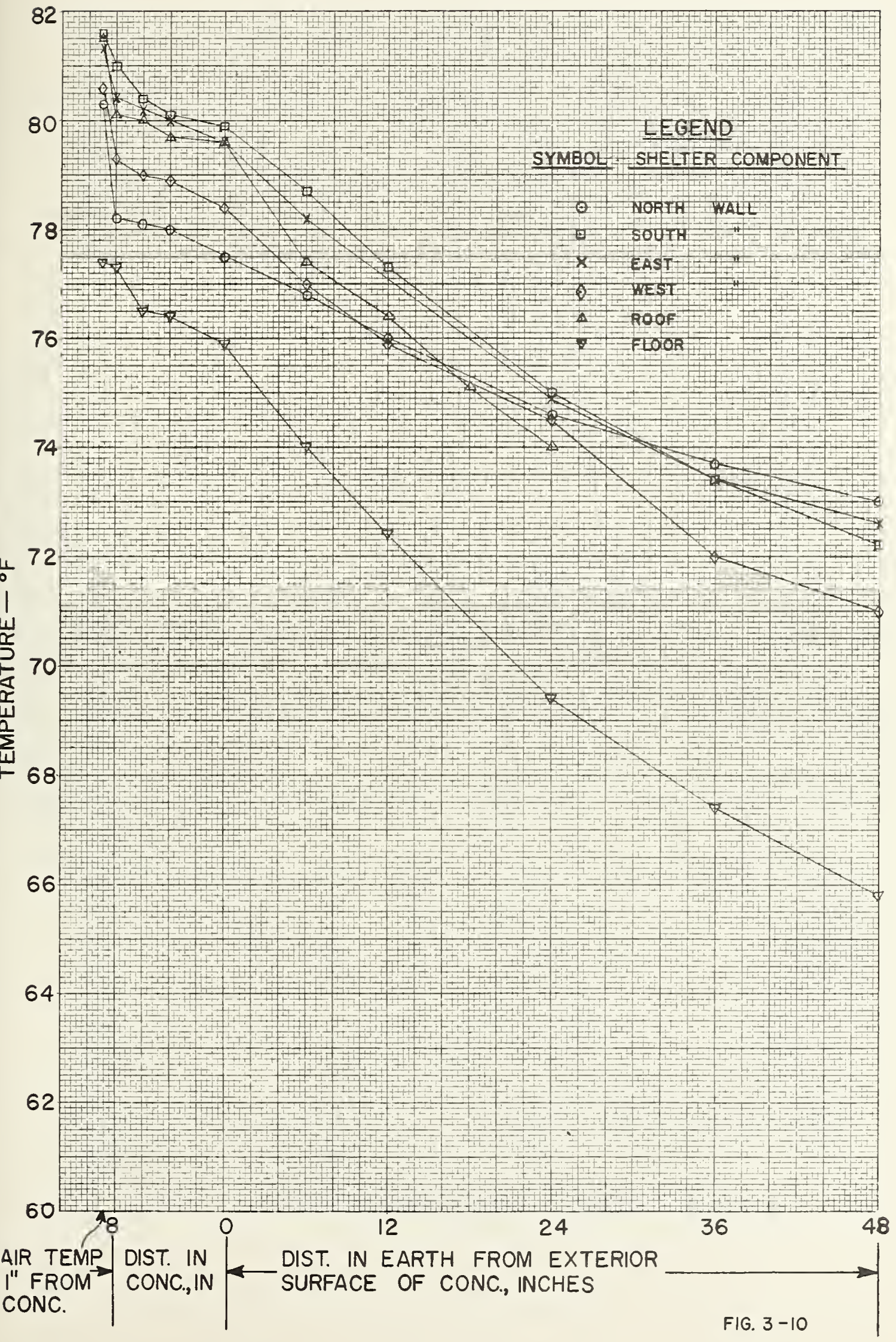





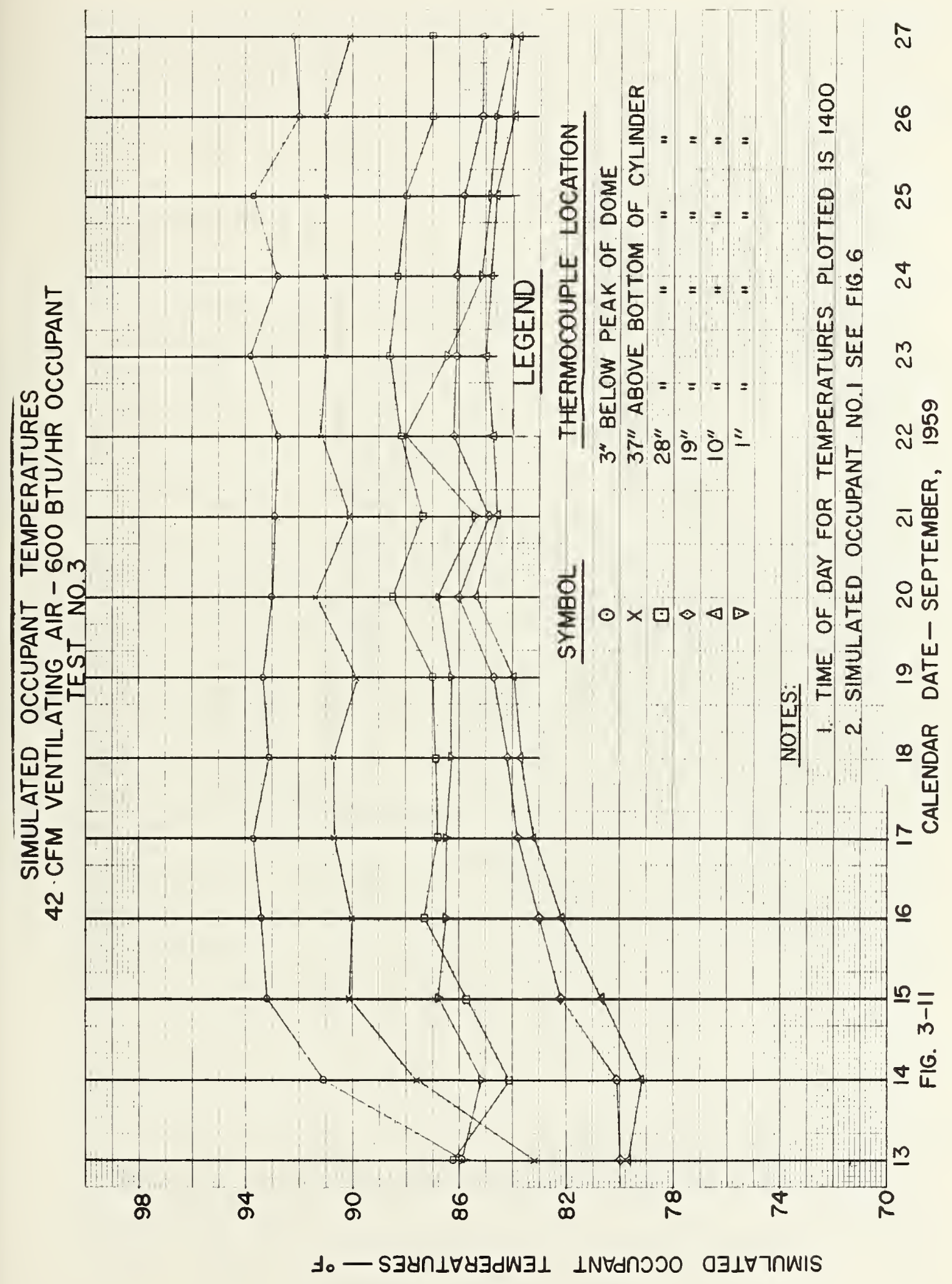





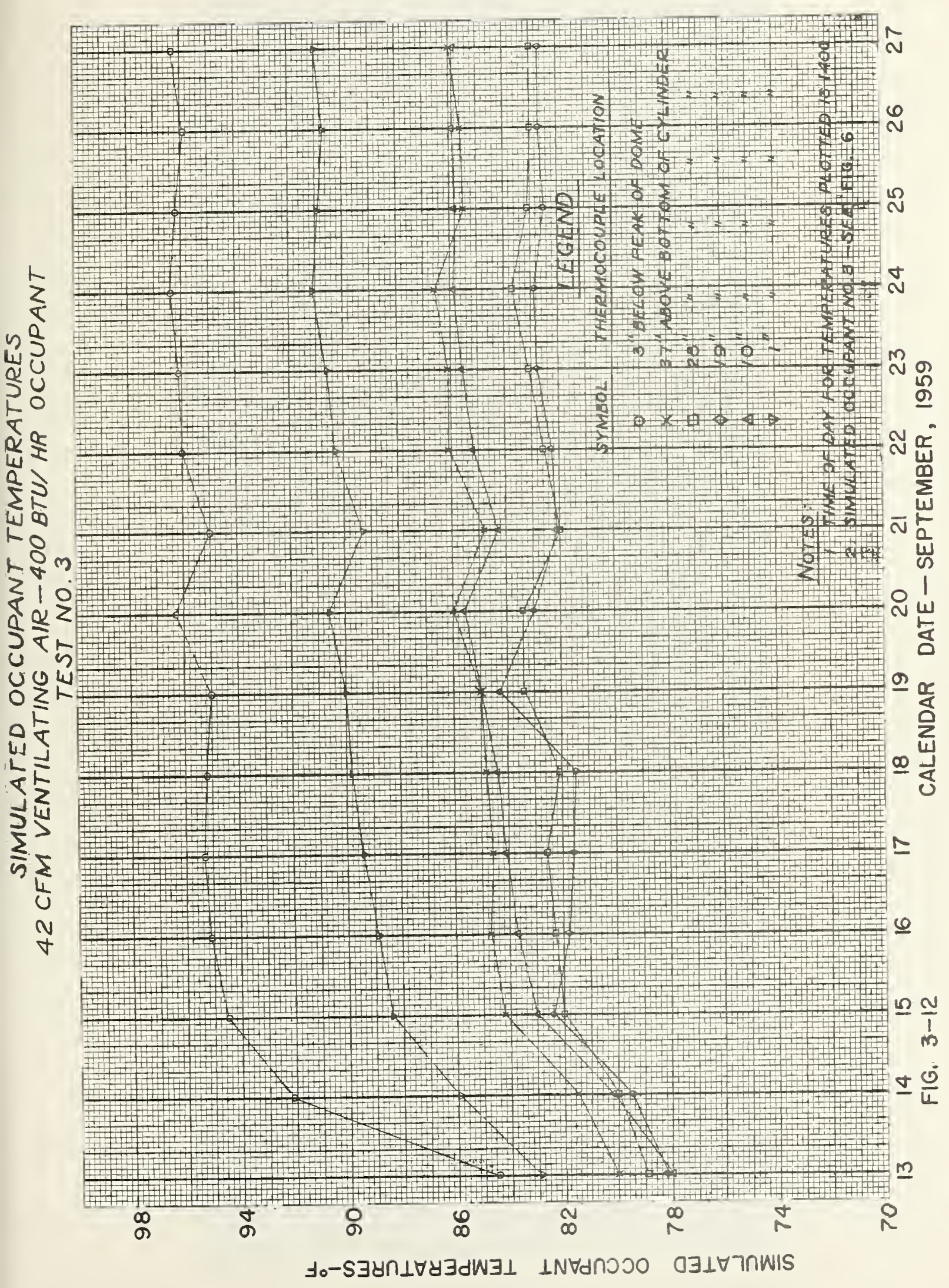





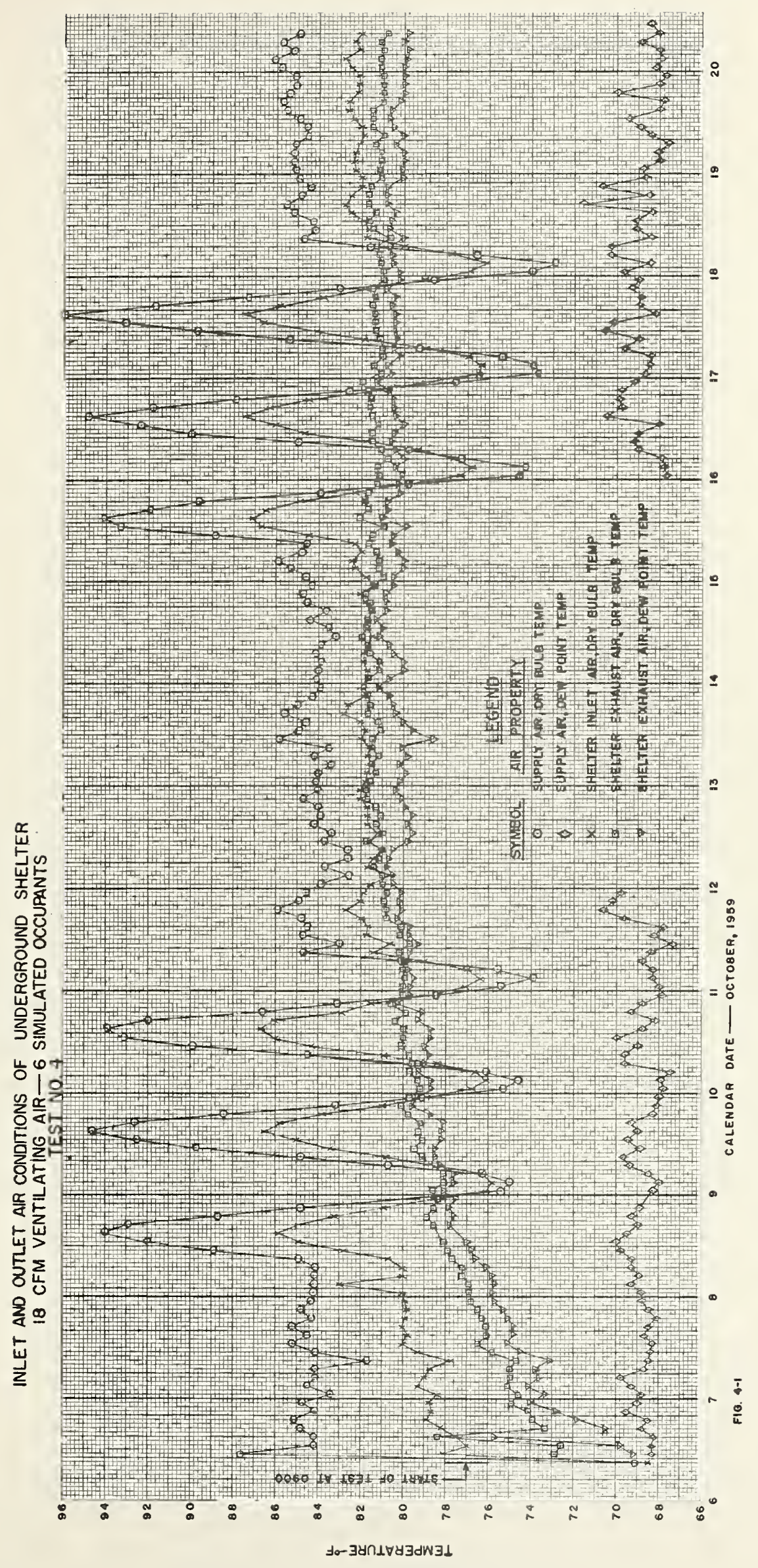





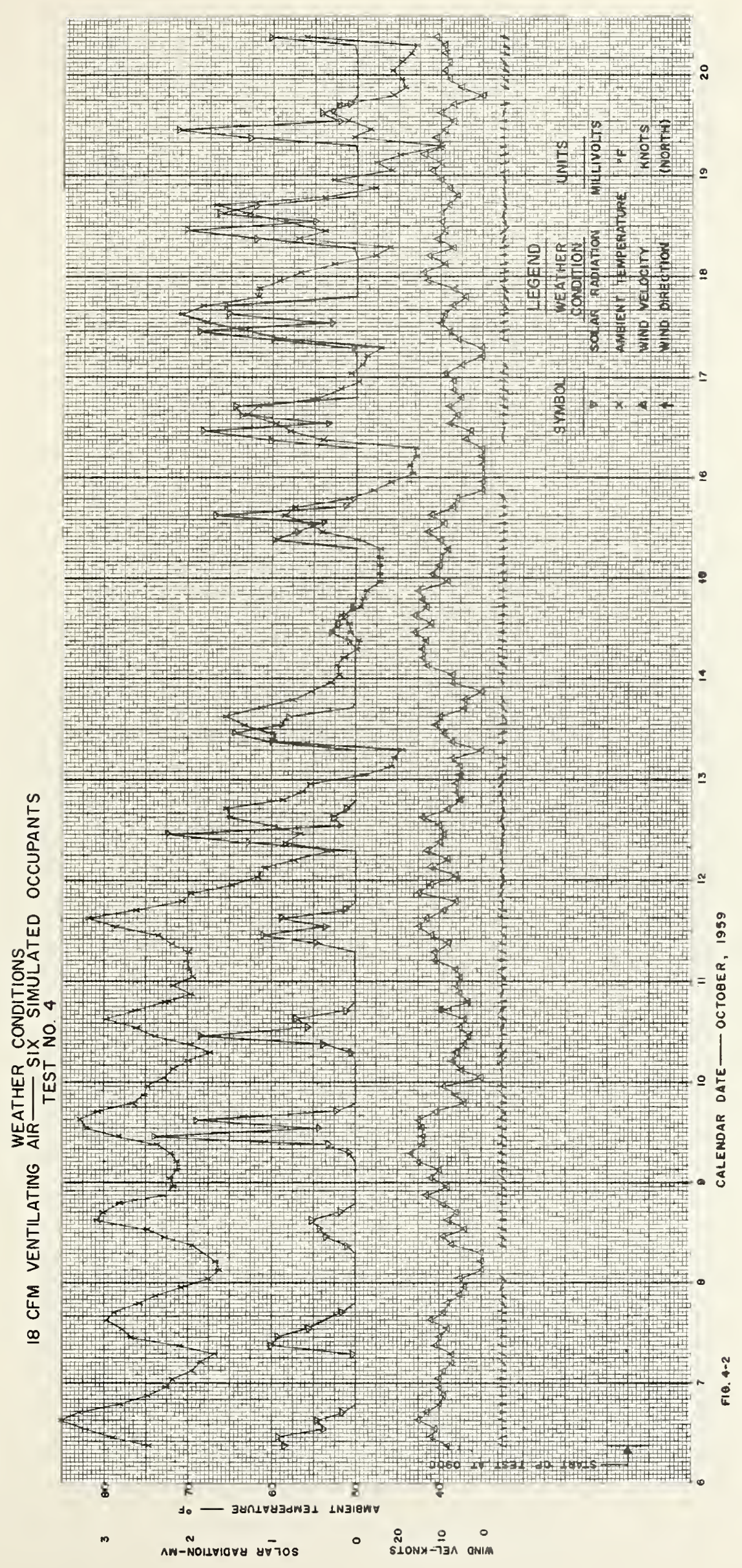





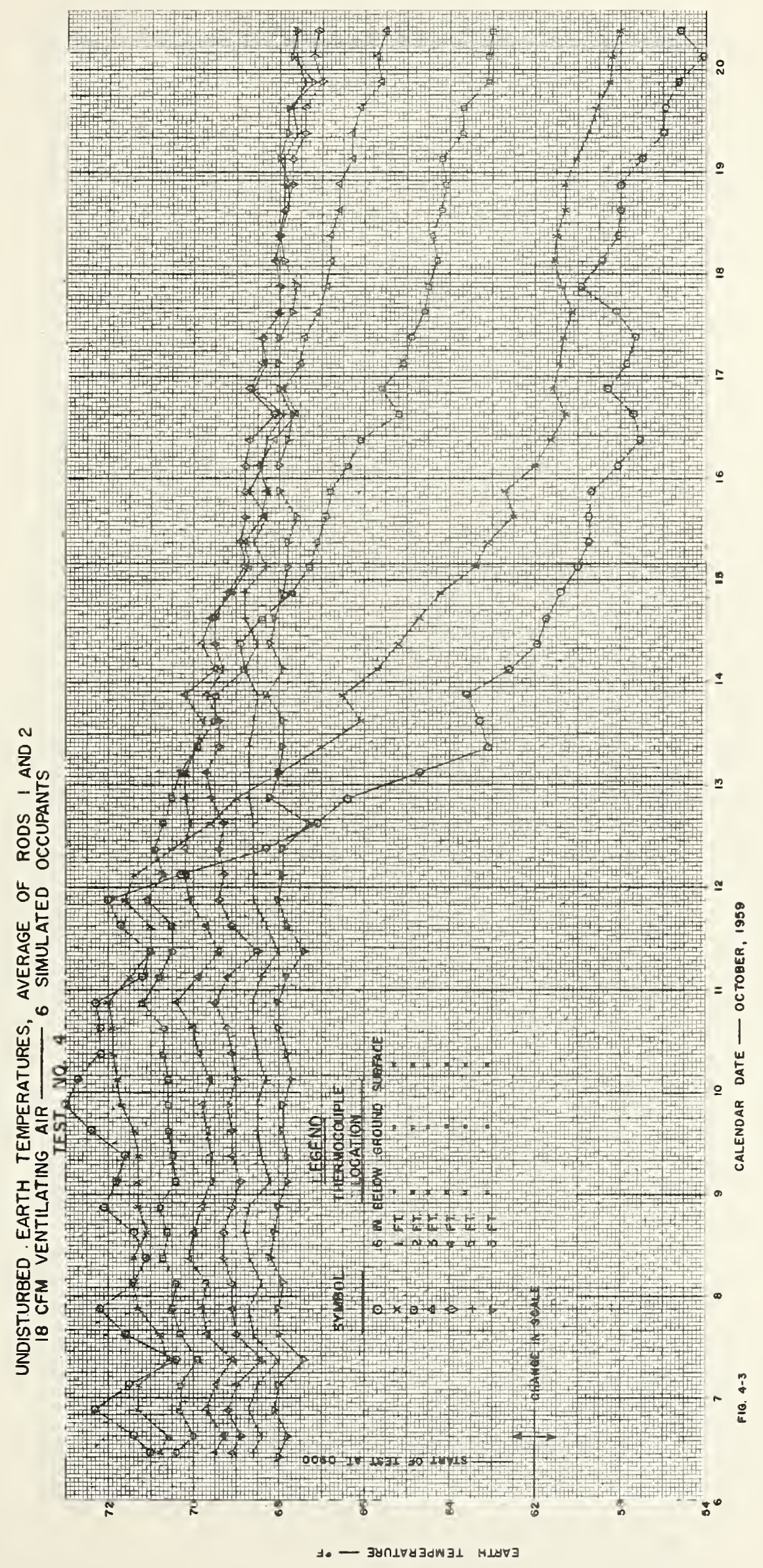





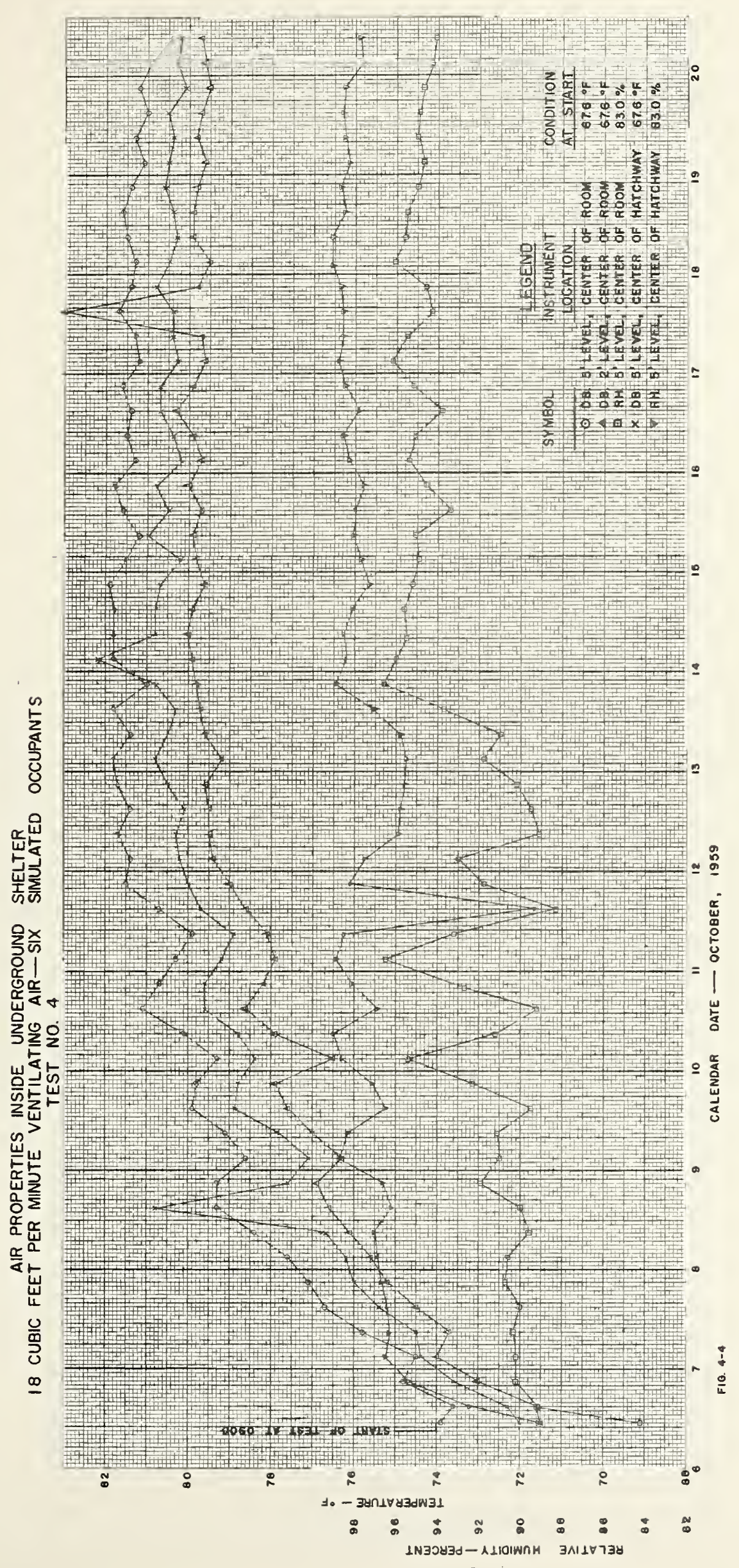





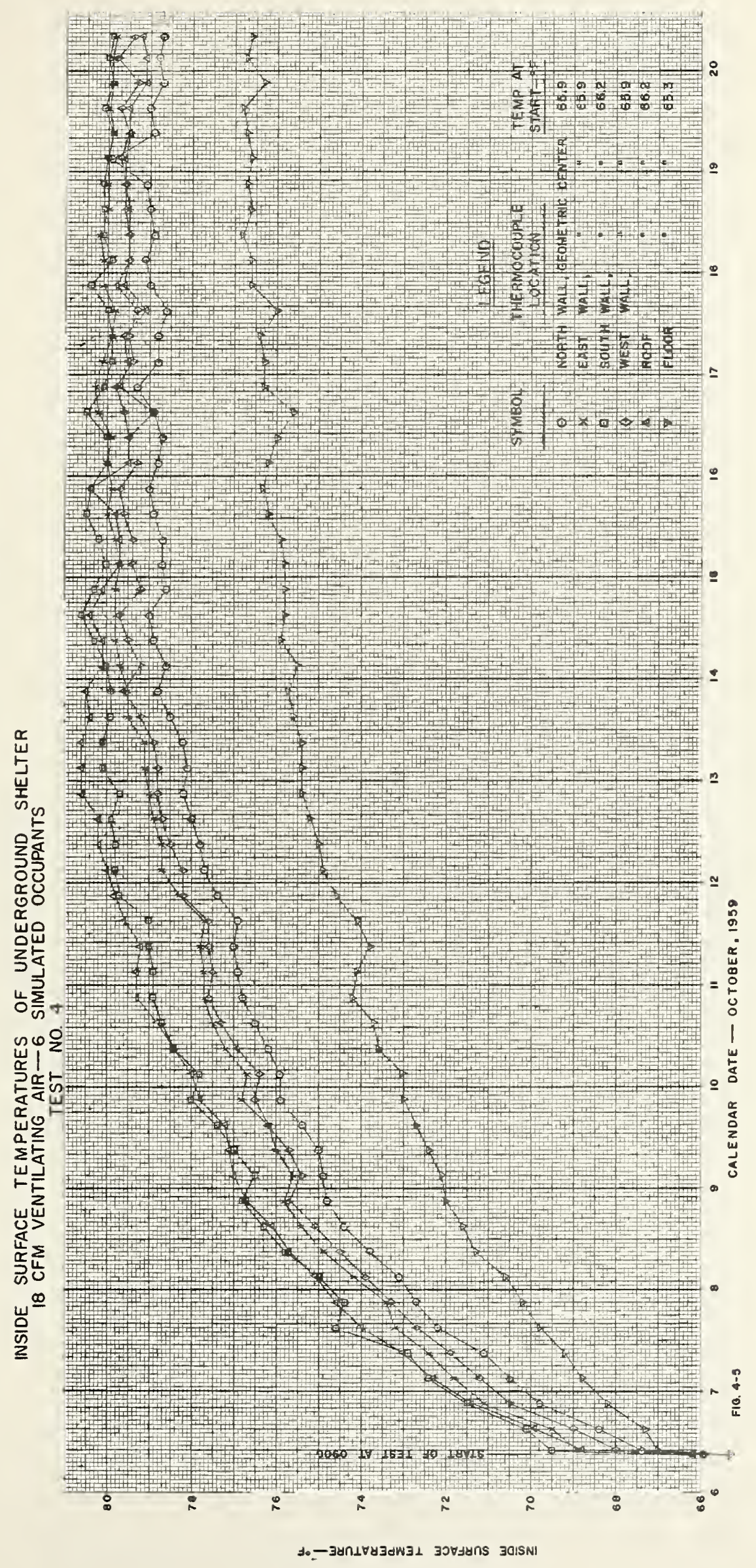





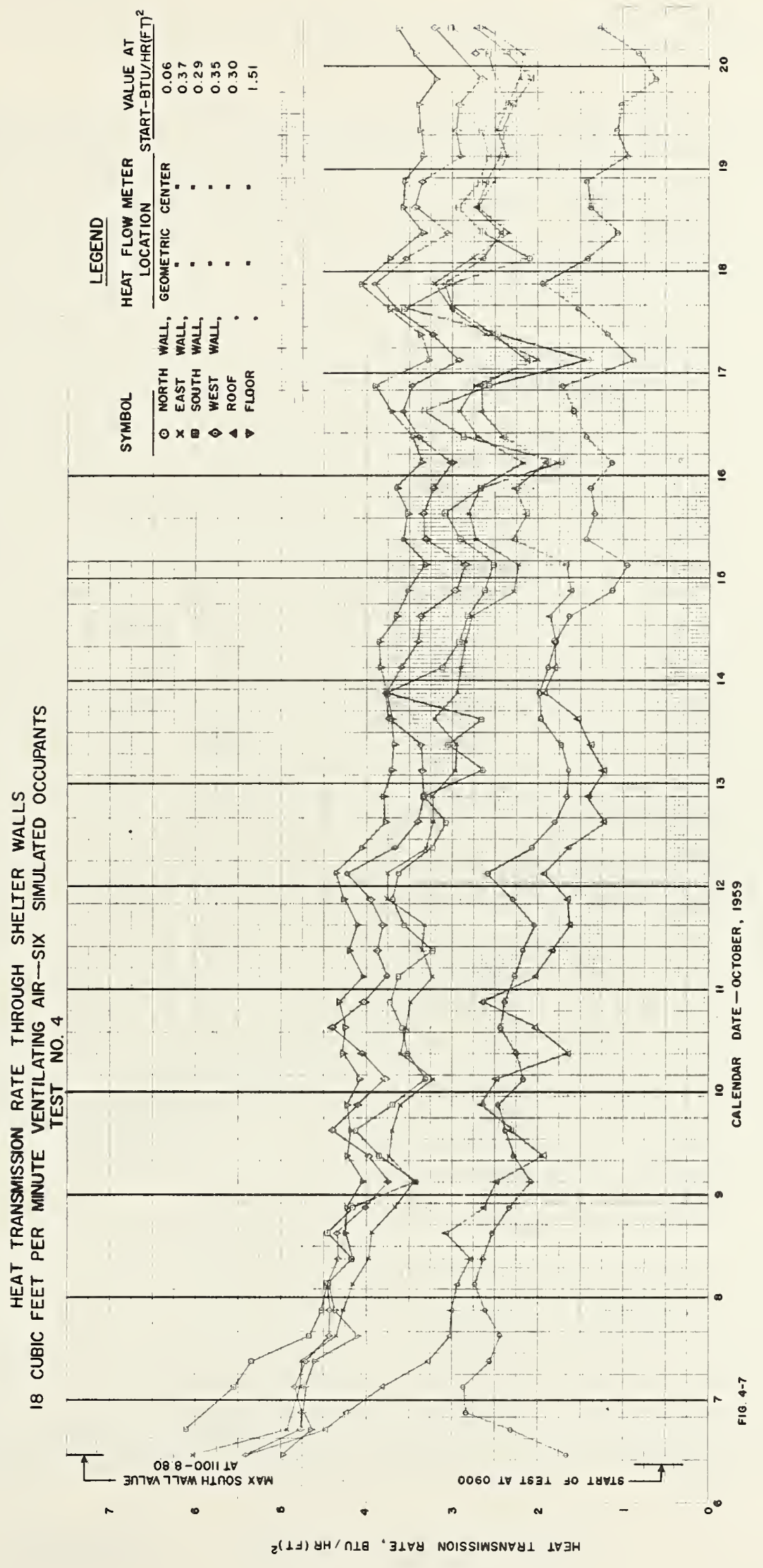



TEMPERATURES IN SHELTER WALLS AND SURROUNDING EARTH

AT START OF TEST 4, OCT. 6, 1959-TIME 0900

82

80

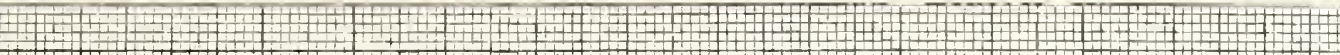

年-

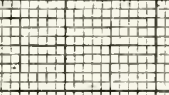

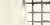

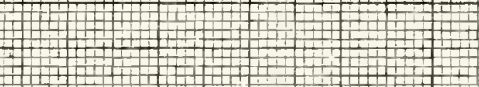

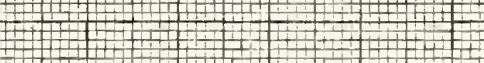

SYMBOH SHELTER COMPONENT

18

2 1.

S
SOUTH

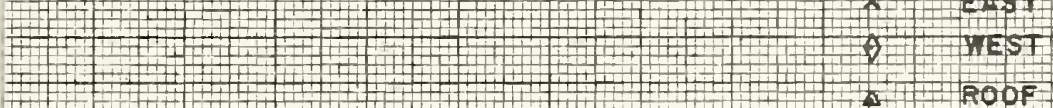

76

\begin{tabular}{l}
$2+$ ROOF \\
\hline+ FLOOF
\end{tabular}

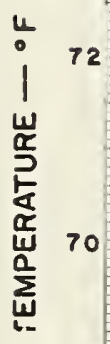

74

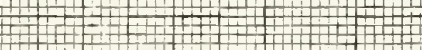

$+1+$

$+4$

72

1 2 +

$+\frac{1+4}{1+4}$

章

707

$+1+$

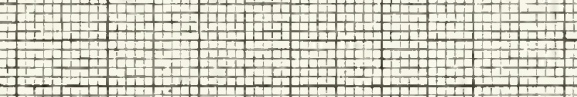

68

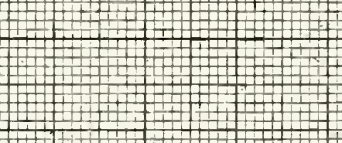

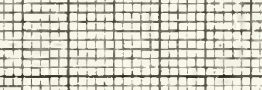



TEMPERATURES IN SHELTER WALLS AND SURROUNDING EARTH AFTER 7 DAYS OF TEST 4, OCT. 13, 1959-TIME 0900

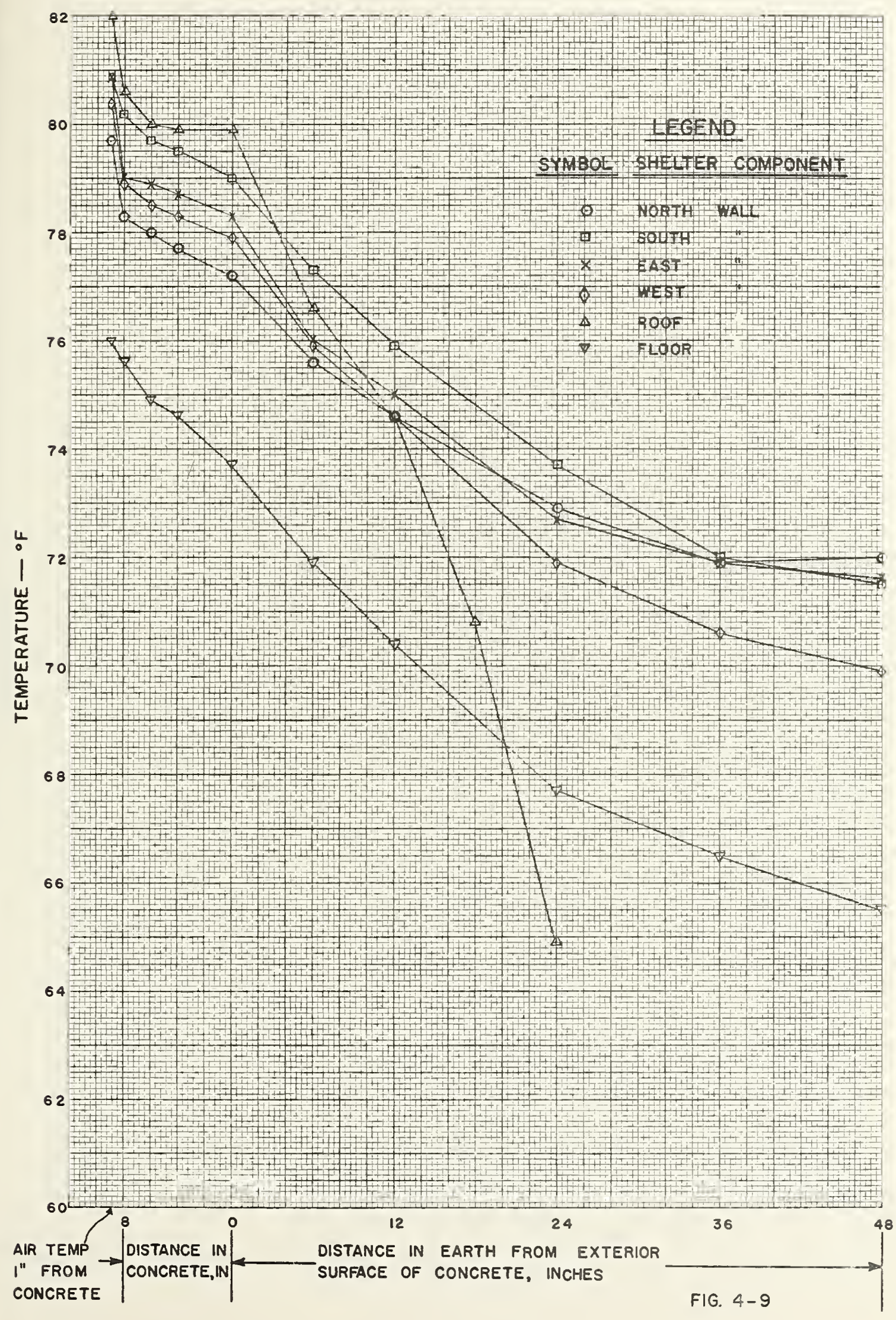



TEMPERATURES IN SHELTER WALLS AND SURROUNDING EARTH AT END OF TEST 4, OCT. 20, 1959-TIME 0900

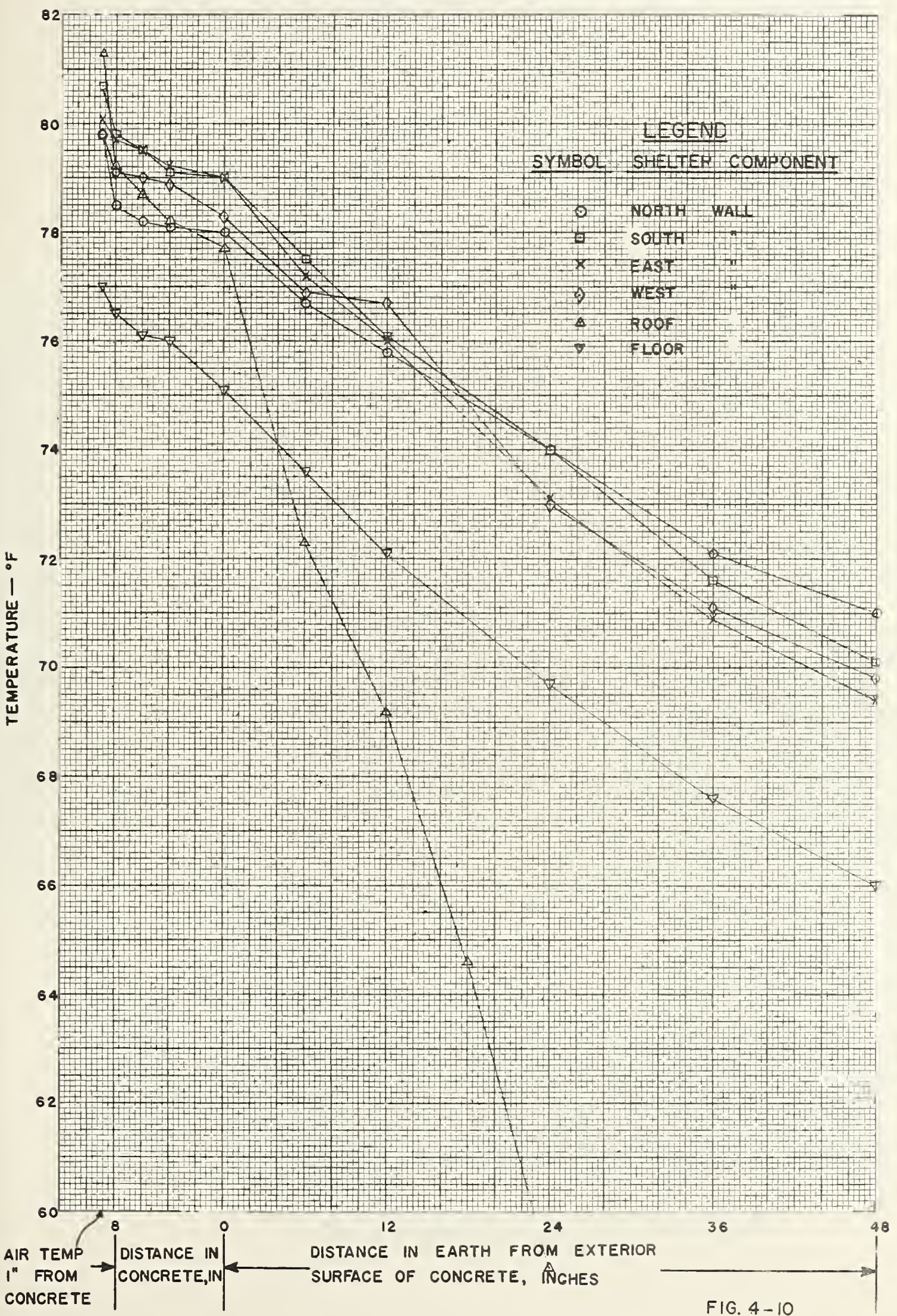





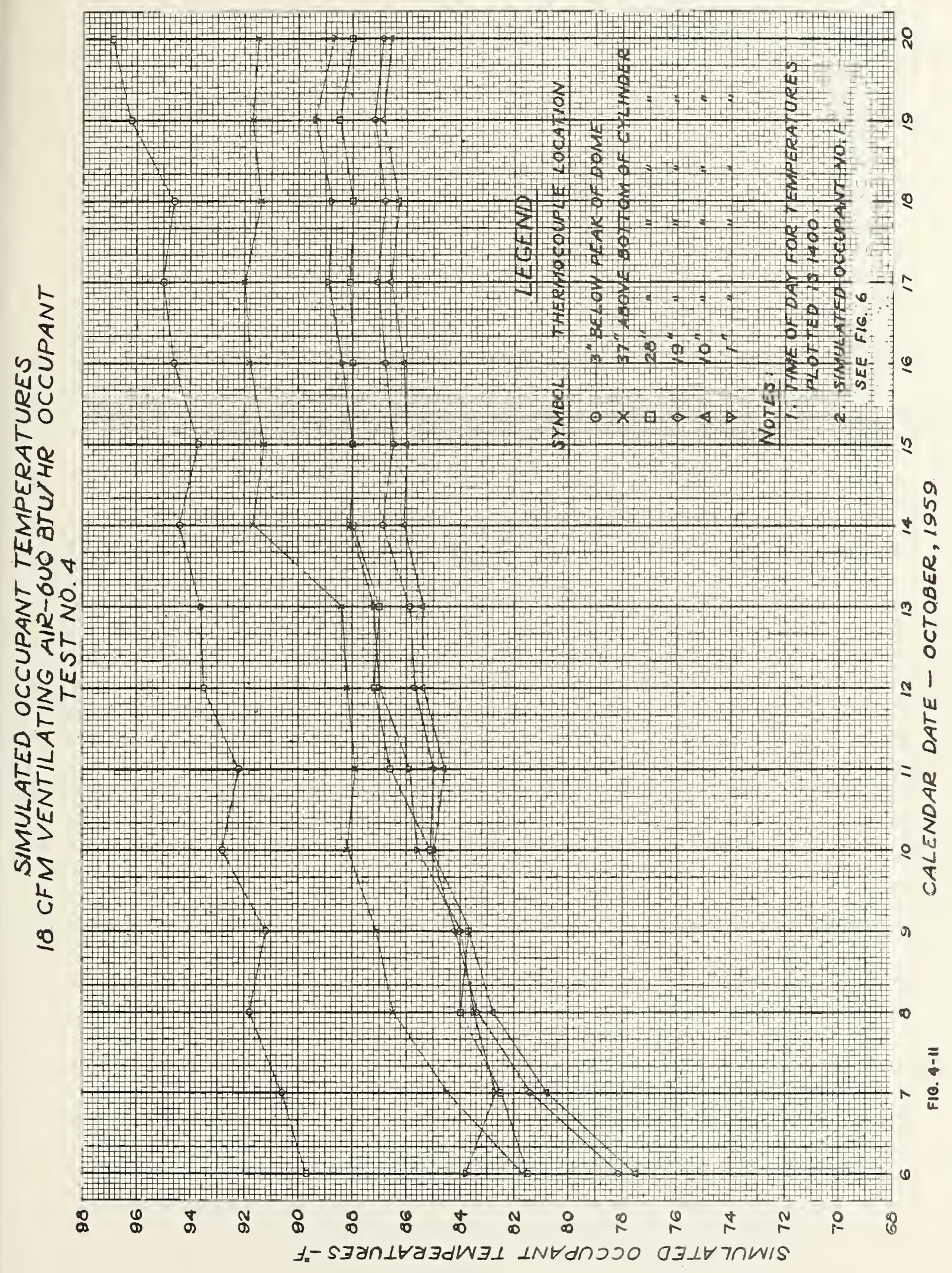





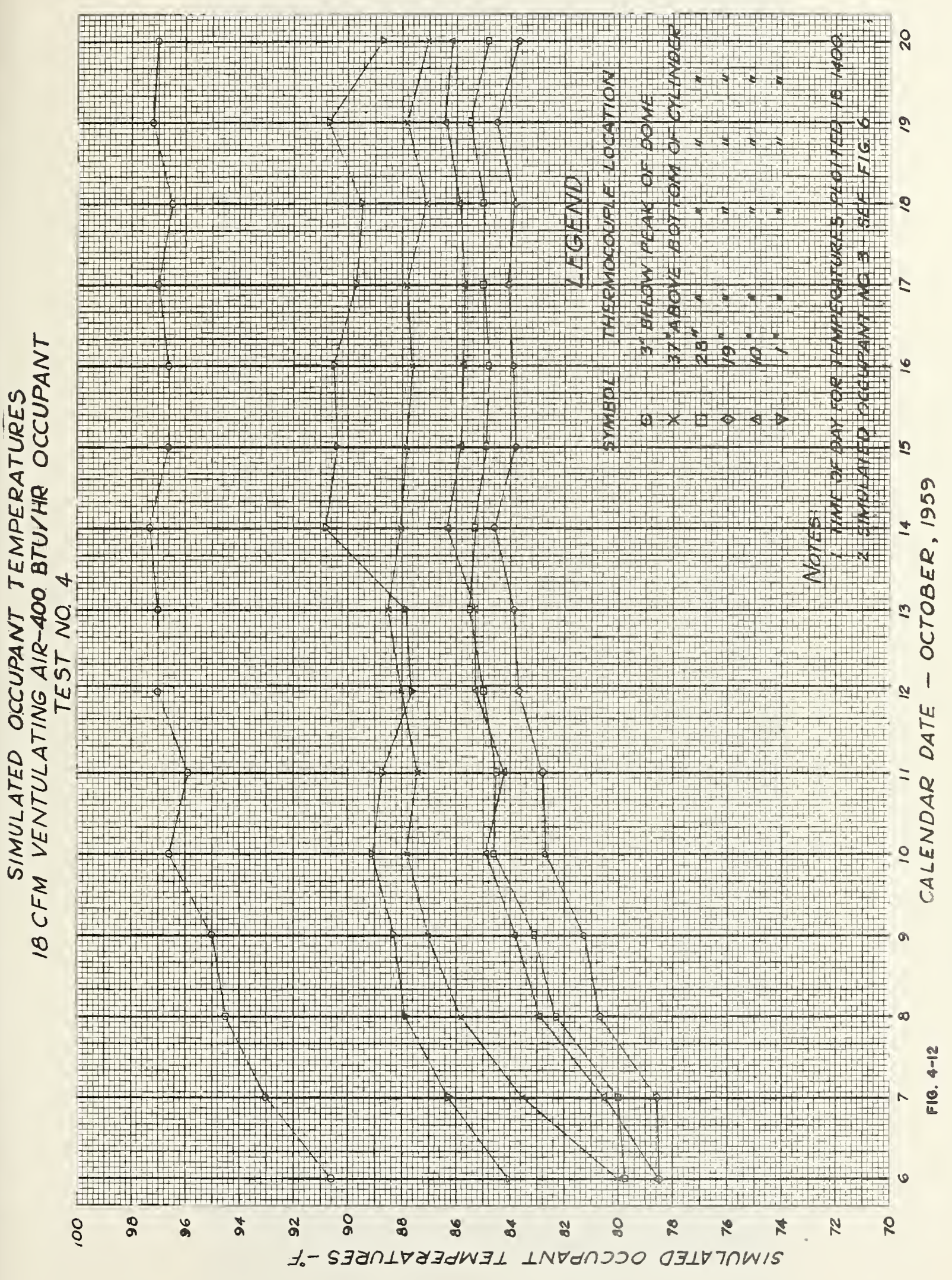





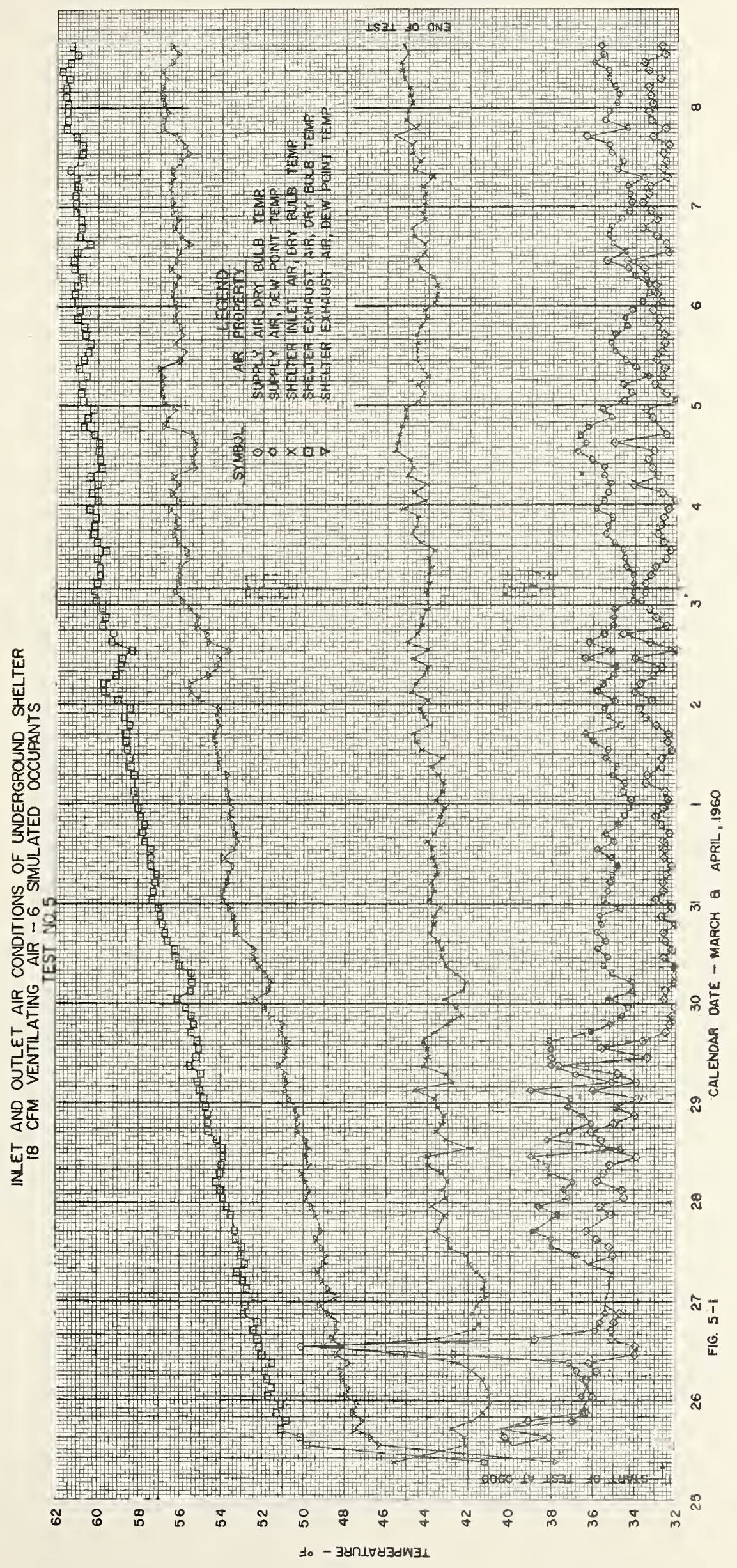





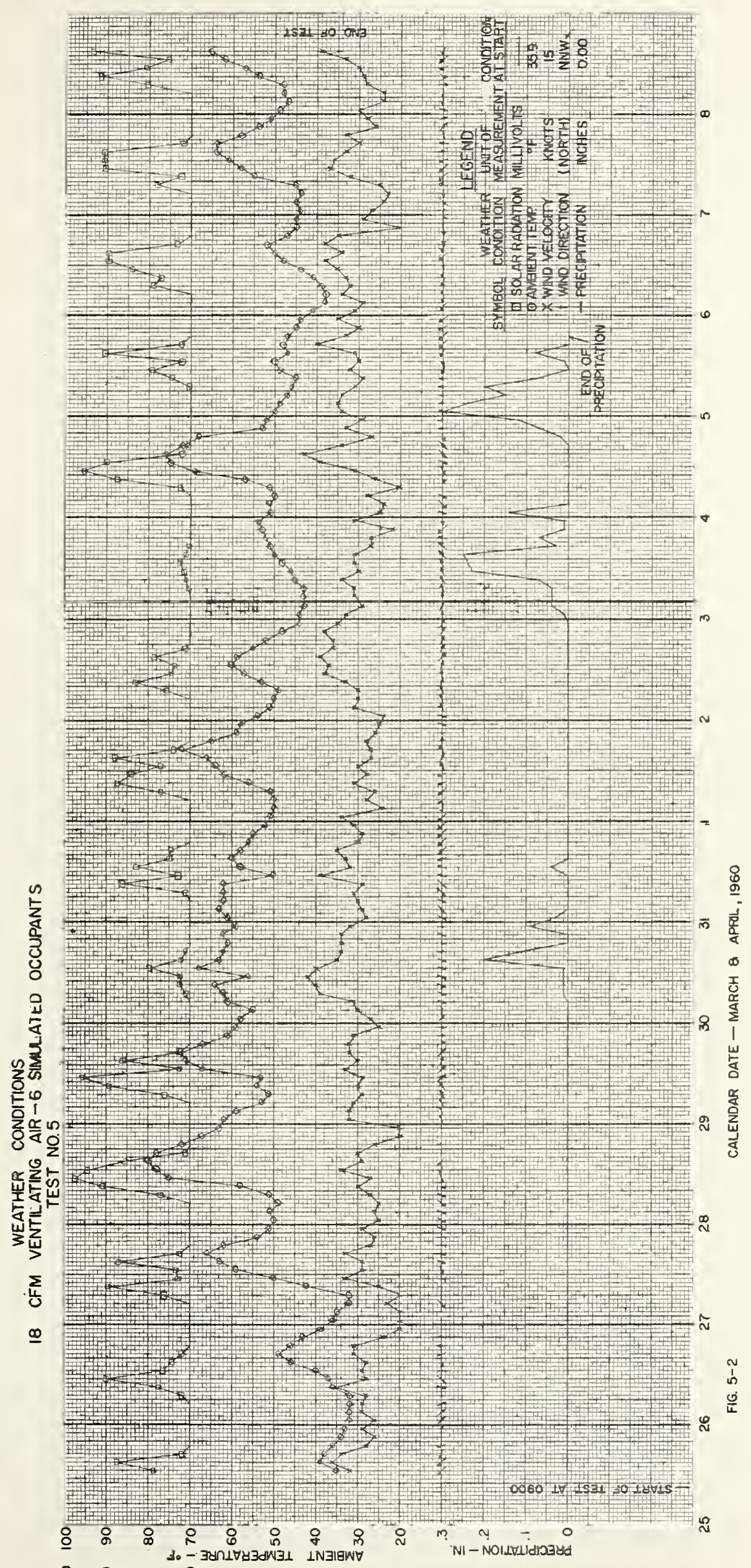

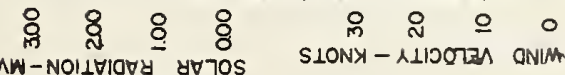





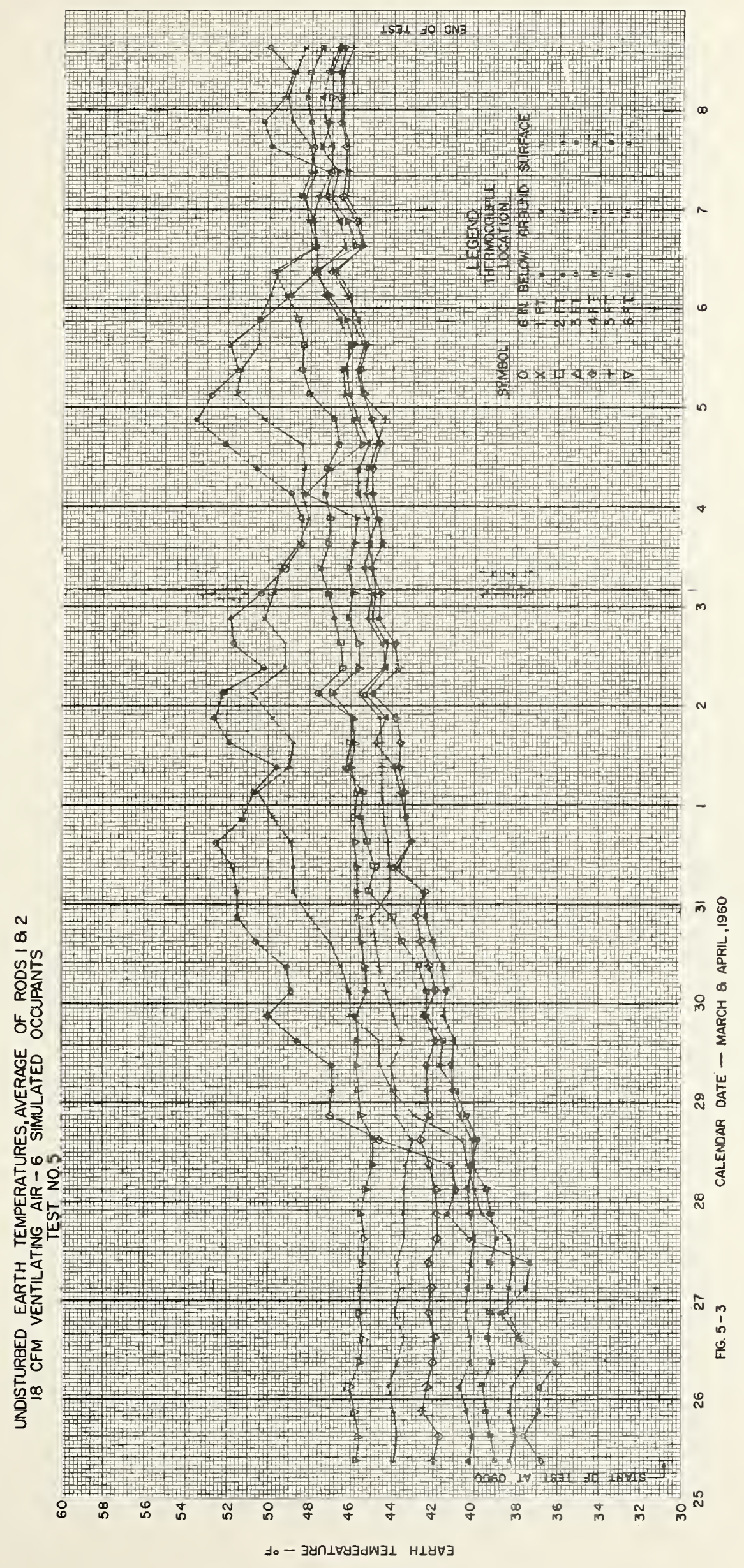





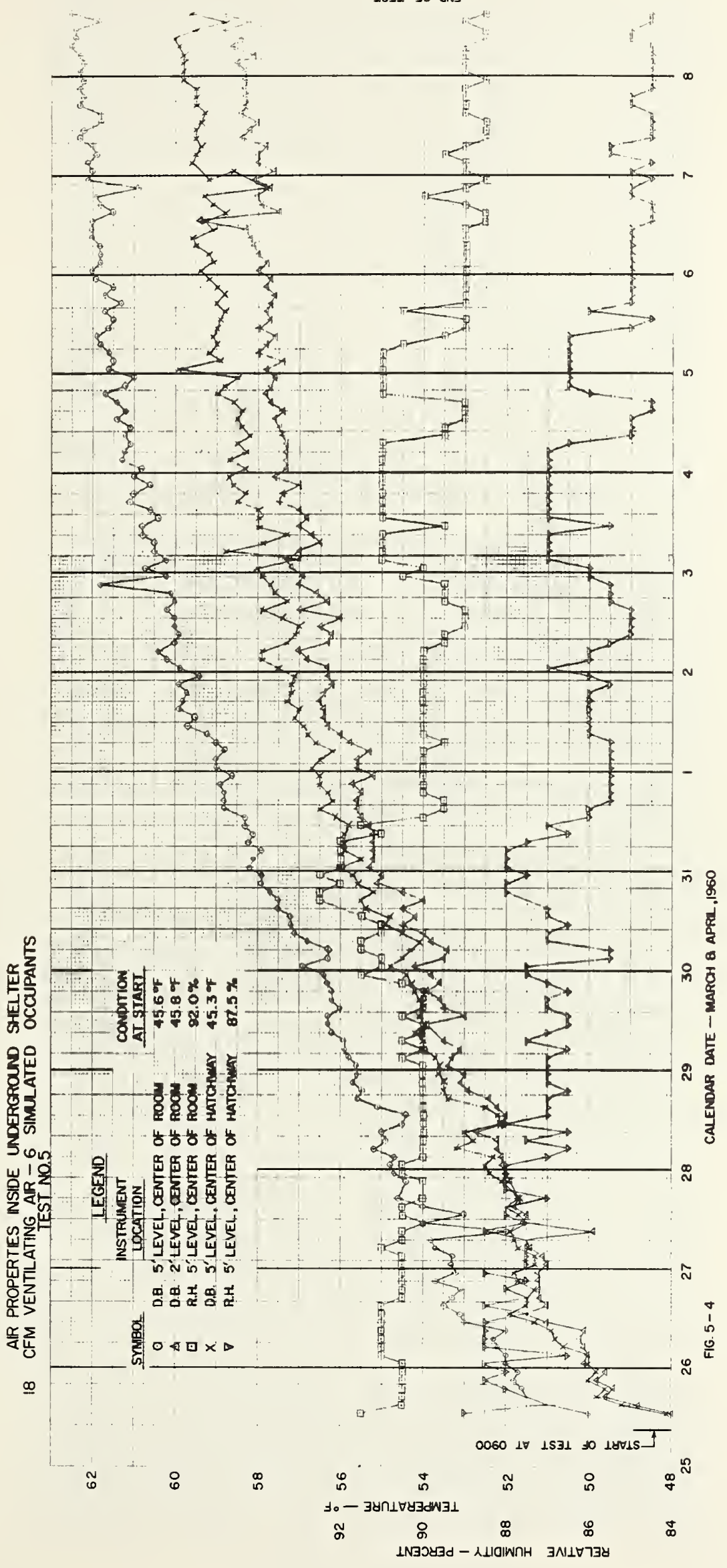





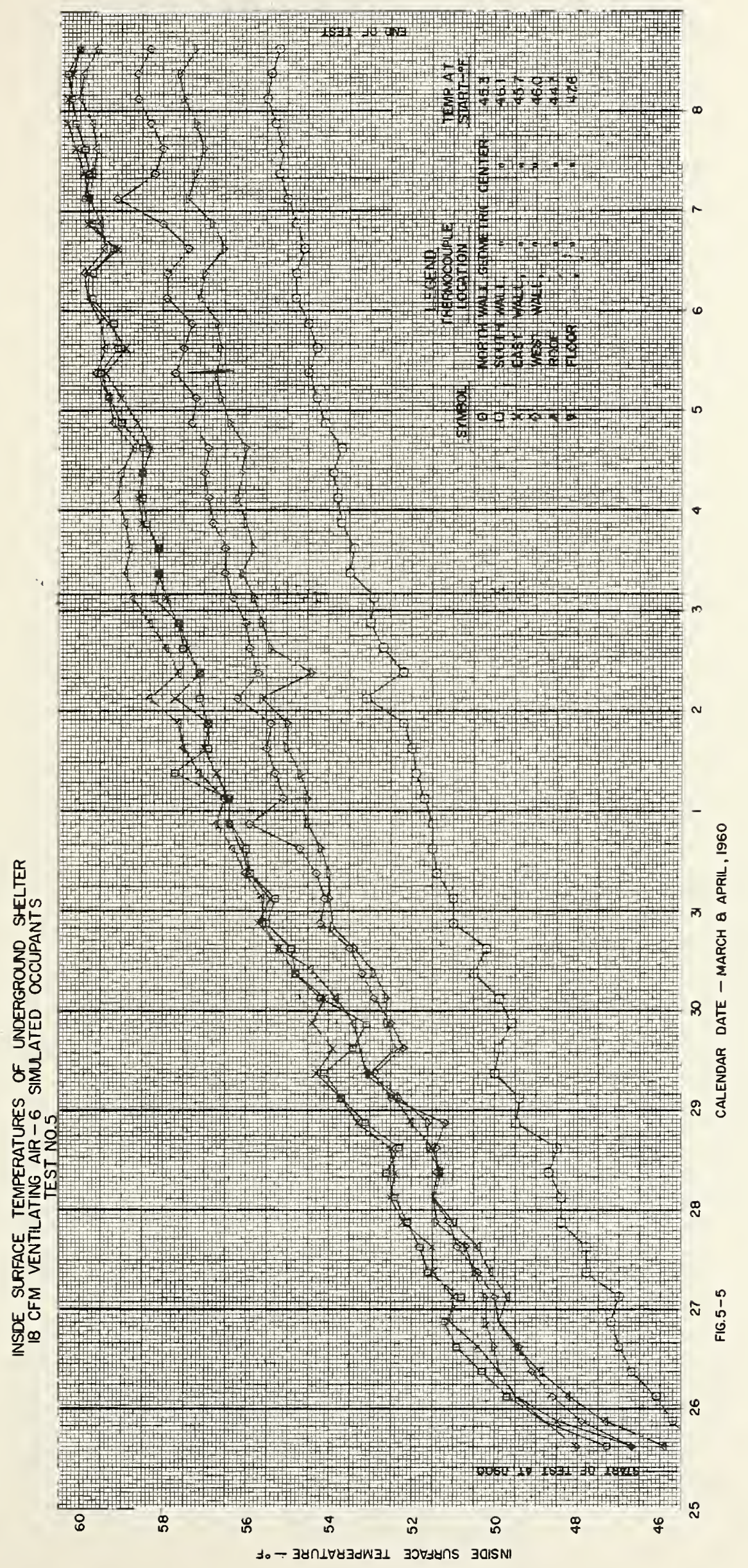





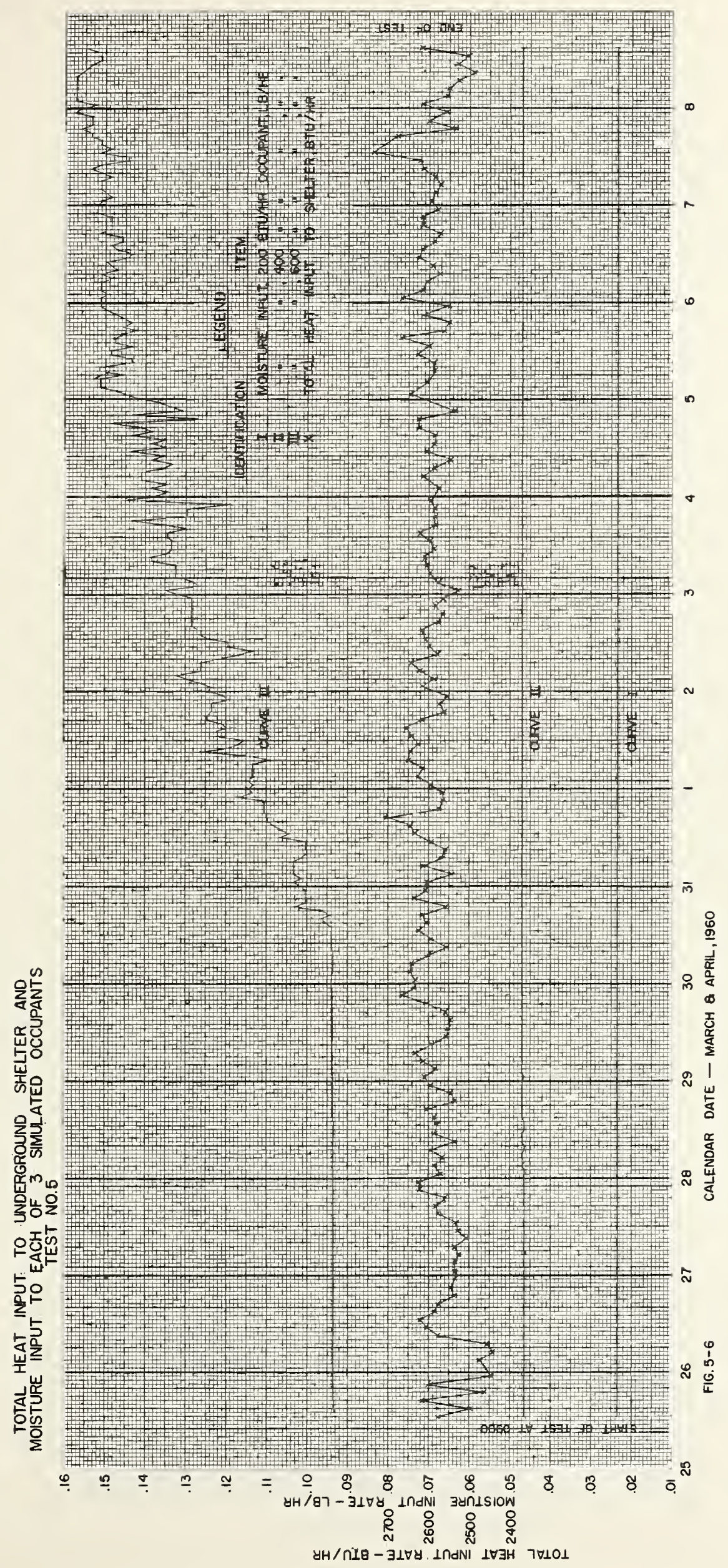





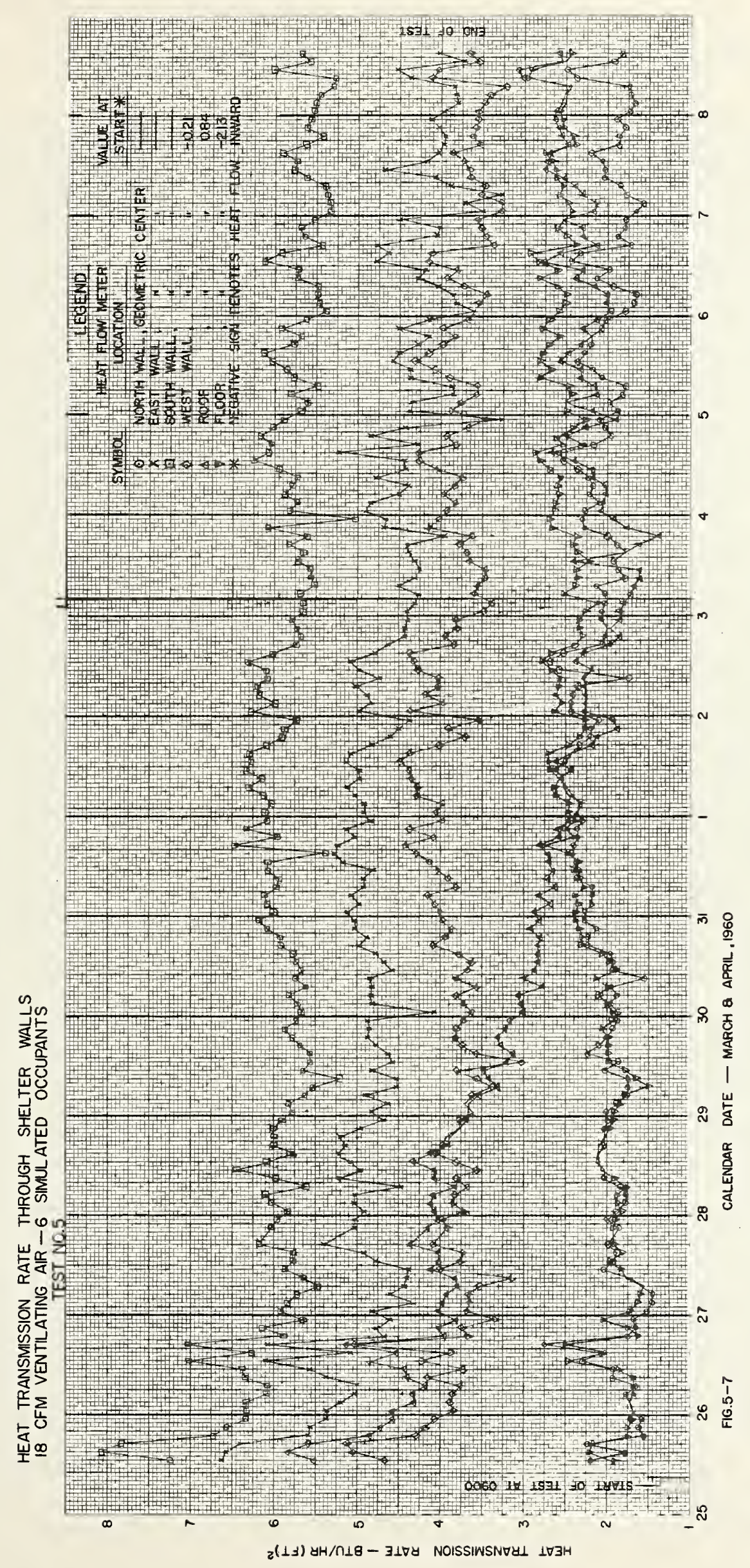





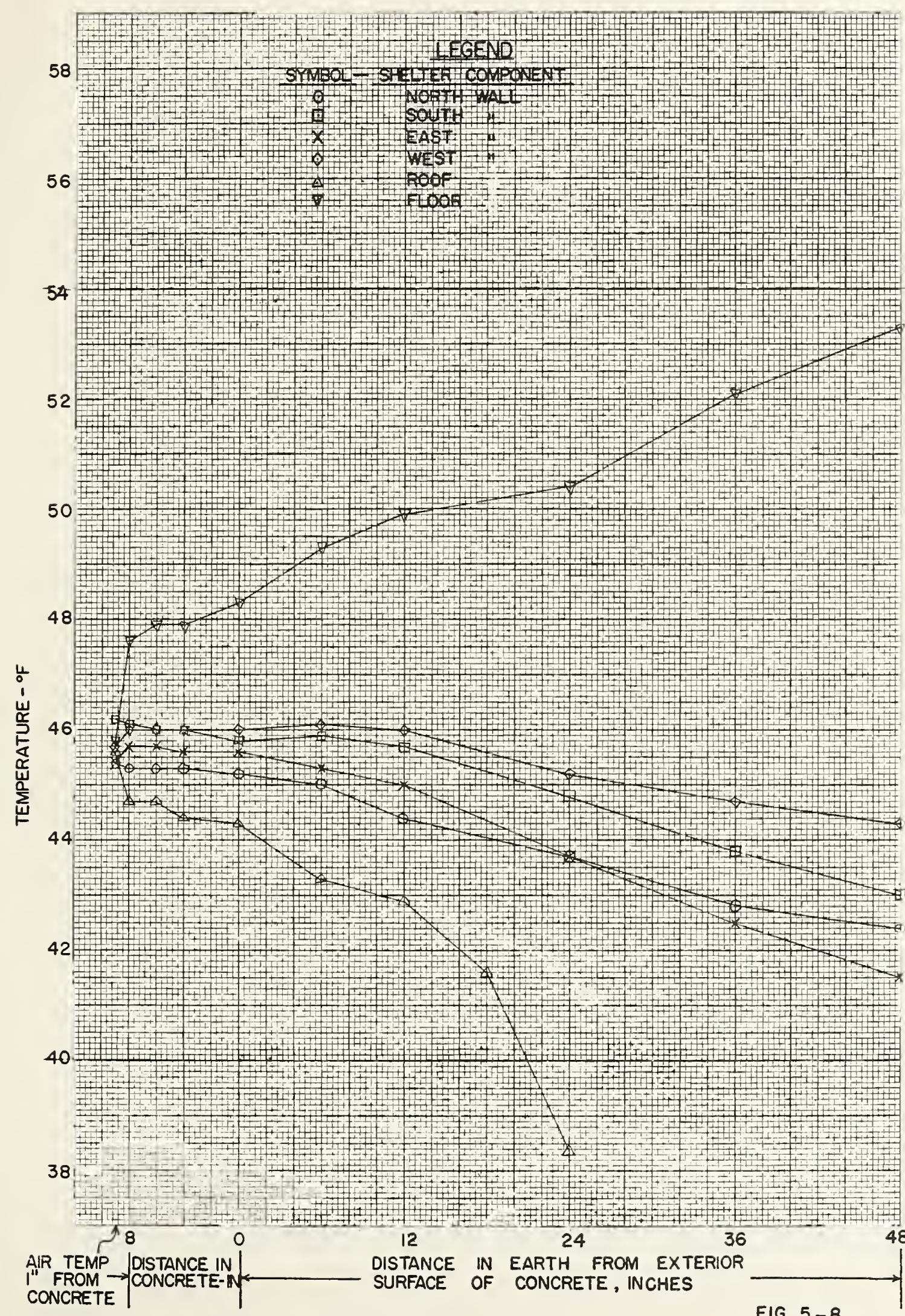

FIG. 5-8 

IEMPERATURES IN SHELTER WALLS AND SURROUNDING EARTH AFTER 7 DAYS OF TEST 5, APRIL 1, 1960-TIME 1300

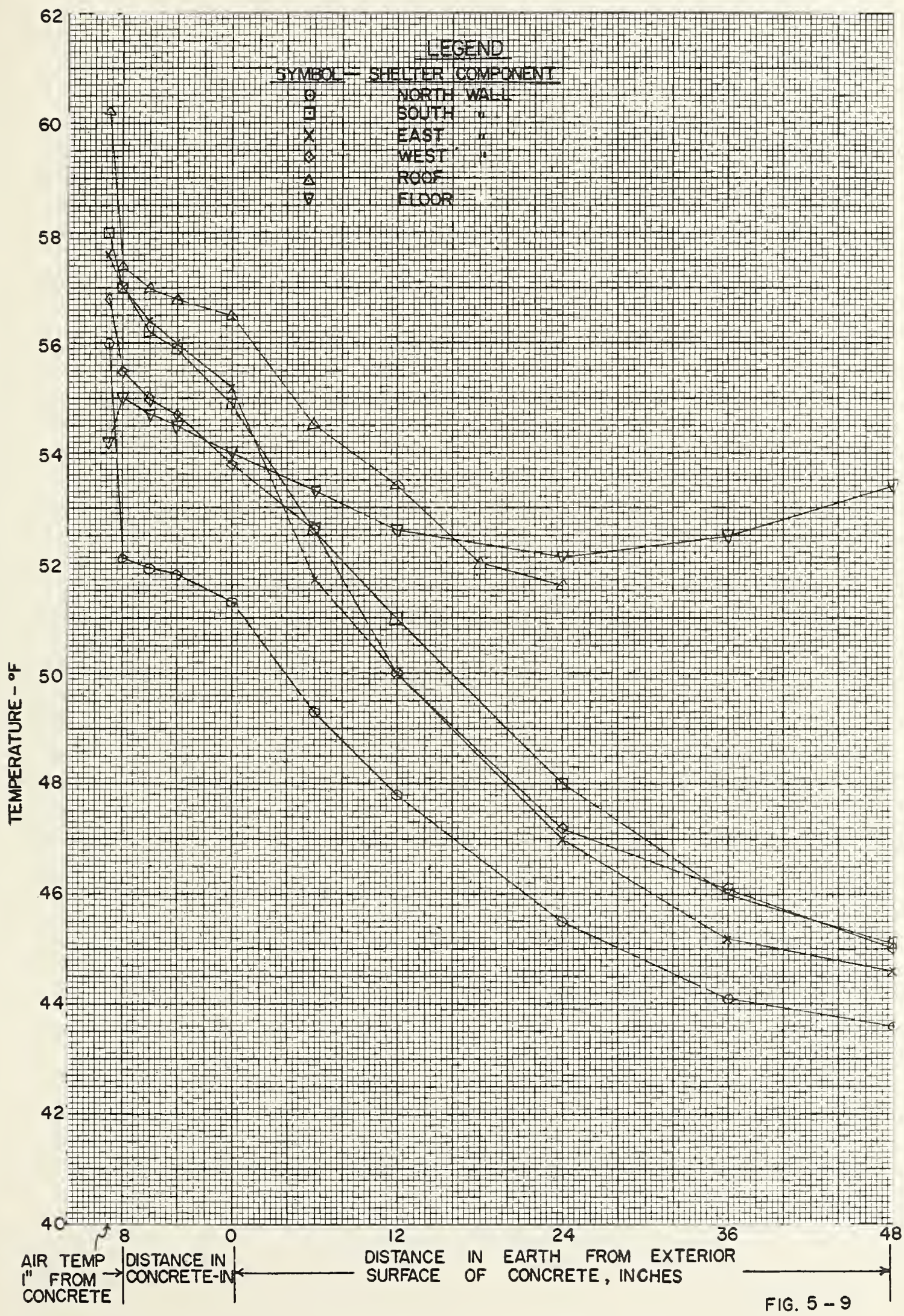



TEMPERATURES IN SHELTER WALLS AND SURROUNDING EARTH AT END OF TEST 5, APRIL 8,1960-TIME 1500

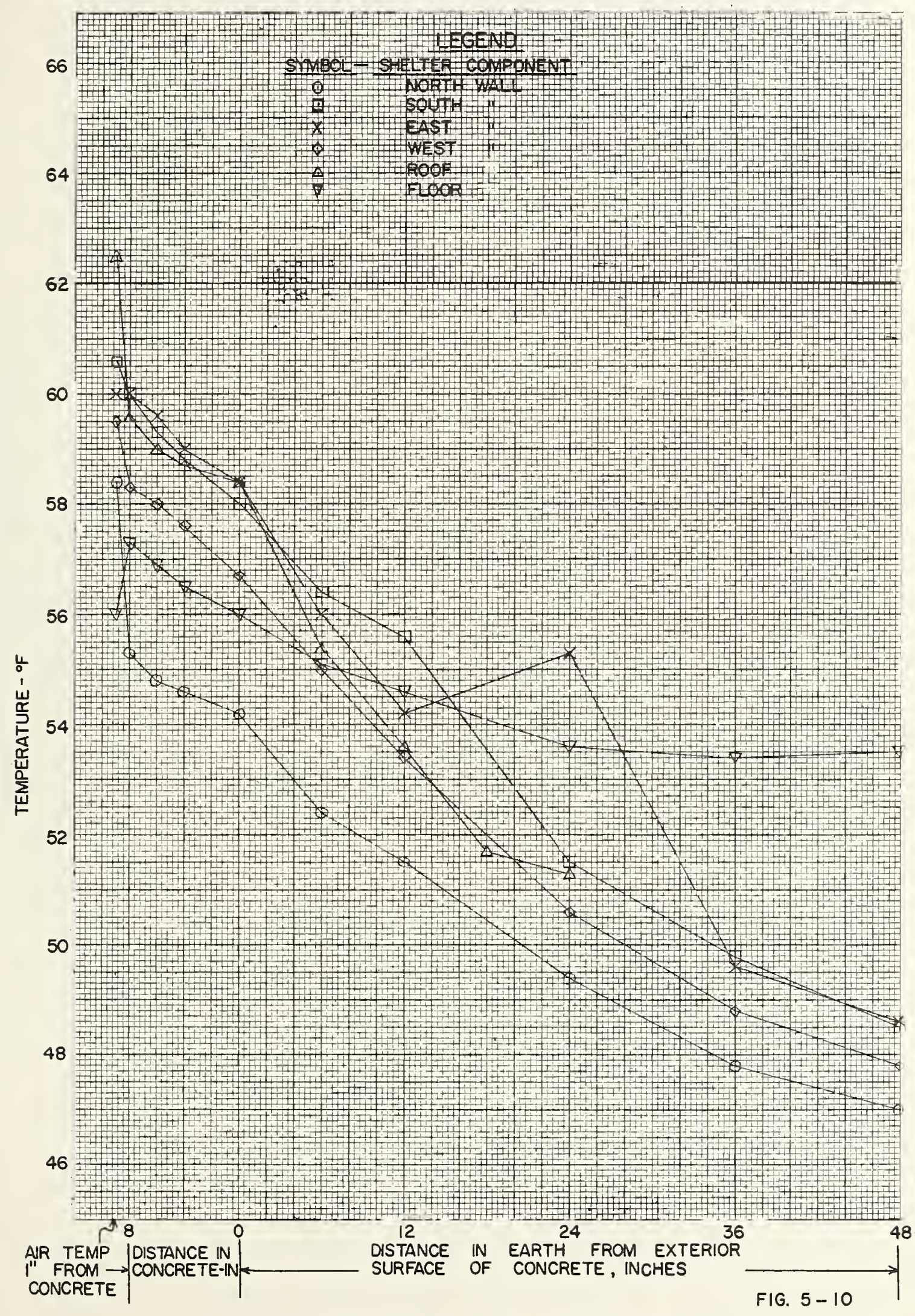





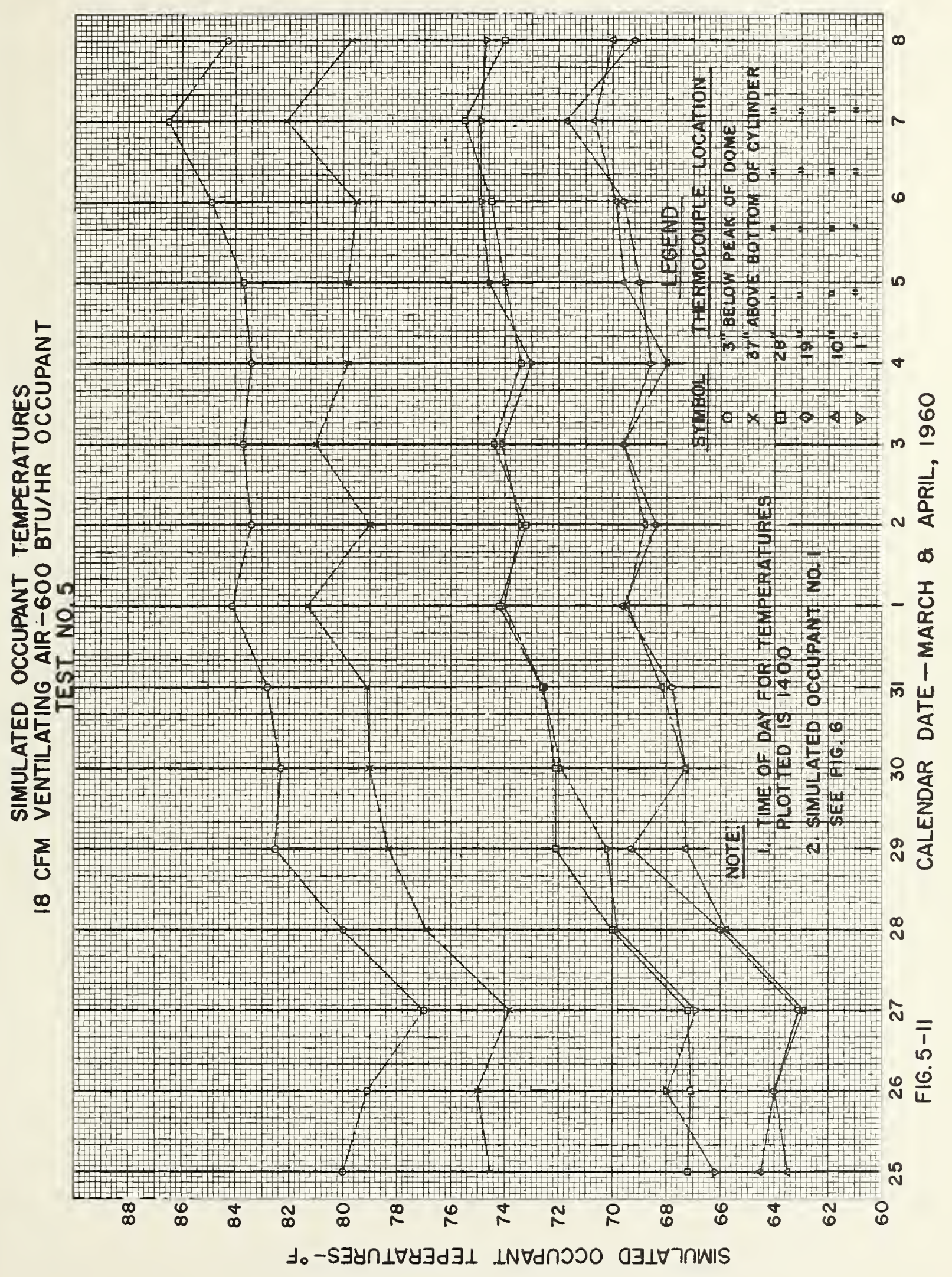





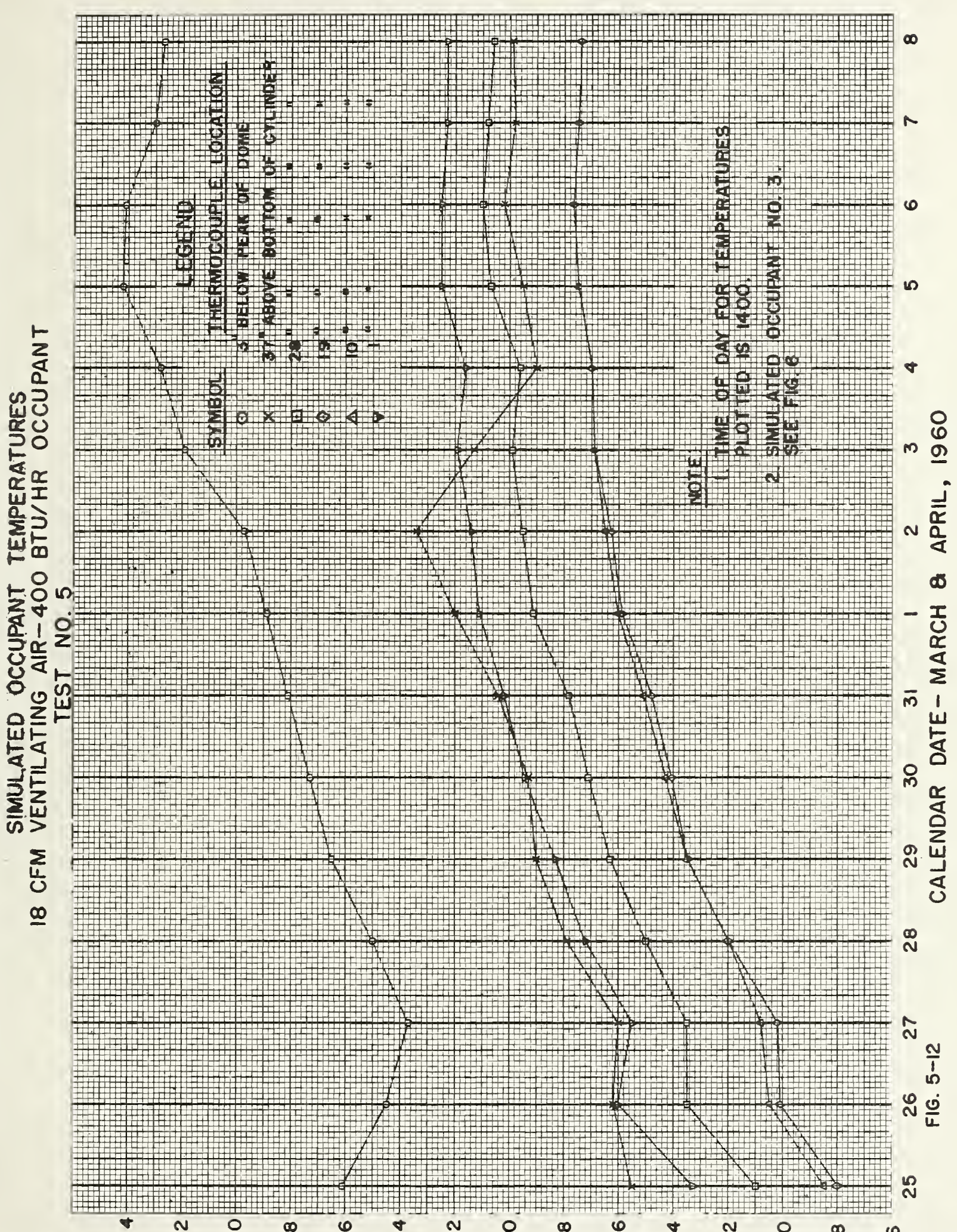

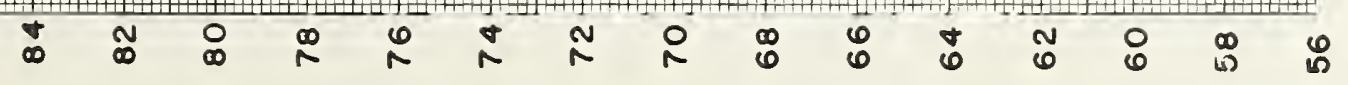

ঊ。-S $\exists y \cap \perp \forall y \exists d W \exists \perp \quad \perp N \forall d \cap 300 \quad 0 \exists \perp \forall 7 n W I S$ 
